GOFF, ANNE-MARIE, Ph.D. Stressors, Academic Performance, and Learned Resourcefulness in Baccalaureate Nursing Students. (2009)

Directed by Dr. David F. Ayers. 135 pp.

Despite extensive research establishing that stress affects problem-solving ability and coping, and leads to decreased learning, academic performance, and retention in nursing students, a paucity of research explores specific factors that could enhance these learning processes and outcomes. This explanatory correlational study examines the mediating effect of learned resourcefulness, the ability to regulate emotions and cognitions, on the relationships of stressors — both personal and academic — to academic performance in baccalaureate nursing students. Gadzella’s Student-life Stress Inventory (SSI) and Rosenbaum's Self-Control Scale (SCS), a measure of learned resourcefulness, were administered to 53 junior level baccalaureate nursing students (92.5\% female; 84.9\% Caucasian; 9.4\% African-American or Black) at a large urban university in North Carolina. High levels of both personal and academic stressors were revealed, but were not significant predictors of academic performance $(p=.90)$. Age was a significant predictor of academic performance $(p<.01)$ and both males and African-American/ Black participants had higher learned resourcefulness scores on the SCS than females and Caucasians. Total stress scores on the Student-life Stress Inventory showed that male participants perceived less stress $(\mathrm{N}=4, M=116.5)$ than females $(\mathrm{N}=41, M=141)$. No significant relationships among learned resourcefulness, stressors, and academic performance were revealed from multiple regression analyses. 
STRESSORS, ACADEMIC PERFORMANCE, AND LEARNED

RESOURCEFULNESS IN BACCALAUREATE

NURSING STUDENTS

by

Anne-Marie Goff

\begin{abstract}
A Dissertation Submitted to the Faculty of The Graduate School at The University of North Carolina at Greensboro in Partial Fulfillment of the Requirements for the Degree Doctor of Philosophy
\end{abstract}

Greensboro

2009

Approved by

Committee Chair 
(C) 2009 by Anne-Marie Goff 


\section{APPROVAL PAGE}

This dissertation has been approved by the following committee of the Faculty of The Graduate School at The University of North Carolina at Greensboro.

\section{Committee Chair}

Committee Members

Date of Acceptance by Committee

Date of Final Oral Examination 
LIST OF TABLES …………………….......................................................... vi

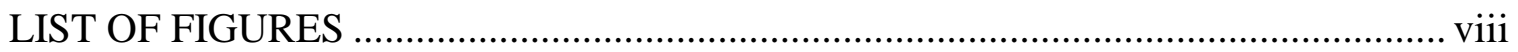

\section{CHAPTER}

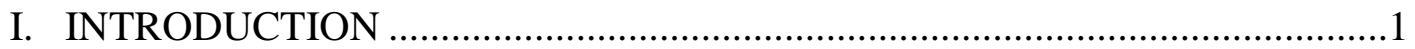

Statement of the Problem................................................................................

Research Questions ..............................................................................

II. REVIEW OF RELATED LITERATURE ......................................................

Sources of College Student Stress .............................................................

Sources of Nursing Student Stress.........................................................10

Perception of Stressors.........................................................................12

Impact of Stressors on Physical and Mental Health ...................................13

Coping with Stress ..................................................................................14

Impact of College Student Stressors on Academic Performance ................15

Learned Resourcefulness ....................................................................17

Conceptual Framework ............................................................................22

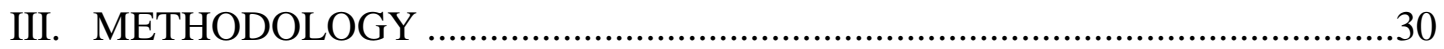

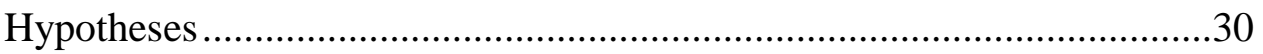

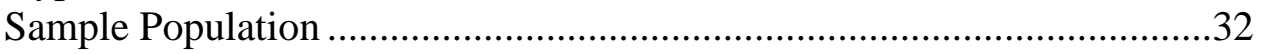

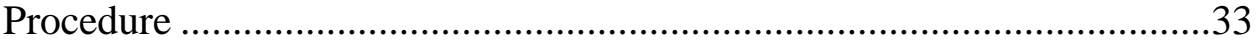

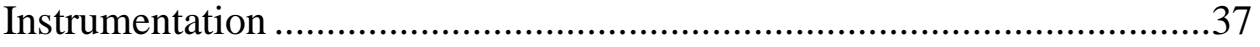

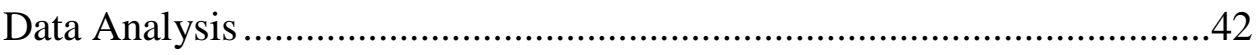

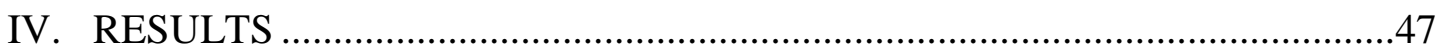

Relationship between Stressors and Academic Performance ......................54

Correlation of Age, Race/Ethnicity, Gender, Marital Status, Work Status, Enrollment Status, Stressors, and Academic

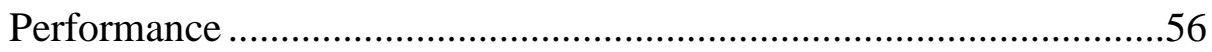

Effect of Learned Resourcefulness on Relationship among Stressors and Academic Performance....................................................59 
Correlation of Age, Race/Ethnicity, Gender, Marital Status, Work Status, Enrollment Status, Learned Resourcefulness, Stressors, and Academic Performance. .65

Further Exploratory Investigation......................................................69

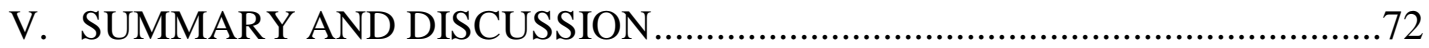

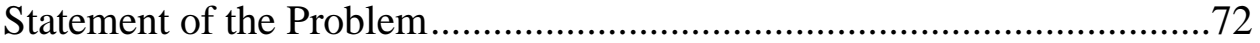

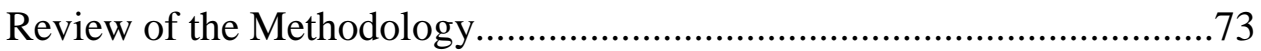

Summary of the Results ......................................................................74

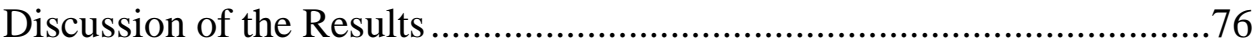

Researcher's Insights and Relationship of Current Study

to Prior Research..................................................................76

Relationship between stressors and academic performance ............................................................76

Correlation of age and academic performance ..................76

Correlation of learned resourcefulness, stressors,

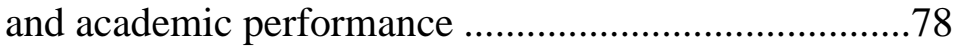

Correlation of age, learned resourcefulness, stressors, and academic performance............................79

Correlation of gender, learned resourcefulness, stressors, and academic performance.

Correlation of race/ethnicity, learned resourcefulness, stressors, and academic performance

Demographics of participants ........................................82

Perception of personal and academic stressors ...................82

Unique stressors of nursing students..................................85

Gender and perception of stress ........................................85

College level and perception of stress .............................86

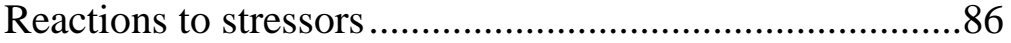

Theoretical Implications of Study .............................................87

Explanation of Unanticipated Findings .....................................89

Implications for Practice ..........................................................95

Recommendations for Further Research....................................98

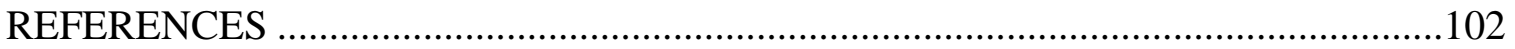

APPENDIX A. LETTER OF INVITATION TO PARTICIPATE..............................125

APPENDIX B. INFORMED CONSENT FORM ….............................................126

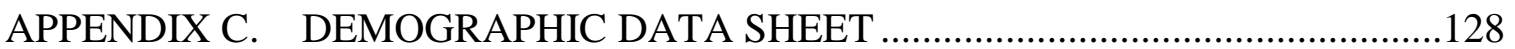




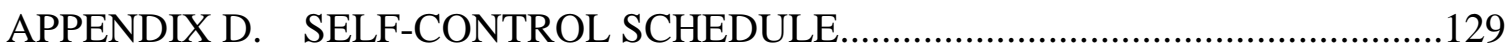

APPENDIX E. STUDENT-LIFE STRESS INVENTORY …...................................132

APPENDIX F. ANSWER SHEET TO STUDENT-LIFE STRESS

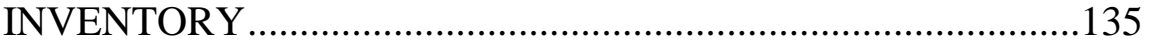




\section{LIST OF TABLES}

Page

Table 1. Distribution of Respondent's Current Age ...............................................48

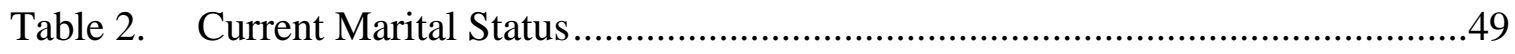

Table 3. Number of Living Children .................................................................49

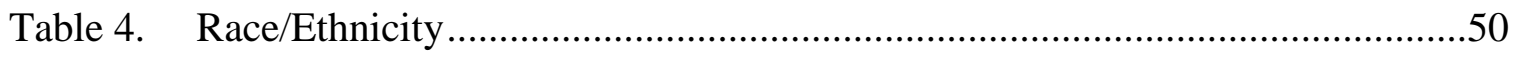

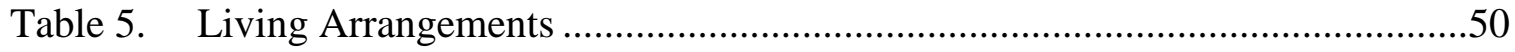

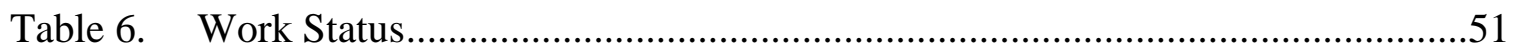

Table 7. Student-Life Stress Inventory (SSI) Scale and Subscale Means, Standard Deviations, and Cronbach’s Alpha ............................................52

Table 8. Correlation Matrix and Descriptive Statistics for Stressors and Academic Performance in Baccalaureate Nursing Students

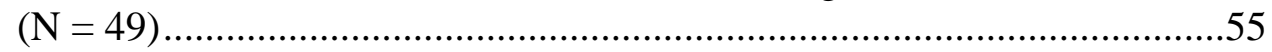

Table 9. Academic Performance Regressed Onto Stressors ........................................55

Table 10. Correlation Matrix and Descriptive Statistics for Age, Stressors, and Academic Performance $(\mathrm{N}=49)$

Table 11. Analysis of Variance for Regression of Age and Stressors on Academic Performance.

Table 12. Multiple Regression Analysis for Age and Stressors Predicting Academic Performance.

Table 13. Correlation Matrix and Descriptive Statistics for Stressors and Learned Resourcefulness .60

Table 14. Multiple Regression Analysis for Stressors and Learned Resourcefulness Predicting Academic Performance

Table 15. Correlation Matrix and Descriptive Statistics for Learned Resourcefulness and Academic Performance. 
Table 16. Regression Analysis of Learned Resourcefulness and Academic Performance

Table 17. Correlation Matrix and Descriptive Statistics for Stressors, Learned Resourcefulness, and Academic Performance.................................65

Table 18. Correlation Matrix and Descriptive Statistics for Age, Stressors, Learned Resourcefulness, and Academic Performance................................66

Table 19. Analysis of Variance for Regression of Predictors on Academic Performance

Table 20. Model Summary for Independent Variables and Learned Resourcefulness .68

Table 21. Multiple Regression Analysis for Age, Stressors, and Learned Resourcefulness Predicting Academic Performance .68 


\section{LIST OF FIGURES}

Page

Figure 1. Stressors, Academic Performance, and Learned Resourcefulness .................23

Figure 2. Path Analysis of Stressors, Academic Performance, and Learned

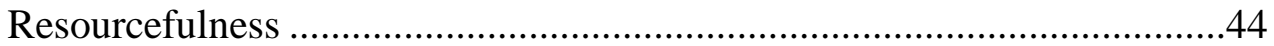

Figure 3. Relationship between Stressors and Academic Performance .........................56

Figure 4. Path Analysis of Stressors, Academic Performance, and Learned

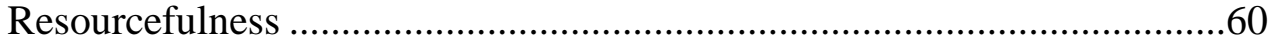

Figure 5. Relationship between Stressors and Learned Resourcefulness .....................62

Figure 6. Relationship between Learned Resourcefulness and Academic

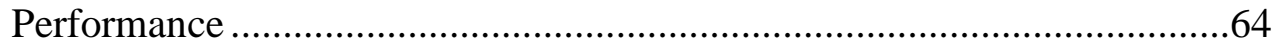

Figure 7. Histogram of Self Control Schedule Scores and Gender ..............................70

Figure 8. Stressors, Academic Performance, and Learned Resourcefulness ..................88 


\section{CHAPTER I}

\section{INTRODUCTION}

\section{Statement of the Problem}

A critical, long-term, and global nursing shortage has increased the significance of preparing nursing students in sufficient numbers to improve the quality of health care (Institute of Medicine, 2001, 2003; North Carolina Institute of Medicine, 2004; PEW, 1995). At the same time, a more complex, rapidly-changing, and acutely-ill health care environment requires nursing graduates to possess higher levels of knowledge and improved clinical judgment (Chitty \& Black, 2007; Curtin, 1996; Joel, 2006; PorterO’Grady, 2001). Although nursing program faculty have responded appropriately by developing more rigorous and challenging curricula, a more competitive, stressful, and high-stakes learning environment has evolved (Gibbons, Dempster, \& Moutray, 2008; Lindop, 1999; Nicholl \& Timmins, 2005; Omigbodun, Onibokun, Yusuf, Odukogbe \& Omigbodun, 2004; Omigbodun et al., 2006; Yonge, Myrick, \& Haase, 2002).

However, extensive and compelling evidence shows that high stress levels in nursing students may affect memory, concentration, and problem-solving ability, and may lead to decreased learning, coping, academic performance, and retention (AlKandari \& Vidal, 2007; Bean, 1990; Beck \& Srivastava, 1991; Dixon \& Robinson Kurpius, 2008; Dyson \& Renk, 2006; Gwele \& Uys, 1998; Gupchup, Borrego, \& Konduri, 2004; Hamill, 1995; Higginson, 2006; Kleehammer, Hart, \& Keck, 1990; 
Misra, McKean, West, \& Russo, 2000; Oermann \& Lukomski, 2001; Wells, 2007). In addition to perceiving stressors that are similar to other college students, nursing students perceive unique stressors, such as clinical experiences, higher levels of stress, and more physical and psychological symptoms than students in other health-related disciplines (Akgun, 2004; Beck, Hackett, Srivastava, McKim, \& Rockwell, 1997; Diekelmann, 1992, 1993; Eddy \& Epeneter, 2002; Gibbons et al., 2008; Gupchup et al., 2004; Higginson, 2006; Jones \& Johnston, 1997; Magnussen \& Amundson, 2003; Oermann, 1998; Oermann \& Lukomski, 2001; Pagana, 1988; Rather, 1992).

Evolving college student demographics and the unstable economy have compounded college student stress and introduced more complex and personal stressors: balancing school, family, and work (Gigliotti, 2004; Gwele \& Uys, 1998; Leppel, 2002; Nicholl \& Timmons, 2005; Pascarella \& Terenzini, 1991, 2005; Pryjmachuk \& Richards, 2007; Vanhanen \& Janhonen, 2000; Wells, 2007; Zeitlin-Ophir, Melitz, Miller, Podoshin, \& Mesh, 2004). In addition, high stress levels have been specifically associated with depression, low self-esteem, poor adjustment to college, lack of social support, and unhealthy and high risk behaviors in nursing and other college students (Dixon \& Robinson Kurpius, 2008; Dyson \& Renk, 2006; Friedlander, Reid, Shupak, \& Cribbie, 2007; Gigliotti, 2004; Hudd et al., 2000; Trockel, Barnes, \& Egget, 2000).

Despite these claims, there is a paucity of research exploring specific factors that could enhance learning processes and outcomes in nursing students. Higher levels of learned resourcefulness, the ability to regulate emotions and cognitions, have been reported to minimize the negative effects of stress and to improve coping effectiveness in 
other populations (Rosenbaum, 1980b, 1990). However, only a few studies, which report similar findings, specifically target the college student population, and this claim has not been explored in nursing students (Akgun \& Ciarrochi, 2003; Kennett \& Keefer, 2006; Kennett \& Stedwill, 1996). The purpose of this explanatory correlational study is to examine the mediating effect of learned resourcefulness on the relationships of stressors_-both personal and academic — to academic performance in baccalaureate nursing students.

Extensive quantitative research, mainly on full-time Caucasian baccalaureate students living in campus residence halls, has established that stress is a major part of the college student’s experience (Pascarella \& Terenzini, 1991, 2005; Robotham \& Julian, 2006; Tinto, 1993). Studies show an increase in college student stress during recent years, an increase as the student progresses, and higher perception levels in females (Akgun, 2004; Beck et al., 1997; Dixon \& Robinson Kurpius, 2008; Gadzella, 1994b; Gadzella \& Carvalho, 2006; Gadzella, Ginther, Tomcala, \& Bryant, 1991; Misra et al., 2000). Several researchers report similar sources of stress in nursing students, plus unique stressors, such as clinical experiences and preparation for the NCLEX-RN licensure exam (Beck \& Srivastava, 1991; Gibbons et al., 2008; Higginson, 2006). In addition, nursing students perceive higher levels of stress than students in other health-related disciplines, leading to higher attrition rates (Beck et al., 1997; Gadzella, 1994a, 1994b; Gadzella \& Carvalho, 2006; Gadzella, Ginther, et al., 1991).

Evolving college student demographics may also be associated with higher stress levels and lack of persistence: older than the traditional age of 17 to 21 and a variety of 
cultural and ethnic backgrounds (Greer \& Chwalisz, 2007; Leppel, 2002; Pascarella \& Terenzini, 1991, 2005; Tinto, 1993). Minority-related stressors and coping processes have been identified and linked to poorer academic outcomes (Greer \& Chwalisz, 2007). The influx of students who are married, have children, are employed, and commute to campus, especially in associate degree programs, plus the influence of unstable national and global economies, have introduced stressors which are more complex and personal (Gigliotti, 2004; Nicholl \& Timmons, 2005; Robotham \& Julian, 2006; Yonge et al., 2002; Zeitlin-Ophir et al., 2004).

For example, a study of 271 Finnish nursing students reveals that life orientation, or the awareness of the need to balance work as a professional nurse with other social roles, such as parenting or wage earner, is associated with the intention to stay in nursing (Vanhanen \& Janhonen, 2000). Balancing school, family, and work may also affect the level of student social and academic involvement on campus, which has been found to significantly influence the decision to either drop out or continue studying (Astin, 1984, 1991; Leppel, 2002; Metzner \& Bean, 1987; Pascarella \& Terenzini, 1991, 2005; ZeitlinOphir et al., 2004).

Although several researchers have established that stress influences academic performance, only one study, conducted in the Republic of South Africa, explores the impact of both categories of college student stressors-personal and academic. The findings of this comparative descriptive study suggest that students who demonstrate higher stress levels describe feelings of anger, apprehension, fear, and being overwhelmed, which, in turn, negatively affects academic performance (Gwele \& Uys, 
1998). However, there is a paucity of research that examines specific factors to decrease nursing student stress and to improve outcomes (Isaak, Graves, \& Mayers, 2006; Jones \& Johnston, 2000; Kanji, White, \& Ernst, 2006; Omigbodun et al., 2004; Sharif \& Armitage, 2004).

One construct that may hold promise is learned resourcefulness, or the ability to regulate emotions and cognitions (Meichenbaum, 1977, 1985, 2007; Rosenbaum, 1980, 1983, 1990). Studies involving the effects of learned resourcefulness in a variety of laboratory tasks found that individuals use these behaviors when faced with everyday problems and that learned resourcefulness can be learned through instruction, conditioning, and modeling (Rosenbaum, 1983, 1990). However, few researchers have explored the construct in a college or university setting (Akgun \& Ciarrochi, 2003;

Kennett, 1994; Kennett \& Stedwill, 1996; Rosenbaum, 1980a, 1990). The sole study regarding the impact of learned resourcefulness on academic stress and academic performance reports a significant level of mediation in undergraduate psychology students at the University of Australia (Akgun \& Ciarrochi, 2003). Further research is needed to explore the relationship of learned resourcefulness on stressors and academic performance in college students, and specifically in nursing students in the United States.

\section{Research Questions}

The following research questions guided the study:

1. What is the relationship between stressors and academic performance in baccalaureate nursing students? 
2. How do age, race/ethnicity, gender, marital status, work status, or enrollment status moderate the relationship between stressors and academic performance in baccalaureate nursing students?

3. What is the effect of learned resourcefulness on the relationship among stressors and academic performance in baccalaureate nursing students?

4. How do age, race/ethnicity, gender, marital status, work status, or enrollment status moderate the relationships among learned resourcefulness, stressors, and academic performance in baccalaureate nursing students?

The purpose of the study was to examine the link between learned resourcefulness, stressors, and academic performance in baccalaureate nursing students. Results of this study may lead to a better understanding of factors associated with nursing student stress. Participants may develop greater personal awareness of their repertoire of learned resourcefulness skills and the types of personal and academic stressors that they are experiencing while a nursing student. This understanding may inform policies and practices designed to reduce nursing student stress and improve learning, academic performance, and retention. Ultimately the findings may increase the number of qualified nursing graduates, address the nursing shortage, and enhance the quality of health care in the United States. Therefore, this study will provide significance to both theory and practice in higher education and professional nursing.

Unfortunately, without this research, many academically qualified nursing students may continue to have difficulty coping with high stress levels, have difficulty learning, and have a tendency to drop out of nursing programs. Without an understanding 
of learned resourcefulness, stress levels, and academic performance in nursing students, high attrition rates will continue, resulting in decreased rather than increased graduates, no improvement of an already critical nursing shortage, and inadequate quality of health care in the United States. 


\section{CHAPTER II REVIEW OF RELATED LITERATURE}

The review of related literature for the study includes sources of stress in college students regardless of major and then specifically focuses on additional sources of stress that are unique to the nursing major. Further segments of the stress literature relate to the perception of stressors, the impact of stressors on physical and mental health, and interventions for decreasing stress in the college student population. Another body of research explores the impact of college student stress on academic performance and, finally, an extensive literature review of learned resourcefulness, with possible relationships to stressors and academic performance, is presented. The conceptual framework developed for the study is based on the work of Lazarus and Folkman (1984), Gadzella (1994b), Bandura (1977, 1982), Rosenbaum (1980a, 1990) and Rosenbaum and Ben-Ari (1985). The main hypothesis is that learned resourcefulness may improve coping with stressors and improve academic performance among nursing students.

\section{Sources of College Student Stress}

An extensive body of research examines sources of stress in the college student regardless of major and focuses on either academic stressors (Abu Tariah \& Al-Sharaya, 1997; Beck et al., 1997; Hamill, 1995; Hudd et al., 2000; Isaak et al., 2006; Jones \& Johnston, 1997; Misra et al., 2000; Oermann, 1998; Sarid, Anson, Yaari, \& Margalith, 2004; Shipton, 2002), personal stressors, such as adjustment to college (Beck \& 
Srivastava, 1991; Friedlander et al., 2007; Gupchup et al., 2004), or both (Haack, 1988; Murphy \& Archer, 1996). Several studies explore college student stress in specific majors, mostly medical, dental, and nursing (Beck et al., 1997; Lo, 2002; Magnussen \& Amundson, 2003), and a few studies investigate pharmacy students (Dutta, 2001; Gupchup et al., 2004). Numerous instruments with various scales measure different types of stressors; however, reliability and validity are not always reported, making it difficult to compare findings across studies (Gadzella, 1991; Beck \& Srivastava, 1991; Cohen, Karmack, \& Mermelstein, 1983; Derogatis, 1987; Oermann, 1998; Pagana, 1989).

Evidence suggests that although academic sources of stress such as grades, assignments, examinations, long hours of study, and lack of free time have continued to exist during the past several years, these sources have increased, and new sources of stress have surfaced (Gigliotti, 2004; Lindop, 1999; Murphy \& Archer, 1996; Robotham \& Julian, 2006). Changing college student demographics, rising tuition, and balancing school, family, and work have created increased personal stressors for college students (Gigliotti, 2004; Nicholl \& Timmons, 2005; Pascarella \& Terenzini, 1991, 2005; Vanhanen \& Janhonen, 2000; Zeitlin-Ophir et al., 2004). Comparing student stressors on a large university campus in 1985 and 1993, Murphy and Archer (1996) found that, although the general pattern of stressors was similar, new stressors appeared in 1993 which may be related to changes in the college climate: a decrease in academic resources, larger class sizes, fewer faculty, and fewer writing assignments in the curriculum. 


\section{Sources of Nursing Student Stress}

Researchers have examined nursing students in several countries and identified sources of academic stress similar to other college students (Beck \& Srivastava, 1991). Qualitative studies have used open-ended surveys, grounded theory, phenomenology, and writing about stress to elicit some of this data (Lumley \& Provenzano, 2003; Shipton, 2002; Wells, 2007). For example, in a qualitative study of 12 nursing students, four major themes emerged from the data: meeting conflicting demands, feeling overworked, feeling unprepared, and seeking support and respect from faculty (Magnussen \& Amundson, 2003). Another qualitative study of 11 nursing students found that departure from the program was a result of a cumulative effect of multiple stressors from a variety of sources (Wells, 2007). These findings corroborate earlier studies, which emphasize that students feel as if there is not enough time to learn everything that is expected in nursing courses and that faculty need to be caring and supportive in the process (Diekelmann, 1992; Vanhanen \& Janhonen, 2000).

In addition to sources of academic stress similar to other college students, nursing students report stressors that are unique. For example, a few qualitative studies explore the lived experience of the nursing student, in order to better understand stress prior to and during the NCLEX-RN examination for professional licensure (Diekelmann, 1992, 1993; Eddy \& Epeneter, 2002; Higginson, 2006; Rather, 1992). Quantitative and qualitative studies in several countries have also found that the clinical experience component of a nursing program is a major stressor, citing feelings of inadequacy and insecurity, fear of making mistakes, and a perceived lack of skill and experience in caring 
for patients (Gibbons et al., 2008; Gwele \& Uys, 1998; Hamill, 1995; Higginson, 2006;

Kleehammer et al., 1990; Oermann \& Lukomski, 2001; Pagana, 1988; Shipton, 2002).

Hamill (1995) found that student perceptions of stress focused on several aspects

of the clinical setting in a nursing program in Northern Ireland, while Jones and Johnston (1997) reported significant levels of stress in two cohorts of Scottish nursing students ( $N=220)$ just before the first clinical experience in the program. Using a grounded theory approach in the United Kingdom, Higginson (2006) reported that all five first-year baccalaureate nursing students expressed fears related to clinical experience: seeing a dead body for the first time, clinical procedures, such as giving injections, and exposure to bodily fluids.

Some researchers have reported that the pediatric clinical experience is the most stressful for both associate degree and baccalaureate nursing students (Oermann \& Standfest, 1997). Students expressed concern about making errors in giving medications to children and interacting with parents of an ill child. In a descriptive exploratory study $(\mathrm{N}=416)$, both quantitative and qualitative data analysis compared student perception of clinical stress in Associate Degree Nursing (ADN) and Bachelor of Science in Nursing (BSN) students (Oermann \& Standfest, 1997). Although moderate levels of stress were found in both groups, the ADN group reported a significantly higher level of stress in the clinical setting, especially in pediatrics courses, than the BSN group. However, the ADN students were significantly older than the BSN students (Oermann \& Standfest, 1997). A subsequent study of 75 ADN and BSN students did not confirm higher stress while enrolled in pediatric clinical courses, as compared to 383 students enrolled in 
nonpediatric nursing courses, but the fear of making medication errors to children was the predominant stressor identified by both groups of students in the study (Oermann \& Lukomski, 2001).

\section{Perception of Stressors}

Research suggests that nursing students perceive higher levels of stress than students in other health-related disciplines (Akgun, 2004; Beck et al., 1997; Gadzella, 1994b; Gadzella \& Carvalho, 2006; Gadzella, Ginther, et al., 1991; Gupchup et al., 2004). Beck et al. (1997) compared perceptions of 552 full-time students regarding level and source of stress in two Canadian baccalaureate nursing programs, and then compared these groups with perceptions of medicine, pharmacy, and social work students. Results suggest that nursing students, regardless of year in the program, experience higher levels of stress and more physical and psychological symptoms than students in the other health-related disciplines. In addition, the study reported that although many commonalities exist in the source of stressors in all student groups, the level of stress management in the nursing group is significantly lower than in the medical, pharmacy, and social work groups. The study suggested that gender may play a major role in this finding, as there were significantly more female students in the nursing program than in the other health-related programs investigated (Beck et al., 1997).

An interesting finding is that in comparison to perceptions of students, faculty perception of student academic stress may be different. One study examined perceptions of academic stress among 249 male and female college students and then compared these perceptions to faculty perceptions of student academic stress (Misra et al., 2000). Using 
congruent forms of Gadzella’s Student-life Stress Inventory (Gadzella, 1991, 1994b), results demonstrated that faculty perception of student academic stress was significantly higher than student perception. There was also evidence of increasing academic stress levels as students progressed in the school and significantly higher stress levels in females. However, this study reported low response rates (42\% students and 33.5\% faculty), surveyed mostly Caucasian students, and did not report the reliability and validity of the instrument used to measure stress (Misra et al., 2000). Further research is warranted to confirm these findings.

\section{Impact of Stressors on Physical and Mental Health}

Students with high levels of stress tend to perceive themselves as less healthy, with low self-esteem, and are more prone to practice a number of poor health habits (Beck et al., 1997; Gupchup et al., 2004). Hudd et al. (2000) reported an increase in unprotected sexual practices, increased consumption of alcohol and junk food, and a decrease in exercise and physical fitness. This study is limited by the skewed nature of the participants, as the majority of respondents were females (55.2\%), Caucasian (62.2\%), and seniors (42.1\%), and only 8.3\% were freshmen (Hudd et al., 2000). However, a cross-sectional survey of Doctor of Pharmacy (Pharm.D.) students (n=166) in the first three years of their program, confirms these findings. As the types and reactions to stressors increased, the mental component of health-related quality of life scores decreased (Gupchup et al., 2004). A study of 552 baccalaureate students reported a significantly higher level of physical and psychological symptoms and stress in nursing 
students at all program levels, as compared to medical, pharmacy, and social work students in the study (Beck et al., 1997).

Students with higher perceptions of stress are more likely to perceive external rather than internal control and to engage in unhealthy and high risk behaviors (Gadzella, 1994a; Haack, 1988; Trockel et al., 2000). In two groups of college undergraduates (123 and 160 participants), significant differences were reported on locus of control scales according to perception of stress level. Individuals with greater stress are more likely to believe that personal decisions and behaviors are influenced by chance or by other people who are more powerful and significant rather than by internal responsibility and control of outcomes (Gadzella, 1994a). A recent study in Kuwait specifically explores the effect of health-related behaviors on academic performance in nursing courses, and reports a significant correlation between health responsibility and enrollment levels (Al-Kandari \& Vidal, 2007). Learned resourcefulness, which promotes internal control, may be important in decreasing stress and shifting locus of control, to promote healthy behaviors and to improve enrollment levels of nursing students.

\section{Coping with Stress}

Only a few studies examine the effect of nursing student stress level when stress management techniques are incorporated into the program (Beddoe \& Murphy, 2004; Kanji et al., 2006; Manderino, Ganong, \& Darnell, 1988; Rollant \& Curlette, 1994). One study of associate degree program students comparing an experimental group with a control group, found a significant decrease in perceived student stress after specific selfdirected and group-related stress management interventions (Rollant \& Curlette, 1994). A 
pilot study examined mindfulness meditation, which involves the process of learning how to be self-reflective, self-aware, accepting of others, and better able to develop positive coping resources, found a decrease in the stress of participants (Beddoe \& Murphy, 2004). A randomized controlled trial of autogenic training had a short-term effect in alleviating stress for 93 nursing students in the United Kingdom (Kanji et al., 2006). In a study of 38 non-nursing college students, perseverance in an academic selfmanagement counseling program was significantly influenced by level of learned resourcefulness (Kennett, 1994). High resourceful participants benefited more from the program and were more capable of implementing the techniques on a long-term basis than the low resourceful participants (Kennett, 1994). Writing about general life stress for four days was found to positively influence academic performance and somatic symptoms in 74 college students taking Introductory Psychology at a large university in the United States (Lumley \& Provenzano, 2003). Further research on larger samples is necessary to explore how specific types of stress management affect stress levels and the potential impact on academic performance.

\section{Impact of College Student Stressors on Academic Performance}

Several studies examine academic performance in the general college student population, but not in nursing students, and not in relation to academic stressors (Mouw \& Khanna, 1993; Ting, 2000; Ting \& Robinson, 1998; Zheng, Saunders, Shelley, \& Whalen, 2002). College grade point average (GPA) is the usual measurement of academic performance in these studies. One study of 1,167 freshmen (52\% male; 90\% White) living in residence halls found that only about $25 \%$ of the variance in academic 
performance was explained by high school GPA and SAT scores (Zheng et al., 2002). Several other predictors of higher academic performance were more significant in the study, including gender, ethnicity, high school rank, parents’ educational level, and selfperception of abilities and emotional health. For example, students with one or more deceased parents demonstrated no significant difference in academic performance, but students with divorced/separated parents scored significantly lower (Zheng et al., 2002).

Academic performance has been examined in relation to student depression (Haines, Norris, \& Kashy, 1996), student retention (Mouw \& Khanna, 1993; Ting \& Robinson, 1998), student self-control (Mansfield, Pinto, Parente, \& Wortman, 2004); student impairment (Haack, 1988), and student health-related behaviors (Trockel et al., 2000; Al-Kandari \& Vidal, 2007). A quantitative study of 92 nursing students in Haifa, Israel, found that positive relationships with peers and teachers and satisfaction with academic facilities produced significantly higher academic integration and performance (Zeitlin-Ophir et al., 2004). Another study of 304 traditional undergraduate business major students revealed that those with low academic performance have significantly less self control, defined as level of persistence and positive interpersonal skills. However, self-report GPA was used to measure academic performance and the variable of selfcontrol was not theoretically linked to major psychological constructs such as learned resourcefulness, in which self-control plays a significant role (Mansfield et al., 2004). Several studies report that academic self-efficacy is a more robust and consistent predictor than stress levels of performance, adjustment, and persistence in college students (Chemers, Hu, \& Garcia, 2001; Zajacova, Lynch, \& Espenshade, 2005). Self- 
efficacy is a major component of the learned resourcefulness construct (Rosenbaum, 1980a, 1990).

Only one study investigates both categories of stressors-personal and academic_-in relation to academic performance in college students (Gwele \& Uys, 1998). Using a comparative descriptive design involving 101 nursing students in two different baccalaureate programs in South Africa, significantly lower levels of student academic and personal stress were found when clinical experience was placed during university vacations and not concurrent with a full course load. Results also demonstrate that when student stress levels were lower, their perceptions of nursing course challenge level were higher. These students were more likely to be excited and exhilarated during the clinical experience. On the other hand, students who demonstrated higher stress levels described feelings of anger, apprehension, fear, and being overwhelmed, which negatively affected academic performance (Gwele \& Uys, 1998).

\section{Learned Resourcefulness}

Several studies examine the construct of learned resourcefulness in Israel, Turkey, Canada, and the United States, and have found an important influence in a variety of situations, such as weight loss (Kennett \& Ackerman, 1995), tolerance of pain (Kennett, O’Hagan, \& Cezer, 2008; Rosenbaum, 1980b), coping with loneliness (Hamama, Ronen, \& Feigen, 2000; McWhirter, 1997a, 1997b), prevention of depression (Burns, Rude, Simons, Bates, \& Thase, 1994; Lewinsohn \& Alexander, 1990), tolerance of seasickness (Rosenbaum \& Rolnick, 1983), compliance with medical advice (Aikens, Wallender, Bell, \& Cole, 1992; Bryant, Simons, \& Thase, 1999; Rosenbaum \& Ben-Ari Smira, 
1986), coping with epilepsy or other chronic condition (Preechawong et al., 2007; Rosenbaum \& Palmon, 1984), and addictive behaviors (Carey, Carey, Carnrike, \& Meisler, 2001). Populations across the life-span have been targeted, including schoolaged children (Zauszniewski, Chung, Chang, \& Krafcik, 2002), adolescents (Bilgin \& Akkapulu, 2007; Turkel \& Tezer, 2008), young adults, middle-aged adults, the homeless (Wenzel, 1992), and elders (Rokke, Tomhave, \& Jocic, 2000; Zauszniewski, Eggenschwiler, Preechawong, Roberts, \& Morris, 2006).

Results of these studies suggest that the controllability of a situation influences the coping skills used. There is strong evidence that individuals with high levels of learned resourcefulness are better able to cope with challenging or threatening situations and are less likely to become anxious or depressed as compared to individuals with lower learned resourcefulness levels (Akgun, 2004; Gintner, West, \& Zarski, 2001; Rosenbaum, 1990). Challenging situations or failure tend to increase the motivation of high resourceful individuals, whereas, low resourceful individuals tend to become more easily frustrated and decrease motivation. Although learned resourcefulness level does not influence perception of stress, it does affect the individual's self-efficacy expectancy. Several laboratory studies have also revealed that after repeated exposure to a stressful event, individual differences in learned resourcefulness play a significant role in the response to the stressor (Rosenbaum, 1980b, 1990; Rosenbaum \& Ben-Ari Smira, 1985; Rosenbaum \& Jaffe, 1983).

A few studies specifically target the examination of learned resourcefulness in the college student population (Akgun, 2004; Akgun \& Ciarrochi, 2003; Brewin, Andrews, 
\& Furnham, 1996; Carey et al., 2001; Ceyhan, 2006; Edwards \& Riordan, 2001; Gintner et al., 2001; Kennett, 1994; Kennett \& Keefer, 2006; Kennett \& Stedwill, 1996; McWhirter, 1997a, 1997b; McWhirter, Burrow-Sanchez, \& Townsend, 2008). Results have shown that, although stress levels are similar in both groups, students with higher learned resourcefulness have greater self-confidence, use more effective coping strategies, vary their coping efforts according to the situation, and show higher academic persistence than students with lower learned resourcefulness (Akgun, 2004; Gintner et al., 2001; Kennett \& Keefer, 2006). Students with higher learned resourcefulness are better able use planning and problem-solving skills to control anxiety when faced with high stress during final exams, whereas those with lower learned resourcefulness use more wishful thinking, self-blame, and self-doubt (Akgun \& Ciarrochi, 2003; Gintner et al., 2001; Rosenbaum, 1990). These results confirm the findings of Lazarus and Folkman (1984), in their classic study of changes in emotions and coping responses of students during three phases of an examination.

There is some evidence of racial/ethnic differences in learned resourcefulness levels, as measured by the Self Control Schedule (SCS) (Rosenbaum, 1980a). In two studies of both Black and White South African university students, Black students scored significantly higher than White students (Edwards \& Riordan, 2001). The first study included a small sample of Black students $(\mathrm{N}=16)$ and 184 White students. However, the second study, which confirmed findings of the first, included a larger sample: 100 Black and 138 White students. The mean scores of the White students $(M=15.2)$ were similar to mean scores of several samples of college students in Israel and the United 
States (Edwards \& Riordan, 2001; Rosenbaum, 1980a, 1988). However, the scores of the Black students were significantly higher $(M=33.0)$.

The White students in these studies were from middle class and affluent backgrounds, while many of the Black students were reported to be from economically deprived areas. Both studies also found that, for the White group, the SCS had sound psychometric properties (Cronbach’s alpha $=.82$ ), while the scale revealed several weak item-scale correlations and a much lower Cronbach’s alpha (.52) for the Black group. These results raise questions regarding the effects of environment on the development of learned resourcefulness abilities and problems of cross-cultural testing (Edwards \& Riordan, 2001; Rosenbaum, 1980a, 1988).

Increased learned resourcefulness does not appear to be a prerequisite for achieving higher grades in college (Kennett, 1994). Students with high levels of general learned resourcefulness are not necessarily academically resourceful. These students may have high levels of self-efficacy expectancy applied to other areas of their lives, but have low levels of self-efficacy in the academic setting. They may not allow enough time to study for exams or prepare for class. In addition, some low resourceful students are able to learn academic resourcefulness skills and achieved higher grades. However, overall, students with high academic resourcefulness are more likely to achieve higher grades than students scoring low in academic resourcefulness (Tuckman \& Sexton, 1990).

An extensive body of research has consistently shown that academic self-efficacy predicts persistence and grades in college (Bandura, 1986a, 1986b, 1993; Bean, 1990; Chemers et al., 2001; Tinto, 1993; Zajacova et al., 2005). Students with high academic 
self-efficacy believe they are capable of achieving high grades and usually obtain them, while those with perceived low academic self-efficacy are more prone to decreasing motivation and goal achievement (Bandura, 1982, 1986a, 1986b, 1993, 1997). Therefore, academic resourcefulness appears to be a more robust and consistent predictor of grades than learned resourcefulness (Chemers et al., 2001; Kennett, 1994; Tuckman \& Sexton, 1990; Zajacova et al., 2005).

Although stress appears to be prevalent in college students and has been shown to influence academic performance, only one study involves the links among learned resourcefulness, stressors, and academic performance (Akgun \& Ciarrochi, 2003; Kennett, 1994), and no researchers have examined nursing students. In support of previous research, a study of 141 first-year undergraduate students at a university in Australia, found that increased academic stress led to decreased academic performance (Akgun \& Ciarrochi, 2003). More importantly, the findings suggest that the impact of stress is moderated by learned resourcefulness. Although all students perceived similar levels of academic stress, there was no effect on the academic performance of the high resourceful students, but a significant negative effect on the academic performance of the low resourceful students (Akgun \& Ciarrochi, 2003).

This link of general learned resourcefulness, stressors, and academic performance needs to be strengthened through further examination in the college student population and specifically established in nursing students. Then, the more specific variable of academic resourcefulness can be explored in relation to academic performance. In addition, the evolving demographics of the college student population, the dynamic 
context of the academic environment, and the changing national and global economic influences, demand an exploration of both major categories of college student stressors: personal and academic. The current study examined the effect of learned resourcefulness among the relationships of personal and academic stressors and academic performance, and specifically in nursing students.

\section{Conceptual Framework}

The conceptual framework for the current study is displayed in Figure 1, which depicts the impact of stressors and learned resourcefulness on nursing student academic performance. Stress is defined as "a particular relationship between the person and the environment that is appraised by the person as taxing or exceeding his or her resources and endangering his or her well-being” (Lazarus \& Folkman, 1984, p. 19). Figure 1, based on the work of Hans Selye $(1974,1976)$ and the Transactional Model (Lazarus \& Folkman, 1984), focuses on the transaction between people and their external environment and suggests that stress is an imbalance between demands and resources and occurs when pressure exceeds the perceived ability to cope. Stress is a result of how a specific stressor and the potential resources to cope with it are appraised. The model proposes that if stressors are perceived as positive or challenging rather than a threat, and if the stressed person is confident that he/she possesses adequate rather than deficient coping strategies, stress may not necessarily occur during the presence of a stressor (Folkman, Lazarus, Gruen, \& DeLongis, 1986; Lazarus \& Folkman, 1984). 


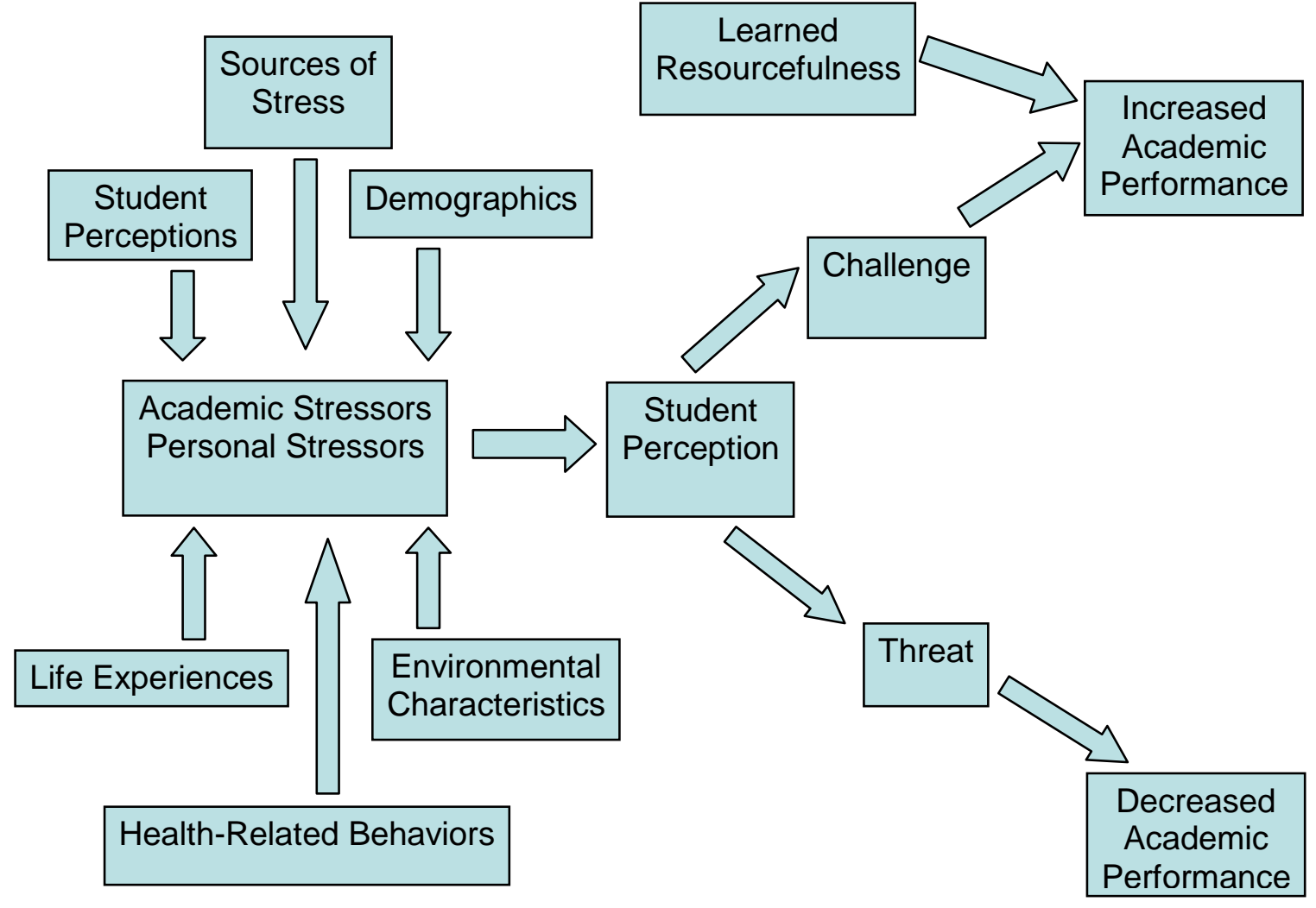

Figure 1. Stressors, Academic Performance, and Learned Resourcefulness

Stress is viewed as controllable by helping people change their perceptions of stressors, providing them with strategies to help them cope, and improving their confidence in the ability to do so (Lazarus \& Folkman, 1984). In order to develop an effective stress management program, it is first necessary to identify the factors that are central to a person controlling his or her stress, and to identify the intervention methods which effectively target these factors. Therefore, if nursing student perception of stress is better understood, stress management strategies can be developed more easily, leading to higher academic performance and lower attrition rates. 
Stressors in the college student may be categorized as either academic or personal (Gadzella, 1994b). Academic stressors may include the ability to adjust to college, intellectual ability, study habits, grades, assignments, examinations, long hours of study, and lack of free time. Personal stressors may include family and work responsibilities, the economic burden of college, and time-management. Stressors unique to the college student include adjustment to college life, changes in lifestyle, inefficient coping skills, and increased pressure of studies and achievement of academic outcomes, leading to increased strain on interpersonal relationships (Friedlander et al., 2007). In addition, there are stressors unique to students in health-related professions, such as nursing, especially related to the clinical area, although testing and competition for grades continues to be a major source of stress in the classroom (Magnussen \& Amundson, 2003; Oermann, 1998; Zeitlin-Ophir et al., 2004).

Figure 1 demonstrates that several factors influence or impact these stressors, including demographics such as gender, age, ethnicity, socioeconomic status, and family structure. The demographics of the college student have evolved to include a significantly larger proportion of "non-traditional” students, who are older, and have additional responsibilities, placing a significantly higher emphasis on the effect of personal stressors on academic performance. Non-traditional students focus more on family-related demands, while traditional students are more influenced by their peers and social activities (Magnussen \& Amundson, 2003).

Other factors impacting stressors are student perceptions, internal or external sources of stress, such as psychological factors or family support, and previous and 
current life experiences (Zajacova et al., 2005). Health-related behaviors also affect stressors and may include either health promotion or health-risk behaviors, such as unprotected sexual practices, increased smoking, drinking, or eating, and decreased exercise and physical fitness (Gupchup et al., 2004). Environmental characteristics include factors on the campus such as type and size of institution, student level of integration, and resources available, and factors in the classroom, such as class size, student age, time in the semester, level and type of course, female-male ratio, instructor gender, student participation, and faculty teaching style, interaction, and innovation (Constantinople, Cornelius, \& Gray, 1988; Howard \& Henney, 1998).

Research has shown that student perceptions of stressors significantly affect satisfaction and persistence in college and commitment to a specific career. When a stressor is perceived as a threat, students are more likely to decrease satisfaction, motivation, persistence, and health-related behaviors, and, therefore, perform more poorly and eventually fail or dropout (Zajacova et al., 2005). On the other hand, when a stressor is viewed as a challenge, the student is much more likely to become more motivated, improve their decision-making, coping style, self-confidence, satisfaction, and health-related behaviors, which leads to an improvement in academic performance (Lazarus \& Folkman, 1984).

Figure 1 displays that the construct of learned resourcefulness may positively influence the student's ability to cope with stressors and result in an improvement in academic performance. Learned resourcefulness has been defined as “an acquired repertoire of behavioural and cognitive skills with which the person is able to regulate 
internal events such as emotions and cognitions that might otherwise interfere with the smooth execution of a target behaviour” (Rosenbaum, 1990, p. xiv). Learned

resourcefulness is not expected to affect the individual's perception of the situation, but is hypothesized to influence the individual's self-efficacy beliefs regarding ability to cope with the situation (Rosenbaum, 1990). "What are the unique human qualities that make people resourceful and creative even under the most dire circumstances?” (Rosenbaum, 1990, p. xix).

The construct of learned resourcefulness is derived from the cognitive-based behavioral self-control models of Bandura (1977, 1978), Kanfer (1977), Kanfer and Hagerman (1981), and Meichenbaum (1977, 1985). Learned resourcefulness expands the cognitive processes to include the role of personality repertoires, or well-learned behaviors, cognitions, and affects, which promote self-control, self-direction, and the capability to adopt health-promoting attitudes and behaviors (Rosenbaum, 1990). Other examples of personality repertoires are hardiness (Kobasa, 1979) and sense of coherence (Antonovsky, 1979, 1987). Hardiness is viewed as three intertwined components: commitment, control, and challenge. "Hardy" individuals tend to emphasize the positive aspects of a stressor, view change and disruption as challenging and desirable, and strive for a healthy adaptation to a stressful environment (Kobasa, 1979).

Similarly, individuals with a high sense of coherence usually evaluate stressors as positive because they believe that both internal and external environments are predictable and that situations will work out as expected (Antonovsky, 1979, 1987). A sense of coherence refers to a personal set of beliefs that guides an individual to cope with stress, 
and expresses that life is comprehensible, manageable, and meaningful (Antonovsky, 1979, 1987). Rosenbaum (1990) ranks learned resourcefulness on a specific-to-global scale as more specific than hardiness and sense of coherence. Major components of learned resourcefulness include controlling emotional responses, problem-solving strategies, the ability to delay immediate gratification, and self-efficacy. Perception of self-efficacy influences self-confidence, problem-solving ability, and mastery experience, which are necessary for coping with stressors in order to increase academic performance (Rosenbaum, 1990).

Learned resourcefulness is also based on the work of Lazarus and Folkman (1984) which includes primary and secondary appraisal of stressors. In primary appraisal, the individual evaluates whether the stressor is desirable or undesirable. If the individual decides there is nothing at stake, no self-control behavior will be enlisted. However, if the individual feels threatened, a secondary appraisal examines potential coping which may maximize potential benefits and minimize adverse effects (Rosenbaum, 1990). During secondary appraisal, individuals develop expectations for the future. Bandura (1977, 1982) proposed two basic expectancies that play a significant role in guiding human behavior: outcome and self-efficacy. Outcome expectancies refer to an individual's belief that, if a specified course of action is followed, the desired goal will be obtained. Selfefficacy expectancies involve the individual's evaluation that he or she is fully capable of performing the necessary acts to attain the desired goal (Bandura, 1977, 1982).

The learned resourcefulness model is a different theoretical orientation than the work of Abramson, Seligman, and Teasdale (1978) regarding learned helplessness, which 
focuses on the individual's actual or perceived control over external events. In contrast, learned resourcefulness focuses on actual or perceived control over an individual's own behavior, or self-control (Rosenbaum, 1980a, 1983; Rosenbaum \& Ben-Ari Smira, 1985). It is believed that all individual behavior is goal-directed and that self-control behaviors are used when facing everyday problems or disruptions (Rosenbaum, 1980a). Learned helplessness is based on the pathogenic model, which focuses on specific reasons why individuals get sick, while learned resourcefulness is based on the broader salutogenic model, which attempts to explain why individuals stay healthy despite exposure to a variety of risk factors. The salutogenic model also examines social, cultural, and personal resources or variables that contribute to human psychological well-being (Rosenbaum, 1990).

Learned helplessness involves the mandatory presence of three components: contingency, cognition, and behavior. Contingency is defined as the objective relationship between the person's actions and outcomes experienced. Contingencies can be either controllable (reliable) or uncontrollable (random). Cognition is the way in which the person perceives, explains, and extrapolates the contingency. Extrapolation involves how the individual uses perception and explanation to form an expectation about the future. The behavior component involves observable consequences of (non) contingency and the individual's cognitions about it. In the learned helplessness model, some individuals learn during previous exposure to uncontrollable events that responding behavior is futile. Therefore, when exposed to subsequent situations, the individual expects the same outcome of failure and uses the previous behaviors regardless of 
controllability of the event (Rosenbaum \& Ben-Ari Smira, 1985; Seligman, 1975;

Seligman, Maier, \& Greer, 1968). Learned resourcefulness, on the other hand, has a broader focus and emphasizes positive aspects of coping with stress (Rosenbaum, 1990).

Only one study examines the impact of learned resourcefulness on academic stress and academic performance in undergraduate psychology students at the University of Australia and reports a significant level of mediation (Akgun \& Ciarrochi, 2003). Further research is needed to explore these findings in college students in the United States, and specifically in nursing students. The current study filled this gap by examining the effect of learned resourcefulness on the relationships of personal and academic stress levels to academic performance in baccalaureate nursing students. 


\section{CHAPTER III}

\section{METHODOLOGY}

The purpose of this explanatory correlational study was to examine the mediating effect of learned resourcefulness on the relationships of stressors-both personal and academic — to academic performance in baccalaureate nursing students. This chapter explains the methodological details used to implement the study. Specifically, presented here are the general perspective and context of the study, an overview of the participants, a description of the instruments and procedures used in data collection, and an explanation of data analysis strategies for each research question.

\section{Hypotheses}

The following research questions guided the study:

Question 1: What is the relationship between stressors and academic performance in baccalaureate nursing students?

Null Hypothesis: Stressors are not related to the academic performance of baccalaureate nursing students.

Alternative Hypothesis: Stressors are related to the academic performance of baccalaureate nursing students.

Variables: stressors (independent); academic performance (dependent). 
Question 2: How do age, race/ethnicity, gender, marital status, work status, or enrollment status moderate the relationship between stressors and academic performance in baccalaureate nursing students?

Null Hypothesis: Age, race/ethnicity, gender, marital status, work status, or enrollment status do not moderate the relationship between stressors and academic performance in baccalaureate nursing students.

Alternative Hypothesis: Age, race/ethnicity, gender, marital status, work status, or enrollment status moderate the relationship between stressors and academic performance in baccalaureate nursing students.

Variables: stressors, age, race/ethnicity, gender, work status, enrollment status (independent), and academic performance (dependent).

Question 3: What is the effect of learned resourcefulness on the relationship among stressors and academic performance in baccalaureate nursing students? Null Hypothesis: Learned resourcefulness does not mediate the effects of stressors on the academic performance of baccalaureate nursing students.

Alternative Hypothesis: Learned resourcefulness mediates the effects of stressors on the academic performance of baccalaureate nursing students.

Variables: stressors (independent); academic performance (dependent), learned resourcefulness (intervening).

Question 4: How do age, race/ethnicity, gender, marital status, work status, or enrollment status moderate the relationships among learned resourcefulness, stressors, and academic performance in baccalaureate nursing students? 
Null Hypothesis: Age, race/ethnicity, gender, marital status, work status, or enrollment status do not moderate the relationships among learned resourcefulness, stressors, and academic performance in baccalaureate nursing students.

Alternative Hypothesis: Age, race/ethnicity, gender, marital status, work status, or enrollment status moderate the relationships among learned resourcefulness, stressors, and academic performance in baccalaureate nursing students.

Variables: stressors, age, race/ethnicity, gender, work status, enrollment status (independent), academic performance (dependent), learned resourcefulness (intervening).

\section{Sample Population}

The convenience sample consisted of 53 baccalaureate nursing students (50 juniors, 3 seniors, 94.3\% enrolled full-time, and 92.5\% female), at a large university located in an urban area in the southeastern United States. This specific university was chosen because of its student diversity, which allowed the researcher to include cultural/ethnic diversity as a variable in the study. The 2007 Student Data Profile for the university reported 361 sophomore School of Nursing students: 324 female and 37 male. Of this group, 251 were White, 75 Black, 17 Asian, 5 Hispanic, 1 American Indian, and 12 other. In the fall of 2008, a high percentage of student diversity was represented within the entire university. For example, $22 \%$ of undergraduates and $15 \%$ of graduate students were reported to be African-American.

Participants in the current study ranged in age from 20 to $54(M=24.8)$, with 84.9\% identifying as Caucasian and 9.4\% identifying as African-American or Black. All participants were enrolled either full-time or part-time and met the following inclusion 
criteria: (a) age 18 or above, (b) adequate English proficiency, both in reading and writing; and (c) able to give informed consent. Study procedures involved minimal foreseeable risks or harm to participants, participation was voluntary, and participants were free to ask questions, and to withdraw at any time. The education of the participant in the nursing program was not affected by participation in this study.

\section{Procedure}

In collecting the data, the researcher adhered to ethical guidelines, principles, and standards for studies conducted with human beings (American Psychological Association, 2001). The University Institutional Review Board and the School of Nursing Research Committee approved the study prior to its implementation. The study included safeguards for protecting humans, which involved three major ethical principles: beneficence, respect for human dignity, and human justice. Beneficence is the protection of participants from physical and psychological harm, exploitation, and performance of some good (Sales \& Folkman, 2000). The risk/benefit ratio of participation weighs the risk to participants against potential benefits to society. Beneficence implies maximizing benefits over risks. Participants in this study may have developed greater personal awareness of their repertoire of learned resourcefulness skills and the types of personal and academic stressors that they were experiencing while a nursing student. The risks were considered minimal and there were no known emotional discomforts during or after participation. There was a slight risk of a breach of confidentiality due to the link between participants’ responses and their identity. 
Respect for human dignity involves the participant's right to self-determination (freedom to control own activities including participation in study) (Sales \& Folkman, 2000). Participation in this study was strictly voluntary. Participants could withdraw from the study at any time, either during or after participation, without negative consequences. Participation was not associated with course grades or status as a nursing student at the university. If a participant had withdrawn from the study, specific data would have been eliminated from the study and destroyed. Information regarding the right of selfdetermination was included in the Informed Consent Form (see Appendix B).

Respect for human dignity also includes the right to full disclosure (Informed Consent Form fully described to prospective participants their rights and full nature of the study prior to gathering data). Justice includes the right to fair treatment (both in the selection of participants and during the course of the study) and right to privacy (through confidentiality procedures that safeguard information that participant's provide). The specific baccalaureate nursing program was chosen for the current study because the researcher, who teaches at another university, was not involved with those students in any way. Every student taking junior level nursing courses had an equal chance of participating in the study and was recruited equitably.

The information participants provided was kept strictly confidential. Participant names were not associated with the research findings in any way and only the researcher knew the identities. Informed consent forms and other identifying information were kept separate from the data, and all study materials were stored in a locked file off the university campus. Only the researcher had access to this file. An ID number was 
assigned to each set of actual data in order to protect the confidentiality of the participants. Any records that would identify the participants in this study will be shredded by the researcher approximately three years after the study is completed. The results of this research, using only aggregate data, will be published in the researcher's dissertation and possibly in subsequent journals or books. Findings published or presented in public forums will not contain any identifiers.

The researcher obtained a list of instructors for each junior nursing class and contacted them to obtain permission to enter the classroom at the end of class. On the day of data collection, the researcher distributed the Letter of Introduction to Participate (see Appendix A) at the end of each junior nursing class offered during Spring 2009 semester and invited students to complete the data collection instruments in a nearby, comfortable classroom, which had been previously reserved. The Letter of Introduction to Participate included a brief overview of the purpose of the study, data collection procedures, inclusion criteria, how potential participants were selected, types of data to be collected, benefits of the study to participants and society, potential risks of participation, and the time commitment involved. The letter (and the researcher) assured participants that their participation was voluntary, and the decision to participate would not affect their course grade or status in the program. The letter also informed students that they were able to withdraw from the study at any time, either during or after participation, without consequence.

The researcher gave potential participants two copies of the Informed Consent Form, which described the purpose of the study and included information needed to make 
a reasoned decision about participation. The form included the following components: study purpose, potential benefits and risks, potential compensation, voluntary consent, confidentiality of data and participant identity, right to withdraw, and contact information. The consent form was written in clear and understandable language. If potential participants had questions about any aspect of the study or their involvement, they had an opportunity to notify the researcher before signing the Informed Consent Form. Participants could also contact the researcher or supervising faculty during any point of the study if they had questions or concerns about participation. Contact information was included at the bottom of the Informed Consent Form.

Nursing students involved in this study had been admitted to the university, which indicated acceptable levels of English language proficiency, both in reading and writing. In addition, participants had been admitted to the nursing program, which suggested that they had successfully passed the required courses to achieve this level. Also, when signing the Informed Consent Form, participants indicated that they had read, understood, and agreed to participate in this research study. The researcher instructed each participant to return one signed copy to the researcher and to retain the other signed copy. This process was completed before participants completed the surveys.

No compensation was provided for participation. However, participants could choose to be entered into a drawing of six Visa gift cards of \$25 each. The drawing and distribution of prizes took place after all data had been collected and was conducted by a graduate student who was not associated with the student participants. Participants were also able to request a copy of the summary of the final results by indicating interest at the 
end of the Informed Consent Form. Following written informed consent, the researcher gathered independent variable data using a brief demographic data sheet and two standardized self-report paper and pencil instruments. Participants had the opportunity to ask questions of the researcher at any time while completing the surveys.

\section{Instrumentation}

The major dependent variable was academic performance, which was measured by previous semester GPA, and was obtained from each student participant on the Demographic Data Sheet (see Appendix C). The independent variable was personal and academic stress level, which was measured by the Student-life Stress Inventory (SSI) (see Appendices E and F) (Gadzella, 1991). The self-report paper and pencil instrument, developed from a theoretical model described by Morris (1990) and major input from college students, is composed of 51 items which are divided into two major sections: types of stressors and reactions to stressors. The types of stressors section includes both personal and academic stressors and is divided into the following five categories: frustrations, conflicts, pressures, changes, and self-imposed. For example, in the pressures category, competition on grades, work, or relationships, deadlines for papers and personal bills, feelings of overload, and family, school, and work interpersonal relationships are assessed. The reactions to stressors section is comprised of the following four categories: physiological, emotional, behavioral, and cognitive. Several examples of signs and symptoms are listed on the instrument to guide participants. Participants respond to a five-point scale using 1 = never, 2 = seldom, $3=$ occasionally, $4=$ often, and $5=$ most of the time. 
The Student-life Stress Inventory (SSI) has been used in numerous studies to measure college student stress and to determine the reliability and validity of the instrument (Gadzella, 1991, 1994a, 1994b, 2004; Gadzella \& Baloglu, 2001; Gadzella \& Carvalho, 2006; Gadzella, Fullwood, \& Ginther, 1991; Gadzella, Fullwood, \& Tomcala, 1992; Gadzella, Ginther, et al., 1991; Gadzella, Masten, \& Stacks, 1998). For example, concurrent validities were reported for the SSI for 95 students in 1991 (Cronbach’s alpha ranging from .52 for the Frustrations scale to .85 for the Changes scale), 290 students in $1994(p=.0009)$, and 381 male and female students enrolled in psychology courses at all levels of a state university in 2001 (Cronbach’s alpha $=$.92) (Gadzella, 1994b; Gadzella \& Baloglu, 2001; Gadzella, Fullwood, et al., 1991). Results using Pearson product moment correlation coefficients revealed the following significant differences in stress levels for two responses in each of the nine categories of the instrument for 87 college students: .78 for all participants, .92 for males, and .72 for females (Gadzella \& Guthrie, 1993).

A study of 126 university undergraduates (51 males, 75 females) investigated whether the scores on the Student-life Stress Inventory (SSI) would correlate significantly with the Inventory of Learning Processes (ILP), developed by Schmeck, Ribich, and Ramanaiah (1977). Results showed several significant relationships with the four scales of the ILP, including a positive correlation between cognitive appraisal of stressors and application of this information to specific experiences (Gadzella et al., 1998). Similar results with 55 undergraduates were reported when the SSI was correlated with the Test Anxiety Inventory (Spielberger, 1980) and when the SSI was correlated with the 
Internality, Powerful Others and Chance Locus of Control Inventory (IPC) (Levenson, 1981), surveying 122 undergraduates enrolled in psychology courses at a southwestern state university (Gadzella et al., 1998).

In another study, internal consistency coefficients for each of the nine sections of the SSI and the total inventory values were computed for 95 students on three-week testretest responses, and ranged from .57 (cognitive) to .76 (emotional) (Gadzella, Fullwood, et al., 1991). In addition, when a comparison of means and standard deviations for responses from three stress groups (mild, moderate, and severe) on the SSI were analyzed in five studies over 13 years, significant differences among the groups were found on all nine sections of the instrument (Gadzella, 2004). Students perceiving severe stress scored higher on both the stressor and reactions subscales than those students reporting moderate or mild stress levels (Gadzella, 2004).

A more recent study using more current and complex statistical methods, confirmatory factor analyses, concurred with the previously reported reliability and validity of the instrument, providing more comprehensive evidence that the SSI is a valid instrument for measuring college student stressors and reactions to those stressors (Gadzella \& Baloglu, 2001). Concurrent validity analyses of 120 men and 258 women demonstrated significant differences among the mild, moderate, and severe stress level groups and reactions to reported stressors and internal consistencies for the 381 participants were .92 for the total instrument, .90 for men, and .92 for women. These data demonstrate stronger evidence that the instrument effectively assesses college student stressors and reactions to stressors in the nine categories (Frustrations, Conflicts, 
Pressures, Changes, and Self-imposed, Physiological, Emotional, Behavioral, and Cognitive Appraisal), and a total stress index. Reliability statistics performed for the SSI in the current study reported a Cronbach's alpha of .91 $(\mathrm{N}=45)$, presenting further evidence regarding the instrument's validity.

The independent control variables in the study were age, race/ethnicity, gender, marital status, work status, and enrollment status. A brief Demographic Data Sheet was created for this study and was used to gather this information.

The intervening variable, learned resourcefulness, was measured by the SelfControl Schedule (SCS) (see Appendix D), a 36-item self-report questionnaire developed in Israel, which assesses the individual's general repertoire of self-control behavior as well as tendencies to use those behaviors when experiencing everyday problems or hassles (Rosenbaum, 1980a, 1990). A 17-item Children's Self Control Scale is also available and has been used in a few studies (Rosenbaum \& Ronen, 1991). In the SCS, a six-point scale, ranging from "very characteristic of me” (+3) to "very uncharacteristic of me” (-3), is used to assess the application of problem-solving strategies, the use of selfstatements to control emotional responses, perceived self-efficacy, and the ability to delay immediate gratification.

Scoring Instructions:

1. Reverse the scoring of the following eleven items: $4,6,8,9,14,16,18,19,21,29,35$. For example: If a subject circled item 4, -3 the reverse score would be +3 . Similarly -1 would be +1 , -2 will be +2

2. Sum up all the scores of the individual items. The total score of the scale could range from $-108(36 x-3)$ to $+108(36 x+3)$. For normal populations the score is usually +25 with a standard deviation of 20 . 
The possible range of the scale is +108 to -108 . Eleven of the items are scored in reverse order. A higher composite score on the scale is reported to indicate greater learned resourcefulness (Rosenbaum, 1980a). A Chronbach’s alpha reliability of .82 was obtained in a sample of 1,000 college students (Redden, Tucker, \& Young, 1983). Testretest reliability of the SCS over four weeks has been reported as 0.86 , with alpha coefficients of 0.78-0.86 (Rosenbaum, 1980a, 1990). In a study of 141 first-year undergraduate students in Australia, which found that academic stress was negatively associated with academic performance, the internal reliability of the Self Control Schedule was reported as 0.83 (Akgun \& Ciarrochi, 2003). For the current study, the Cronbach’s alpha was .77 $(\mathrm{N}=49)$.

Numerous studies have supported the construct, convergent, and discriminate validity of the instrument, mostly in adult clinical samples (Boonpongmanee, Zauszniewski, \& Boonpongmanee, 2002; Lewinsohn \& Alexander, 1990; McWhirter et al., 2008; Redden et al., 1983; Richards, 1985; Rosenbaum 1980a; Rosenbaum \& Rolnick, 1983). Only two studies have analyzed the factor structure in college students (Redden et al., 1983; McWhirter et al., 2008). A principal axis factor analysis with oblique (Oblimin) rotation used on SCS data from 583 male and female college students revealed a three-factor solution accounting for $36.37 \%$ of the variance, indicating that the SCS is adequate in that population. The study suggests that, with additional confirmation, the unidimensional SCC has the potential to consist of fewer items and to measure three aspects of learned resourcefulness that are theoretically consistent with Rosenbaum's 
(1980a) original formulation of the construct (McWhirter et al., 2008). Rosenbaum (1980a) did not factor analyze the original 36-item measure.

\section{Data Analysis}

Descriptive statistics summarized the overall trends or general tendencies in the data. Variance, standard deviation, and range determined the spread of stressor scores or learned resourcefulness scores, and z-scores and percentile rank showed a comparison of how one score related to all others. Analyzed descriptive data are displayed using tables, scatter plots, and histograms. The researcher computed reliability statistics for the two standardized instruments used in the study: Self-Control Schedule (SCS) and Student-life Stress Inventory (SSI). A discussion of inferential statistics, which were used for each research question, follows below. Analyzed inferential data are displayed using various correlation matrices (Howell, 2007).

Question 1: What is the relationship between stressors and academic performance in baccalaureate nursing students?

A Pearson product-moment correlation coefficient determined the strength of the linear relationship between the independent variable of personal and academic stressors and the dependent variable of academic performance. The correlation coefficient is a point on a scale between -1 and 1 , and the closer it is to either of those limits, the stronger is the relationship between the two variables of stressors and academic performance.

Question 2: How do age, race/ethnicity, gender, marital status, work status, or enrollment status moderate the relationship between stressors and academic performance in baccalaureate nursing students? 
The researcher selected multiple regression to determine the effect of multiple continuous independent variables (stressors, age) on a single dependent variable (academic performance). Independent t-tests explored the relationships between race/ethnicity, gender, marital status, work status, or enrollment status on academic performance.

Question 3: What is the effect of learned resourcefulness on the relationship among stressors and academic performance in baccalaureate nursing students?

The researcher employed multiple linear regression because it predicts a single dependent variable (academic performance), based on more than one independent variable (stressors and learned resourcefulness). Question \#3 involved a mediating relationship, as displayed in Figure 2, in which learned resourcefulness was examined as a possible mediator, or significant influence, on the relationship between the independent variable, stressors, and the dependent variable, academic performance.

A mediating relationship exists if a significant relationship is found between the independent variable (stressors) and the mediator (learned resourcefulness) (relationship A in Figure 2). Once this relationship was determined, the next step was to identify a significant relationship between the mediator (learned resourcefulness) and the dependent variable (academic performance). This is shown as relationship B. Subsequently, a significant relationship between the independent (stressors) and dependent (academic performance) variable was explored by the researcher. This is displayed as relationship C. Pearson product-moment correlation coefficients determined the strength of these linear relationships. 


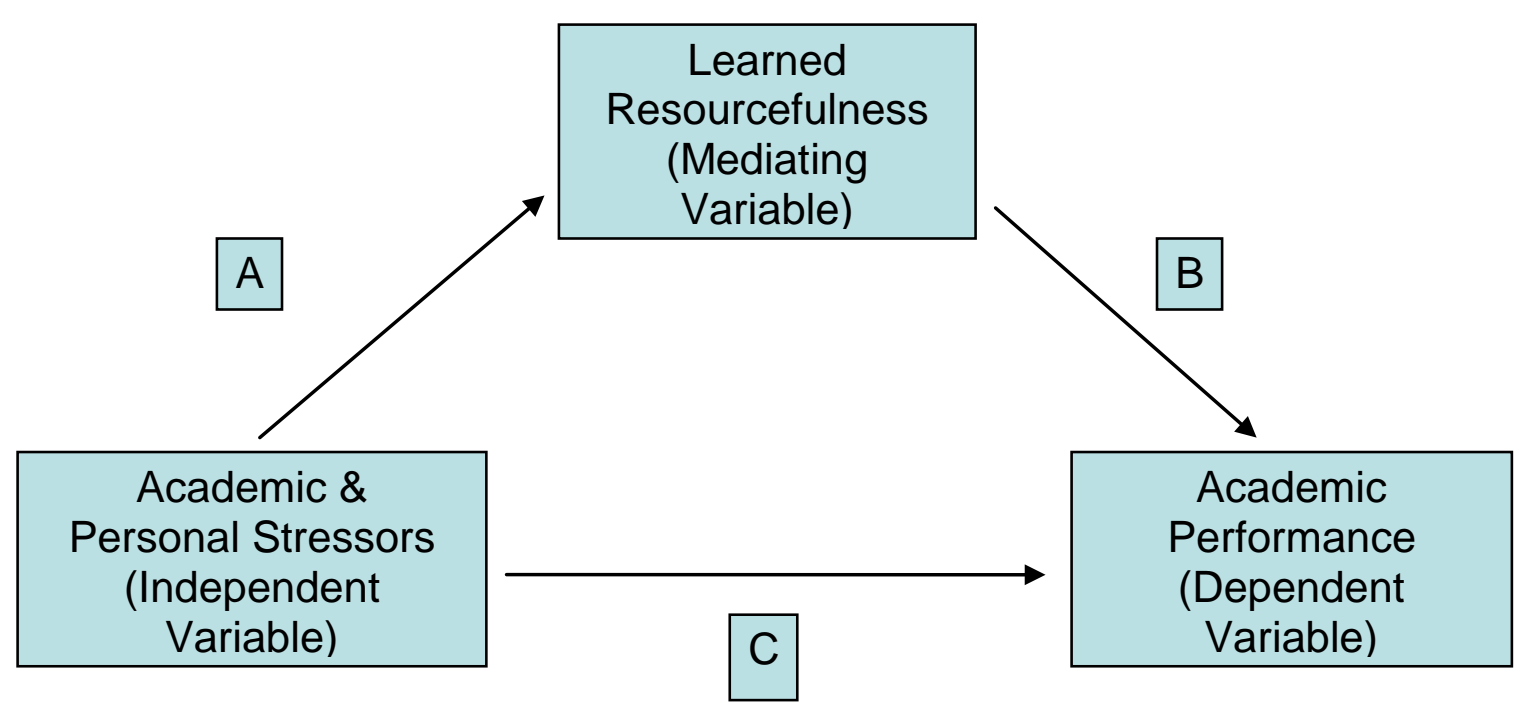

Figure 2. Path Analysis of Stressors, Academic Performance, and Learned Resourcefulness

The final step of the mediating process was to determine if the previously significant path between the independent and dependent variables (relationship C) was greatly reduced, if not non significant, when the mediator and independent variables were entered as simultaneous predictors of the dependent variable, academic performance. If the regression coefficient for the direct path from stress to academic performance was not significant, the main influence of stress was through its mediating relationship with learned resourcefulness (Baron \& Kenny, 1986; Howell, 2007). Multiple regression was used to investigate these relationships.

Included in the multiple regression analysis were partial and semipartial correlations. A partial correlation determined the amount of variance that the intervening variable of learned resourcefulness explained in both the independent variable (stressors) 
and dependent variable (academic performance). The partial correlation between personal and academic stressors and academic performance was determined after controlling for the influence of learned resourcefulness. The partial correlation represented the independent or unique contribution of stressors toward the prediction of academic performance, partialling out learned resourcefulness. A partial correlation less than the zero order correlation would have indicated the magnitude of learned resourcefulness. A semipartial correlation would have determined the correlation between academic performance and the residual predicted on learned resourcefulness. A significant correlation would have indicated that highly resourceful baccalaureate nursing students will be more effective than others at protecting themselves from the adverse effects of personal and academic stressors on academic performance.

Question 4: How do age, race/ethnicity, gender, marital status, work status, or enrollment status moderate the relationships among learned resourcefulness, stressors, and academic performance in baccalaureate nursing students?

The researcher used multiple regression because it determined the effect of more than one continuous independent variable (stressors, learned resourcefulness, age) on a single dependent variable (academic performance). When testing the overall model, if the results had been not statistically significant, the null hypothesis cannot be rejected, suggesting that there were no relationships among stressors, learned resourcefulness, age, and academic performance. Therefore, none of the predictors would have made a significant contribution to academic performance in the presence of all other variables in this model. However, if the critical value of the F distribution had been statistically 
significant, the researcher would have rejected the null hypothesis. In this case, the researcher could assume a significant relationship among stressors, learned resourcefulness, and academic performance. A stepwise regression procedure was performed to determine which of the independent variables were most significant to academic performance. Independent t-tests were used to examine the relationships among race/ethnicity, gender, work status, enrollment status, and academic performance. 


\section{CHAPTER IV}

\section{RESULTS}

As stated in Chapter I, in this explanatory correlational study, the researcher examined the mediating effect of learned resourcefulness on the relationships of stressors — both personal and academic — to academic performance in baccalaureate nursing students. This chapter begins with a description of the sample and reliability of the scale scores from the data collection instruments. It then proceeds to findings related to the four specific research questions posed in Chapter I. First, the relationship between stressors and academic performance is reported and how age, race/ethnicity, gender, marital status, work status, or enrollment status of baccalaureate nursing students affected this relationship. The effect of learned resourcefulness on the relationships among stressors and academic performance and how age, race/ethnicity, gender, marital status, work status, or enrollment status influenced this effect are examined. In the final section

of the chapter, the researcher presents exploratory data in addition to the original research questions.

The sample consisted of 53 baccalaureate nursing students (50 juniors, 3 seniors, 94.3\% enrolled full-time, and 92.5\% female), at a large university located in an urban area in the southeastern United States. Participants ranged in age from 20 to $54(M=$ 24.8), with $83.2 \%$ of the respondents between the ages of 20 and 29 and almost half (49.1\%) reporting current age as 20 or 21 (see Table 1). 
Table 1

Distribution of Respondent's Current Age

\begin{tabular}{lccc}
\hline Age & $f$ & $\%$ & Cum. \% \\
\hline 20 & 9 & 17.0 & 17.0 \\
21 & 17 & 32.1 & 49.1 \\
22 & 9 & 17.0 & 66.1 \\
$23-29$ & 9 & 17.1 & 83.2 \\
$31-38$ & 5 & 9.5 & 92.7 \\
$40-54$ & 4 & 7.6 & 100.0 \\
Total & 53 & 100.0 & \\
\hline
\end{tabular}

Table 2 shows that $18.9 \%$ of the participants reported current marital status as married, 23\% having children (see Table 3), and 84.9\% identifying as Caucasian, 9.4\% African-American or Black, and 1.9\% each of Asian, Pacific Islander, or Other (see Table 4). While $13.2 \%$ of the participants reported living in a residence hall or apartment on campus, the majority (71.7\%) lived off campus without a roommate (see Table 5). Regarding work status, 52.8\% were working part-time, and 32.1\% reported being unemployed, laid off, or looking for work (see Table 6). 
Table 2

Current Marital Status

\begin{tabular}{lrrrr}
\hline & $f$ & $\%$ & Valid \% & Cum. \% \\
\hline Married & 10 & 18.9 & 19.2 & 19.2 \\
Divorced & 1 & 1.9 & 1.9 & 21.2 \\
Separated & 2 & 3.8 & 3.8 & 25.0 \\
Never Married & 37 & 69.8 & 71.2 & 96.2 \\
No Answer & 2 & 3.8 & 3.8 & 100.0 \\
Total & 52 & 98.1 & 100.0 & \\
Missing & 1 & 1.9 & & \\
Total & 53 & 100.0 & & \\
& & & & \\
\hline
\end{tabular}

Table 3

Number of Living Children

\begin{tabular}{lrrrr}
\hline & $f$ & $\%$ & Valid \% & Cum. \% \\
\hline 0 & 40 & 75.5 & 76.9 & 76.9 \\
1 & 7 & 13.2 & 13.5 & 90.4 \\
2 & 3 & 5.7 & 5.8 & 96.2 \\
3 & 1 & 1.9 & 1.9 & 98.1 \\
4 & 1 & 1.9 & 1.9 & 100.0 \\
Total & 52 & 98.1 & 100.0 & \\
Missing & 1 & 1.9 & & \\
Total & 53 & 100.0 & & \\
& & & & \\
\hline
\end{tabular}


Table 4

\section{Race/Ethnicity}

\begin{tabular}{lrrr}
\hline Race/Ethnicity & $f$ & $\%$ & Cum. \% \\
\hline & 5 & 9.4 & 9.4 \\
African American or Black & 45 & 84.9 & 94.3 \\
Caucasian & 1 & 1.9 & 96.2 \\
Asian & 1 & 1.9 & 98.1 \\
Pacific Islander & 1 & 1.9 & 100.0 \\
Other & 53 & 100.0 & \\
Total & & & \\
\hline
\end{tabular}

Table 5

Living Arrangements

\begin{tabular}{lrrr}
\hline Living Arrangements & No & Yes & $\%$ Yes \\
\hline & & & \\
Live on Campus & 46 & 32 & 13.2 \\
Live Off Campus & 21 & 15 & 60.4 \\
Have Roommates & 38 & 15 & 28.3 \\
Live With Parents/Other Family Members & 38 & & \\
\hline
\end{tabular}


Table 6

Work Status

\begin{tabular}{lrrr}
\hline Work Status & $f$ & $\%$ & Cum. \% \\
\hline Full-time & 1 & 1.9 & 1.9 \\
Part-time & 28 & 52.8 & 54.7 \\
Unemployed, Laid Off, Looking & & & \\
For Work & 17 & 32.1 & 86.8 \\
Other & 6 & 11.3 & 98.1 \\
No Answer & 1 & 1.9 & 100.0 \\
Total & 53 & 100.0 & \\
& & & \\
\hline
\end{tabular}

Table 7 displays the means and standard deviations for the entire Self Control Schedule scale and for each subscale of the Student-life Stress Inventory. The Self Control Schedule mean (23.02) is consistent with previously reported means between 23 and 27 and the standard deviation of 21.38 is consistent with standard deviations of 21-25 reported in previous studies (Kennett \& Stedwill, 1996; Redden et al., 1983; Richards, 1985; Rosenbaum, 1980a). Reliability and item statistics for the 36-item Self Control Schedule $(\mathrm{N}=49)$ revealed Cronbach's alpha of .77 and reported the highest mean $(M=$ 2.00) for the ability to plan work when the student is faced with several things to do. The next highest mean $(M=1.83)$ states that the student tries to approach a difficult problem in a systematic way, followed by an increase in self-esteem when able to overcome a bad habit $(M=1.81)$ and usually exploring alternatives, rather than making a quick and spontaneous decision $(M=1.59)$. 
Table 7

Student-Life Stress Inventory (SSI) Scale and Subscale Means, Standard Deviations, and Cronbach's Alpha

\begin{tabular}{|c|c|c|c|c|}
\hline Scale or Subscale & $\mathrm{N}$ & $M$ & $S D$ & $a$ \\
\hline Self Control Schedule Scale & 49 & 23.02 & 21.38 & .77 \\
\hline SSI Frustration Subscale & 51 & 17.51 & 4.25 & \\
\hline SSI Conflicts Subscale & 53 & 8.83 & .94 & \\
\hline SSI Pressures Subscale & 53 & 15.83 & 2.58 & \\
\hline SSI Changes Subscale & 53 & 8.57 & 2.63 & \\
\hline SSI Self-Imposed Subscale & 53 & 22.43 & 3.75 & \\
\hline Total Stressor Score & 51 & 72.86 & 9.97 & .91 \\
\hline SSI Physiological Reactions Subscale & 51 & 33.16 & 8.67 & \\
\hline SSI Emotional Reactions Subscale & 53 & 11.60 & 3.23 & \\
\hline SSI Behavioral Reactions Subscale & 53 & 17.77 & 4.35 & \\
\hline SSI Cognitive Reactions Subscale & 53 & 4.53 & 1.95 & \\
\hline Total Reactions Score & 51 & 67.20 & 13.55 & \\
\hline Total Stress & 49 & 140.22 & 21.26 & \\
\hline
\end{tabular}

Table 7 also shows the five subscales of stressors for the Student-life Stress Inventory (SSI), with Self-Imposed stressors having the highest mean score (22.43), followed by Frustrations (17.51) and Pressures (15.83). Self-imposed stressors include competition and winning, being noticed and loved, worrying, procrastination, perfectionism, and anxiety about taking tests. Delays in reaching goals, daily hassles, and lack of money are some of the items in the Frustrations sub-scale, while Pressures involves competition on grades, work, and relationships, meeting deadlines, overload, and interpersonal relationships (Gadzella, 1991). The Physiological Reactions Subscale 
in the SSI had the highest mean of 33.16, followed by Behavioral Reactions (17.77), Emotional Reactions (11.60), and Cognitive Reactions (4.53). The Cronbach’s alpha for the entire Student-life Stress Inventory (SSI) is reported as .91.

The major type of stressor revealed by the participants was in the Pressures Subscale (4.31) and involved deadlines, such as the ability to hand in papers when they are due or the ability to make payments on time. The next highest stressors in this subscale were an overload of things to do $(M=4.11)$ and competition on grades, work, or relationships $(M=4.00)$. Stressors from the Self-Imposed Subscale were reported as the next highest priority, including competition $(M=3.93)$, worry and anxiety about taking tests $(M=3.75)$, worry about everything and everybody (mean = 3.73), liking to be noticed and loved by all $(M=3.71)$, procrastination $(M=3.60)$, and perfectionism $(M=$ 3.48). Students also cited stressors from the Frustration Subscale, mostly delays $(M=$ 3.11) and daily hassles $(M=3.17)$, which affected them in reaching goals and lack of money $(M=2.80)$.

Emotional reactions to stressors were reported as the most frequent, with fear, anxiety and worry displaying the highest mean $(M=4.11)$. Behavioral responses were cited next. In this category, the mean for both crying and "was irritable toward others" items had a mean of 3.33. Cognitive reactions (thought and analysis) were next, with physiological reactions last, mostly exhaustion $(M=3.46)$ and sweating $(M=3.11)$. As part of the SSI, participants in the sample were first asked to rate their overall level of stress as 1 = Mild, 2 = Moderate, and 3 = Severe. The mean for this sample was 2.16, which is designated as Moderate. 


\section{Relationship between Stressors and Academic Performance}

In response to Question 1, the researcher examined the relationship between stressors (personal and academic) and academic performance in baccalaureate nursing students. A Pearson product-moment correlation coefficient was conducted to measure the strength of the linear relationship between the independent variable of stressors and the dependent variable of academic performance. Self-report grade-point average (GPA) the previous semester, as a measure of academic performance, ranged from 2.92 to 4.0 for the sample $(M=3.59)$.

Table 8, Correlation Matrix and Descriptive Statistics for Stressors and Academic Performance in Baccalaureate Nursing Students $(\mathrm{N}=49)$, demonstrates that the relationship between stressors and academic performance is positive and not statistically significant $(\mathrm{r}(52)=.008, p=.955)$.

Table 9, Academic Performance Regressed Onto Stressors, shows that $p=.955$, which is greater than 0.05 . Therefore the null hypothesis cannot be rejected. The researcher concluded that stressors and academic performance are not related. In addition, the data show that $0 \%$ of the variation in academic performance can be predicted on the basis of total stress $\left(\mathrm{R}^{2}=.00\right)$. Figure 3 displays a scatterplot relating stressors and academic performance and further confirms that there is no apparent linear relationship between the two variables under consideration. 
Table 8

Correlation Matrix and Descriptive Statistics for Stressors and Academic Performance in Baccalaureate Nursing Students $(N=49)$

\begin{tabular}{lcc}
\hline & 1 & 2 \\
\hline Academic Performance & 1.000 & .008 \\
Stressors & .008 & 1.000 \\
Mean & 3.588 & 140.225 \\
Standard Deviation & .276 & 21.264 \\
\hline
\end{tabular}

Table 9

Academic Performance Regressed Onto Stressors

\begin{tabular}{lccccc}
\hline Variable & $\mathrm{b}$ & SEb & Beta & $\mathrm{t}$ & $p$ \\
\hline Intercept & 3.555 & .275 & & 12.943 & .000 \\
Stressors & .000 & .002 & .017 & .115 & .955 \\
\hline
\end{tabular}


Relationship Between Stressors and Academic Performance

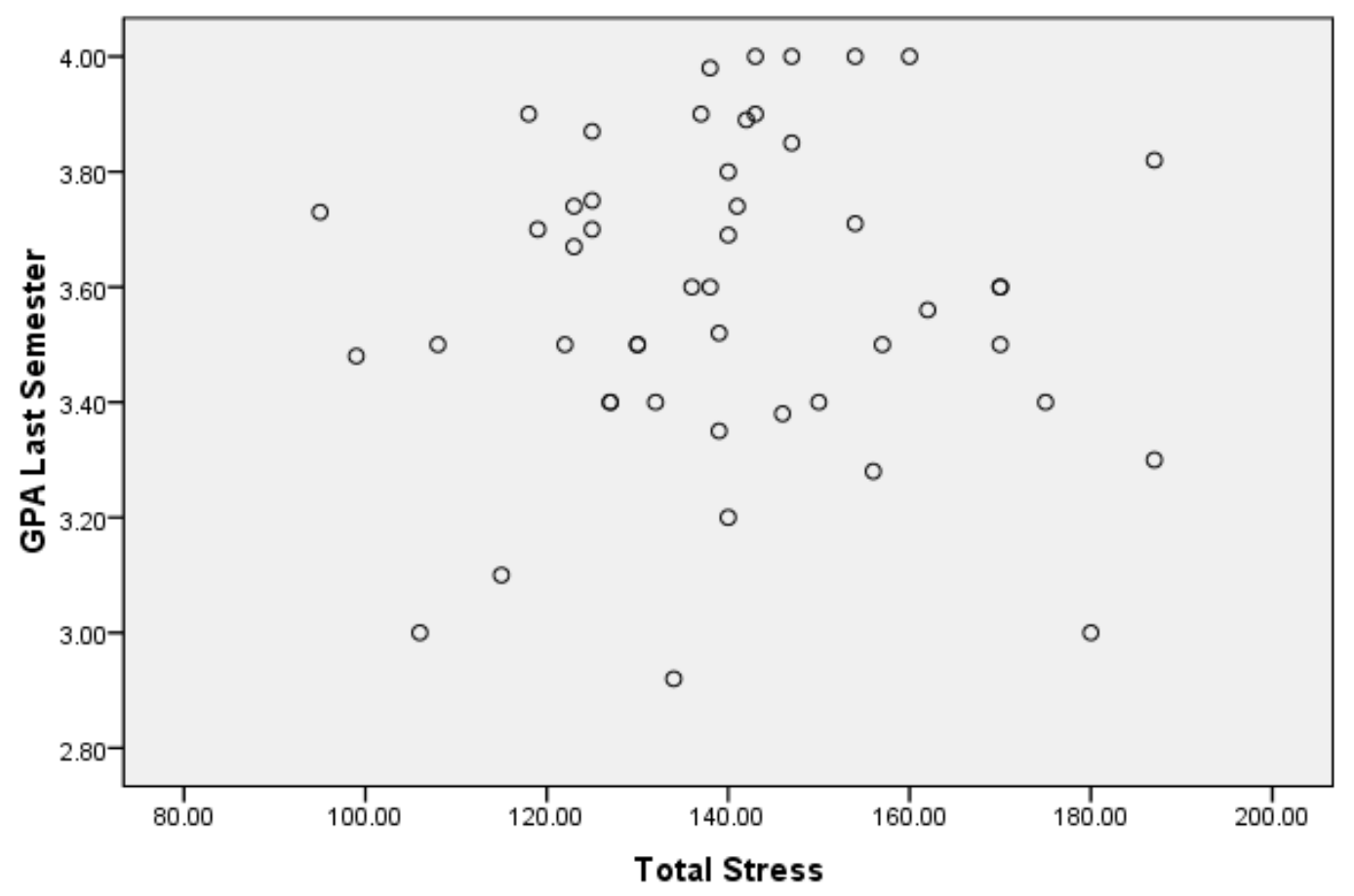

Figure 3. Relationship between Stressors and Academic Performance

Correlation of Age, Race/Ethnicity, Gender, Marital Status, Work Status, Enrollment Status, Stressors, and Academic Performance

In Question 2, the researcher determined the correlation of age, race/ethnicity, gender, marital status, work status, enrollment status, stressors, and academic performance. First, the researcher used multiple regression to examine relationships of age, stressors, and academic performance. Table 10 displays a correlation matrix and descriptive statistics for age, stressors, and academic performance $(\mathrm{N}=49)$. Race/ethnicity, gender, marital status, work status, and enrollment status were not included in this analysis because they are categorical variables, and the number of students in the total sample and subgroups in each category are too small (94.3\% enrolled 
full-time, 92.5\% female, 84.9\% Caucasian, 18.9\% married, 52.8\% working part-time). None of the variables have a strong correlation to each other. However, age has a higher correlation with academic performance than the correlation of stressors and academic performance $(\mathrm{F}(2,46)=4.83, p=.012)$.

Table 10

Correlation Matrix and Descriptive Statistics for Age, Stressors, and Academic Performance $(N=49)$

\begin{tabular}{lrrr}
\hline & 1 & \multicolumn{1}{c}{2} & \multicolumn{1}{c}{3} \\
\hline Academic Performance & 1.000 & .008 & .416 \\
Stressors & .008 & 1.000 & .059 \\
Age & .416 & .059 & 1.000 \\
Mean & 3.588 & 140.225 & 25.143 \\
Standard Deviation & 0.276 & 21.264 & 7.678 \\
\hline
\end{tabular}

Note: Academic performance (GPA last semester) is the dependent variable

When testing the model, the overall $(\mathrm{F}(2,46)=4.83, p=.012)$ is statistically significant (see Table 11). Therefore, the null hypothesis is rejected. There is a relationship among the variables of age, stressors, and academic performance.

Table 12 shows the results of the multiple regression analysis of age and stressors as independent variables predicting academic performance, the dependent variable. Stressors was not a significant predictor of academic performance $(p=.90)$. Age was a significant predictor $(p<.01)$. For every 1 standard deviation increase in age, there would be a .42 standard deviation increase in academic performance. This effect is fairly large. 
Current age is an important predictor of academic performance, but the stressors variable is not. Additional data not included in Table 12 revealed that, when age was entered as the only predictor variable for academic performance, approximately $16 \%$ of the variation in academic performance can be predicted on the basis of this variable $\left(\mathrm{R}^{2}=\right.$ $.16)$ and the results are significant at the .01 level $(\mathrm{F}(1,43)=7.001, \mathrm{p}=.011)$.

\section{Table 11}

Analysis of Variance for Regression of Age and Stressors on Academic Performance

\begin{tabular}{lrrrrr}
\hline & SS & df & MS & F & $p$ \\
\hline $\begin{array}{lrlll}\text { Regression } \\
\text { Residual }\end{array}$ & .635 & 2 & .317 & 4.830 & .012 \\
\hline
\end{tabular}

\section{Table 12}

Multiple Regression Analysis for Age and Stressors Predicting Academic Performance

\begin{tabular}{lccccc}
\hline Variable & $\mathrm{B}$ & SEb & Beta & $\mathrm{t}$ & $p$ \\
\hline Stressors & .000 & .002 & -.016 & -.122 & .903 \\
Age & .015 & .005 & .417 & 3.107 & .003 \\
\hline
\end{tabular}

Note: Academic performance is the dependent variable

A t-test examining the effects of race/ethnicity on academic performance, using only African American or Black $(M=3.55, S D=.21, \mathrm{~N}=5)$ and Caucasian participants $(M=3.60, S D=.28, \mathrm{~N}=45)$, did not demonstrate significant differences among the 
means of the groups $(\mathrm{t}=-.43, \mathrm{df}=48, p=.31)$. The race/ethnicity groups in the entire sample are unequal and small and the analysis must be interpreted with caution. In addition, a t-test examining differences in academic performance of males $(M=3.50$, $S D=.39, \mathrm{~N}=4)$ and females $(M=3.60, S D=.26, \mathrm{~N}=49)$ did not demonstrate significant differences among the means of the groups $(\mathrm{t}=-.70, \mathrm{df}=51, p=.26)$. However, with only four males in the sample of 53 participants, the two groups are unequal and the results of this analysis must also be interpreted with extreme caution. A minimum group size of five is often used with ANOVA. Therefore, these results are only for exploratory purposes. Analyses with a one-way ANOVA for academic performance and marital status $(\mathrm{F}(4,47)=2.58, p=.06)$, and work status $(\mathrm{F}(4,48)=2.57, p=.14)$, and a t-test regarding college enrollment $(\mathrm{F}(1,51)=4.03, p=.64)$ produced similar results, because the groups were small and unequal.

\section{Effect of Learned Resourcefulness on Relationship among Stressors and Academic Performance}

The researcher examined the effect or mediating relationship of learned resourcefulness on the relationship among stressors and academic performance in the third Question, as shown in Figure 4. The results in Question 1 revealed no significant correlation between the relationship of personal stressors and academic performance. Therefore, mediation of learned resourcefulness on this relationship would not occur. However, for Question 3, the following analyses demonstrate the results for each step of how a potential mediating relationship is examined. First, a relationship between the independent variable (stressors) and the mediator (learned resourcefulness) was explored 
(shown as relationship A in Figure 4). A Pearson product-moment correlation coefficient was conducted to measure the strength of the linear relationship between these two variables, and the results in Table 13 reveal that the relationship is negative and not statistically significant $(\mathrm{r}(46)=-.198, p=.553)$.

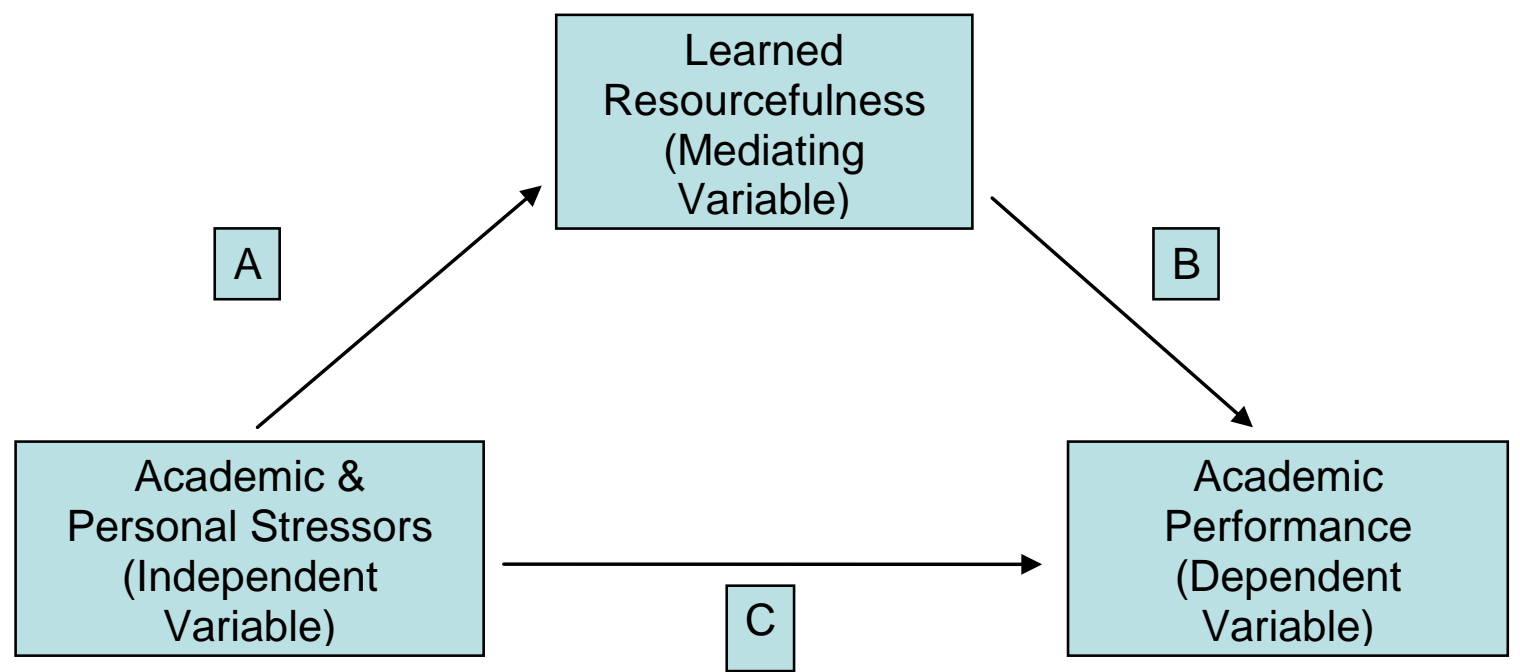

Figure 4. Path Analysis of Stressors, Academic Performance, and Learned

Resourcefulness

\section{Table 13}

Correlation Matrix and Descriptive Statistics for Stressors and Learned

\section{Resourcefulness}

Stressors

Learned Resourcefulness

Mean

Standard Deviation
1.000

$-.198$

140.304

21.767
$-.198$

1.000

21.391

20.622 
Table 14, Multiple Regression Analysis for Stressors and Learned Resourcefulness Predicting Academic Performance, shows $p=.94$ for stressors and $p=$ .28 for learned resourcefulness, which is greater than 0.05 . Therefore the null hypothesis cannot be rejected. Stressors and learned resourcefulness are not predictive in the model with academic performance as the dependent variable. Figure 5 displays a scatterplot comparing stressors and learned resourcefulness and further confirms this finding. There appears to be no apparent linear relationship between these variables.

\section{Table 14}

Multiple Regression Analysis for Stressors and Learned Resourcefulness Predicting Academic Performance

\begin{tabular}{lccccc}
\hline Variable & $\mathrm{b}$ & SEb & Beta & $\mathrm{t}$ & $p$ \\
\hline Stressors & 0.000 & .002 & .012 & .076 & .939 \\
Learned Resourcefulness & 0.002 & .002 & .167 & 1.086 & .283 \\
Intercept & 3.510 & .289 & & 12.165 & .000 \\
\hline
\end{tabular}

The next step in Question 3 was to show a significant relationship between the mediator (learned resourcefulness) and the dependent variable (academic performance) (Relationship B in Figure 4). A Pearson product-moment correlation coefficient was used to determine the strength of this relationship. 
Relationship Between Stressors and Learned Resourcefulness

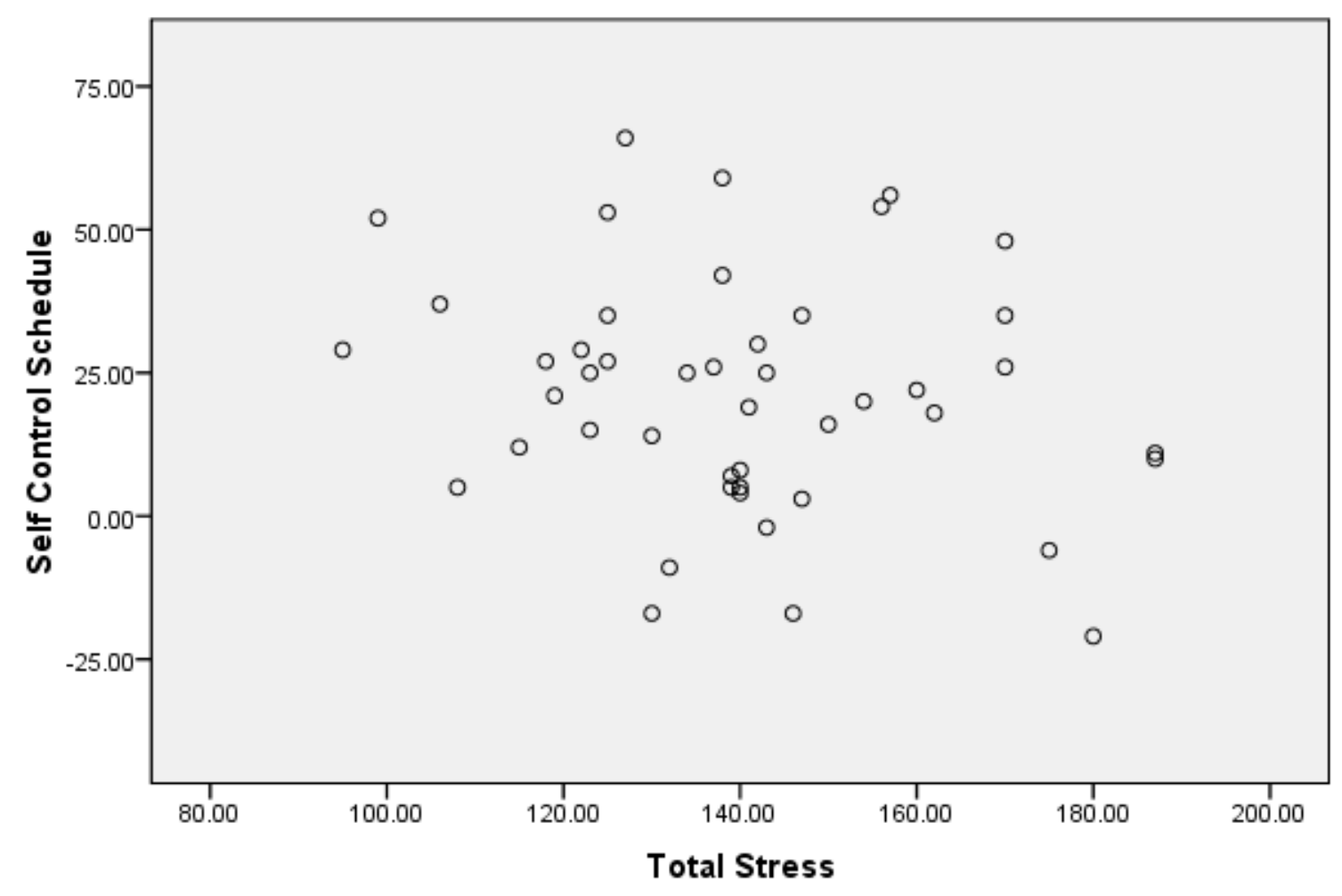

Figure 5. Relationship between Stressors and Learned Resourcefulness

Table 15, which displays the correlation matrix and descriptive statistics for learned resourcefulness and academic performance, reports $\mathrm{r}(49)=.198$ and $p=.172$, demonstrating that the relationship between these two variables is positive and not statistically significant.

In Table 16, Regression Analysis of Stressors and Learned Resourcefulness, $p=$ .172 for learned resourcefulness, which is greater than 0.05 . Therefore the null hypothesis cannot be rejected. The researcher concluded that learned resourcefulness and academic performance are not related. The scatterplot in Figure 6 also displays this finding. 
Table 15

Correlation Matrix and Descriptive Statistics for Learned Resourcefulness and Academic Performance

\begin{tabular}{lcc}
\hline & 1 & 2 \\
\hline Learned Resourcefulness & 1.000 & .198 \\
Academic Performance & .198 & 1.000 \\
Mean & 23.020 & 3.589 \\
Standard Deviation & 21.387 & 0.271 \\
\hline
\end{tabular}

Table 16

Regression Analysis of Learned Resourcefulness and Academic Performance

\begin{tabular}{lccccc}
\hline Variable & $\mathrm{b}$ & SEb & Beta & $\mathrm{t}$ & $p$ \\
\hline Learned Resourcefulness & .003 & .002 & .198 & 1.387 & .172 \\
Intercept & 3.531 & .057 & & 62.363 & .000 \\
\hline
\end{tabular}

The next step was to show a significant relationship between the independent variable (stressors) and the dependent variable (academic performance) (Relationship C in Figure 4). This correlation was previously discussed, as it is also Research Question 1. The data presented in that section revealed that the relationship between stressors and academic performance is positive and not statistically significant $(\mathrm{r}(52)=.008, p=.955)$. 


\section{Relationship Between Learned Resourcefulness and Academic Performance}

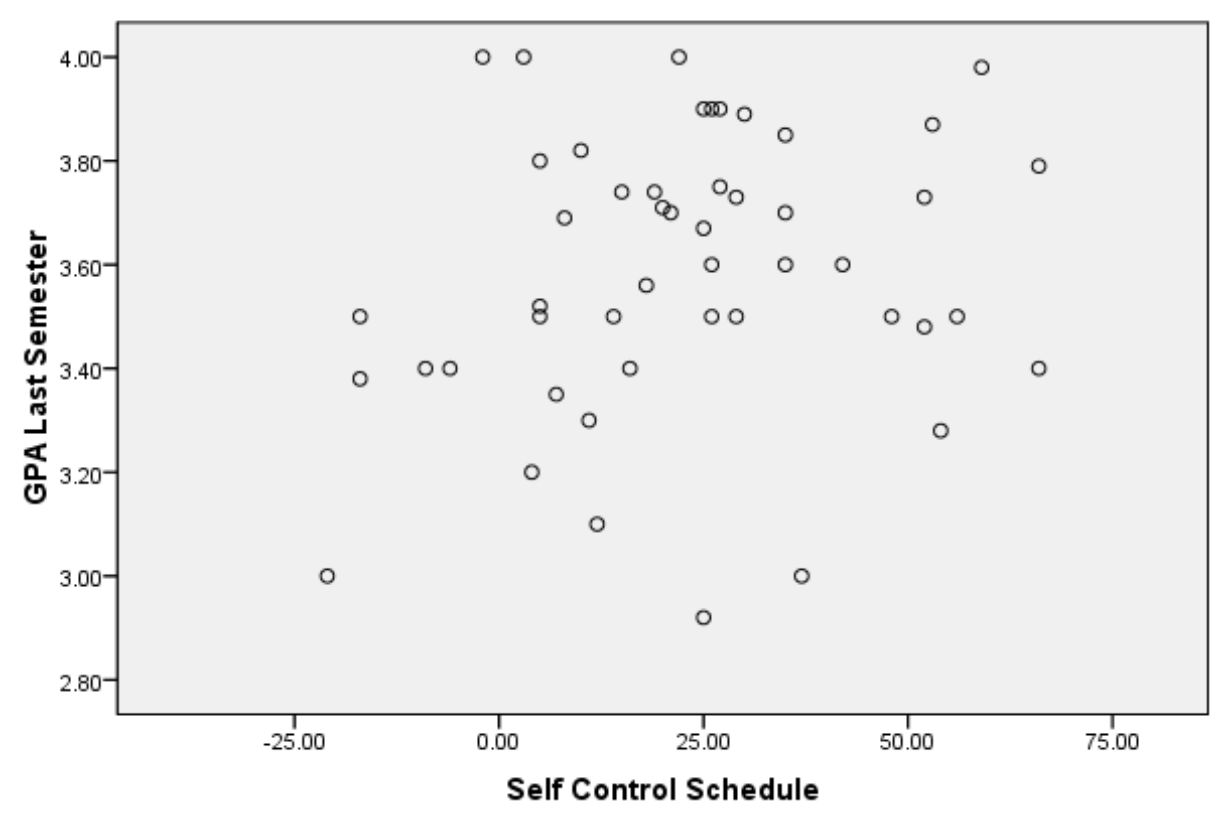

Figure 6. Relationship between Learned Resourcefulness and Academic Performance

The final step of the mediating process was to determine if the previous significant path between the independent and dependent variables (relationship C) was greatly reduced, if not non significant, when the mediator and independent variables were entered as simultaneous predictors of the dependent variable, academic performance. If the regression coefficient for the direct path from stress to academic performance was not significant, the main influence of stress was through its mediating relationship with learned resourcefulness (Baron \& Kenny, 1986; Howell, 2007).

The results in Table 17, Correlation Matrix and Descriptive Statistics for Stressors, Learned Resourcefulness, and Academic Performance, show that the relationship between stressors and learned resourcefulness was negative and not statistically significant $(\mathrm{r}(46)=-.198, p=.283)$. The relationship between stressors and 
academic performance was negative and not statistically significant $(\mathrm{r}(46)=-.021, p=$ .939). Finally, the correlation between learned resourcefulness and academic performance was positive and not statistically significant $(\mathrm{r}(46)=.164, p=.283)$. In summary, steps 1 through 4 in Question 3 revealed no significance in the current study.

\section{Table 17}

Correlation Matrix and Descriptive Statistics for Stressors, Learned Resourcefulness, and Academic Performance

\begin{tabular}{lccc}
\hline & 1 & 2 & 3 \\
\hline Stressors & 1.000 & -.198 & -.021 \\
Learned Resourcefulness & -.198 & 1.000 & .164 \\
Academic Performance & -.021 & .164 & 1.000 \\
Mean & 140.304 & 21.391 & 3.583 \\
Standard Deviation & 21.767 & 20.622 & .277 \\
\hline
\end{tabular}

\footnotetext{
Correlation of Age, Race/Ethnicity, Gender, Marital Status, Work Status, Enrollment Status, Learned Resourcefulness, Stressors, and Academic Performance

In Question 4, the researcher explored the effects of age, race/ethnicity, gender, marital status, work status, enrollment status, stressors, learned resourcefulness, and academic performance. This question was similar to Question 2, but added learned resourcefulness as another independent variable in the model. The researcher used multiple regression to determine the relationships of age, stressors, learned
} 
resourcefulness, and academic performance, the dependent variable. Table 18 displays a correlation matrix and descriptive statistics for these variables $(\mathrm{N}=46)$.

Table 18

Correlation Matrix and Descriptive Statistics for Age, Stressors, Learned Resourcefulness, and Academic Performance

\begin{tabular}{lrrrr}
\hline Variable & 1 & 2 & 3 & 4 \\
\hline & & & & \\
Academic Performance & 1.000 & -.012 & .165 & .379 \\
Stressors & -.021 & 1.000 & -.201 & .026 \\
Learned Resourcefulness & .164 & -.201 & 1.000 & -.043 \\
Age & .379 & .026 & -.043 & 1.000 \\
Mean & 3.583 & 140.304 & 21.391 & 25.000 \\
Standard Deviation & 0.277 & 21.767 & 20.622 & 7.560 \\
\hline
\end{tabular}

Note: Academic performance is the dependent variable

As in Question 2, race/ethnicity, gender, marital status, work status, and enrollment status were not included in this analysis because they are categorical variables, and the number of students in the total sample and subgroups in each category were too small. Of the independent variables in the model, age continued to have the highest correlation to academic performance (.374). The stepwise regression procedure resulted in age as the only independent variable predicting academic performance. Age might be a variable that could be examined as a predictor of academic performance, excluding the other variables in this model. 
Table 19 displays the analysis of variance for regression of age, stressors, and learned resourcefulness on academic performance $(\mathrm{N}=46)$. When the researcher tested the model, the overall $(\mathrm{F}(3,42)=2.83, p=.042)$ was found to be statistically significant. The researcher rejected the null hypothesis, suggesting that there is a relationship among the variables of age, stressors, learned resourcefulness, and academic performance. The means of the independent variables are the same in the population.

\section{Table 19}

Analysis of Variance for Regression of Predictors on Academic Performance

\begin{tabular}{lccccc}
\hline & SS & df & MS & F & $p$ \\
\hline Regression & .608 & 3 & .203 & 2.991 & .042 \\
Residual & 2.844 & 42 & .068 & & \\
Total & 3.451 & 45 & & \\
\hline
\end{tabular}

In Table 20, the model summaries for stressors, current age, and learned resourcefulness as predictors of academic performance are displayed. It shows that approximately $18 \%$ of the variation in academic performance can be predicted on the basis of these variables ( $\mathrm{r}$ squared $=.176)$.

Table 21 shows the multiple regression analysis of age, stressors, and learned resourcefulness on academic performance. Neither stressors $(p=.98)$ or learned resourcefulness ( $p=.21)$ were significant predictors of academic performance. 
Table 20

Model Summary for Independent Variables and Learned Resourcefulness

\begin{tabular}{cccccc}
\hline $\mathrm{R}$ & $\mathrm{R}^{2}$ & $\mathrm{~s} \mathrm{y}-\mathrm{x}$ & $\mathrm{R}^{2}$ Change & F Change & $\mathrm{df}$ \\
\hline .420 & .176 & .26 & .176 & 2.99 & 3 \\
\hline
\end{tabular}

\section{Table 21}

Multiple Regression Analysis for Age, Stressors, and Learned Resourcefulness

Predicting Academic Performance

\begin{tabular}{lccccc} 
Independent Variable & $\mathrm{b}$ & SEb & Beta & $\mathrm{t}$ & $p$ \\
\hline Stressors & 5.841 & .002 & .005 & .032 & .975 \\
Age & .014 & .005 & .386 & 2.755 & .009 \\
Learned Resourcefulness & .002 & .002 & .182 & 1.272 & .211 \\
\hline
\end{tabular}

Note: Academic performance is the dependent variable

Current age is revealed as a significant predictor $(p=.009)$. For every one standard deviation increase in age, there would be a .39 standard deviation increase in academic performance. This effect is fairly large. When current age is entered as the only predictor variable for academic performance, using regression, the results are also significant at the .01 level $(\mathrm{F}(1,43)=7.001, p=.011)$. Current age is an important predictor of academic performance, but stressors and learned resourcefulness are not. 


\section{Further Exploratory Investigation}

The scores for the Self Control Schedule ranged from -21.00 to $66.00(\mathrm{~N}=49$, $M=23.02$ ), which is in normal range for this scale (Rosenbaum, 1980a). The median was 25.00. An examination of the means for learned resourcefulness and gender revealed that, although there were only four males in the sample, they scored higher on the Self Control Schedule than the 45 female participants. The mean score for males was $41.25(S D=$ 17.06), while the mean score for females was $21.40(S D=21.12)$. Figure 7, Histogram of Self Control Schedule Scores and Gender, displays this finding. In addition, the mean score for African American or Black participants $(\mathrm{N}=4 ; M=34.75, S D=21.34)$ was higher on the Self Control Schedule than the mean score of Caucasian participants $(\mathrm{N}=$ 43; $M=22.98, S D=21.24)$. Total stress scores on the Student-life Stress Inventory showed that the four male participants $(M=116.5)$ perceived less stress than females ( $\mathrm{N}$ $=41, M=141$ ). Scores for males ranged from 106 to 127, while scores for females ranged from 95 to 187, with a higher score indicating higher perception of stress.

The results of the current study indicate perception of stressors in nursing students, but no significant relationships among learned resourcefulness, stressors, and academic performance in this sample. However, when examining the relationship of age, race/ethnicity, gender, marital status, work status, enrollment status, and stressors as independent variables, on the dependent variable, academic performance, there is a significant relationship among the variables. Although stressors was not a significant predictor of academic performance $(p=.90)$, age was a significant predictor $(p<.01)$. 


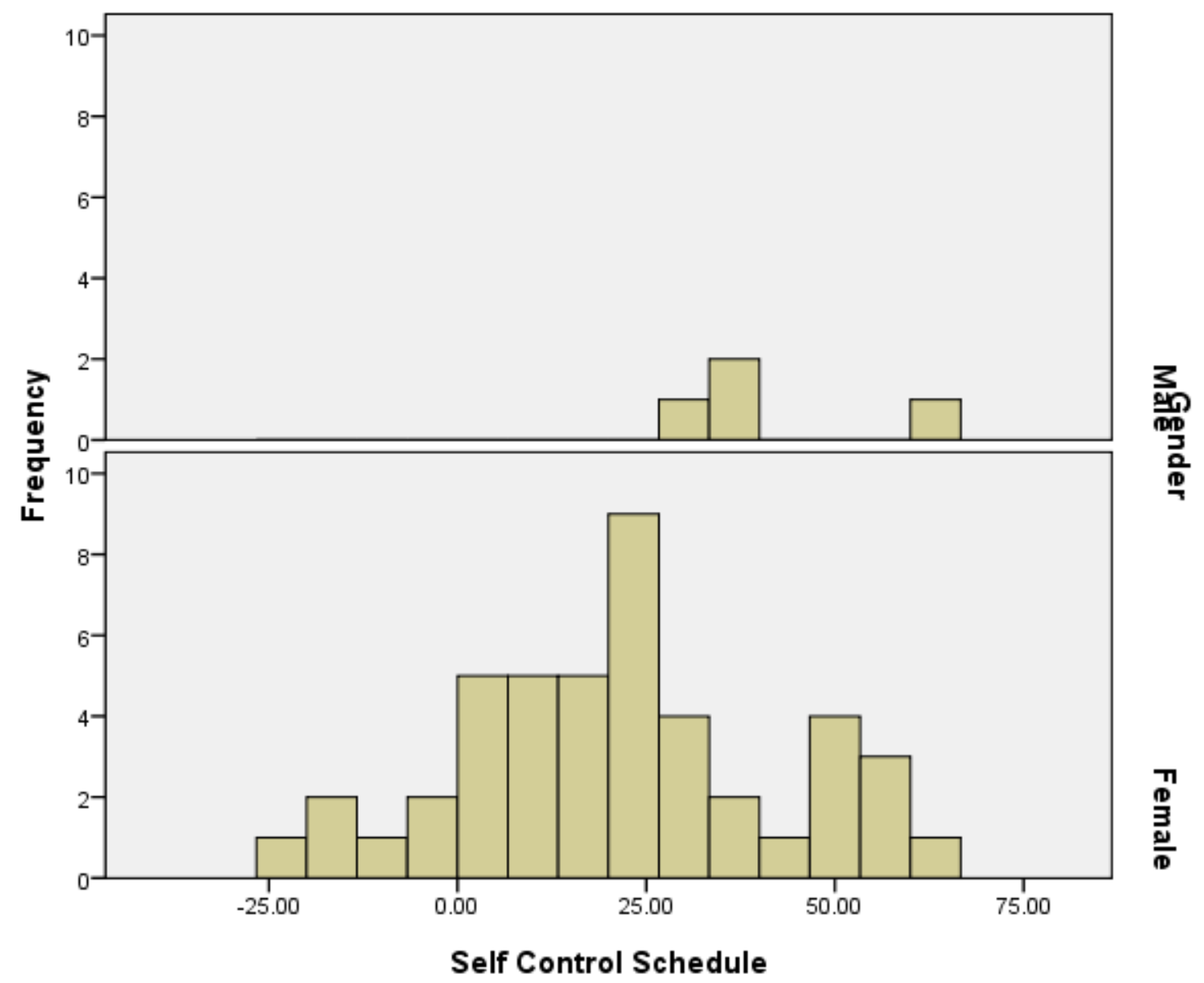

Figure 7. Histogram of Self Control Schedule Scores and Gender

For every 1 standard deviation increase in age, there would be a .42 standard deviation increase in academic performance. This effect is fairly large. When learned resourcefulness was added to the model, neither stressors $(p=.98)$ or learned resourcefulness $(p=.21)$ were significant predictors of academic performance, but current age was still a significant predictor $(p=.009)$. For every one standard deviation increase in age, there would be a .39 standard deviation increase in academic performance. When current age is entered as the only predictor variable for academic performance, using regression, the results are also significant at the .01 level $(F(1,43)=$ 
7.001, $p=.011)$. Current age is an important predictor of academic performance, but stressors and learned resourcefulness are not. Both males and African-American/ Black participants had higher learned resourcefulness scores than females and Caucasians. Total stress scores on the Student-life Stress Inventory showed that male participants perceived less stress than females. A detailed summary and discussion of the study findings are presented in the next chapter. 


\section{CHAPTER V \\ SUMMARY AND DISCUSSION}

This final chapter of the dissertation provides a summary of the problem, methodology used, and the study results, followed by an extensive discussion of the findings. This includes interpretations, reflection, relationship of the current study to previous research, recommendations for higher education educators, and suggestions for future research. The purpose of this explanatory correlational study was to examine the mediating effect of learned resourcefulness on the relationships of stressors-both personal and academic — to academic performance in baccalaureate nursing students.

\section{Statement of the Problem}

Extensive research has established that a critical nursing shortage affecting health care, the necessity of high level clinical judgment, evolving demographics, and the status of the economy have compounded nursing student stress. Decreased learning, academic performance, and retention have been the result. However, a paucity of research examines specific factors that could enhance these learning processes and outcomes. Learned resourcefulness, or the ability to regulate emotions and cognitions, has been reported to decrease stress and enhance coping effectiveness in other populations, and a few studies specifically targeting the college student population report similar findings. However, no researchers have examined these relationships in nursing students. An increased understanding of these factors may inform policies and practices designed to 
reduce nursing student stress, in order to improve learning, academic performance, and retention, and ultimately alleviate the nursing shortage and improve the quality of health care.

\section{Review of the Methodology}

As explained in Chapter II, following approval by the University Institutional Review Board and School of Nursing Research Committee, the researcher obtained a list of instructors for all junior nursing classes and contacted them to obtain permission to enter each classroom. The researcher distributed the Letter of Introduction to Participate to students at the end of each junior nursing class and invited interested students to go to a nearby, comfortable classroom, which had been previously reserved. Following written informed consent, the researcher gathered independent variable data using a brief Demographic Data Sheet and two standardized paper and pencil instruments (Gadzella’s Student-life Stress Inventory and Rosenbaum’s Self-Control Scale, a measure of learned resourcefulness), to 53 baccalaureate nursing students, enrolled full-time or part-time in Junior level nursing courses.

The dependent variable, academic performance, or previous semester GPA, was obtained from each student participant, and was included on the Demographic Data Sheet. The independent control variables in the study were age, race/ethnicity, gender, marital status, work status, and enrollment status. The Demographic Data Sheet was also used to gather this information. The sample ranged in age from 20 to $54(M=24.8)$ with 84.9\% Caucasian and 9.4\% African-American or Black. Descriptive statistics, Pearson 
product-moment correlation coefficients, t-tests, reliability statistics, and multiple regression were employed by the researcher to analyze the data.

\section{Summary of the Results}

Although high levels of both personal and academic stressors were found on the Student-life Stress Inventory, they were not significant predictors of academic performance $(p=.90)$. Age was a significant predictor of academic performance $(p<.01)$ and both males and African-American/ Black participants had higher learned resourcefulness scores than females and Caucasians. No significant relationships among learned resourcefulness, stressors, and academic performance were found, using multiple regression analyses. Total stress scores on the Student-life Stress Inventory showed that male participants perceived less stress $(\mathrm{N}=4, M=116.5)$ than females $(\mathrm{N}=41, M=$ 141). On the Self-Control Schedule, participants reported the ability to plan work when faced with several things to do, approaching a difficult problem in a systematic way, an increase in self-esteem when able to overcome a bad habit, and usually exploring alternatives, rather than making quick and spontaneous decisions. For the current study, the Cronbach’s alpha for the Self Control Schedule was .77 ( $\mathrm{N}=49)$.

The results of the current study indicated perception of stressors in baccalaureate nursing students $(\mathrm{N}=53)$. Participants responded to a five-point scale using $1=$ never, $2=$ seldom, $3=$ occasionally, $4=$ often, and $5=$ most of the time. The types of stressors section on the SSI includes both personal and academic stressors and is divided into five categories: frustrations, conflicts, pressures, changes, and self-imposed. Reliability of the Student-life Stress Inventory (SSI) used to measure the stressors was revealed 
(Cronbach’s alpha $=.91, \mathrm{~N}=45$ ). Participants reported stressors in the pressures category, followed by self-imposed, frustrations, changes, and conflicts. The pressures subscale involves competition on grades, work, and relationships, meeting deadlines, overload, and interpersonal relationships. Self-imposed stressors include competition and winning, being noticed and loved, worrying, procrastination, perfectionism, and anxiety about taking tests, while delays in reaching goals, daily hassles, and lack of money were the major items reported in the frustrations subscale (Gadzella, 1991). Males reported lower levels of perceived stressors than females. In addition to specific stressors, participants in the study reported an overall level of stress in the moderate range $(M=$ 2.1).

The reactions to stressors section of the SSI is comprised of four categories: physiological, emotional, behavioral, and cognitive, and lists several examples of signs and symptoms. Fear, anxiety, and worry in the emotional reaction subscale had the highest item mean of 4.11. Behavioral responses were cited next. In this category, the mean for both crying and "was irritable toward others" items had a mean of 3.33. Critical thinking, problem-solving, and analysis, in the cognitive reaction subscale, had the next highest response $(M=3.6)$, with physiological reactions last, mostly exhaustion $(M=$ 3.46) and sweating $(M=3.11)$. The results of the cognitive reactions to stressors on the SSI correspond to the results on the Self Control Schedule regarding problem-solving. 


\section{Discussion of the Results}

\section{Researcher's Insights and Relationship of Current Study to Prior Research}

Relationship between stressors and academic performance. Unlike Akgun and

Carriochi (2003), which supported past research, the current study found that stressors was not a significant predictor of academic performance $(p=.90)$. However, in contrast, the Akgun and Carrioci study focused on academic stressors, rather than both personal and academic stressors, and used the Undergraduate Stress Questionnaire rather than Gadzella’s Student-life Stress Inventory. In addition, the Akgun and Carrioci study had a larger sample (141, rather than 53 participants) and examined first-year undergraduate non-nursing students in Australia, rather than third-year nursing students in the United States. Grade point averages were used to measure academic performance in both studies, but the current study used student self-report and Akgun and Carrioci were able to obtain GPA’s from university records.

Correlation of age and academic performance. The current study found that age was a significant predictor of academic performance $(p<.01)$. For every 1 standard deviation increase in age, there would be a .42 standard deviation increase in academic performance. This effect is fairly large and is in congruence with previous research (Busato, Prins, Elshout, \& Hamaker, 1998; Entwistle \& McClune, 2004; Leppel, 2002; Lonka \& Lindblom-Ylanne, 1996; Sheard, 2009; Vermunt \& Vermetten, 2004). In a study of 134 undergraduate college students, a subset of 46 mature age students (above 21) achieved higher final degree GPA when compared to 88 younger age students 
(Sheard, 2009). The study also revealed higher scores in females than males in all measured academic assessment criteria, such as hardiness and commitment.

Vermunt (2005) found that learning patterns leading to stronger academic performance were associated with age, type of academic discipline, and gender in 795 second-year college students in the Netherlands. Meaning-directed learning, which includes critical thinking, problem-solving, and self-regulation (the major focus of learned resourcefulness) was most correlated with academic discipline and age ( $M=$ 22.5). The study also found that other types of learning were less related to positive student outcomes (Vermunt, 2005). There were seven disciplines studied, including law, economy, management information science, econometry, sociology, psychology, and the arts, but not nursing. Academic performance was measured by mean exam score, percentage of exams passed, and study pace (per cent of courses from first year that student passed).

One study reported that older college students are better able to differentiate various learning strategies and to have stronger interrelations among strategies than younger, less experienced students (Vermunt \& Vermetten, 2004). Older students tend to be employed and have families and may have a clearer idea of how degree completion may affect ability to earn a higher salary and job promotion. This may make older students work harder to achieve higher grades and to complete academic goals. However, because of family and employment constraints, older students are more likely to take less credit hours per semester and to take longer to complete a degree. This may increase the 
likelihood of higher grades, but may also increase levels of discouragement and stressors and lead to lower persistence rates (Leppel, 2002).

Other studies have reported higher college student GPA's according to gender and race, rather than age, such as higher GPA's in Caucasian female students as compared to males and minorities (Betts \& Morell, 1998; Ting \& Robinson, 1998; Zimmerman, Goldston, \& Gadzella, 1977). Several researchers have suggested that self-perception of academic abilities, study strategies, learning styles, and learning environments are related to increased academic performance (Entwistle \& Tait, 1990; Lonka \& Lindblom-Ylanne, 1996; Severiens \& Ten Dam, 1997; Zheng et al., 2002).

\section{Correlation of learned resourcefulness, stressors, and academic performance.}

No significant relationships were found among learned resourcefulness, stressors, and academic performance in the present study. On the Self-Control Schedule, participants most frequently reported the ability to plan work when faced with several things to do, approaching a difficult problem in a systematic way, an increase in self-esteem when able to overcome a bad habit, and usually exploring alternatives, rather than making quick and spontaneous decisions. These characteristics have been found to positively influence academic performance in prior research (Lindop, 1999; Mansfield et al., 2004). For example, in a study of 238 undergraduate students attending a public college in the northeastern United States (58\% female, 94\% single, and 93\% Caucasian), higher levels of self-control in higher academic performers were reported (Mansfield et al., 2004). A 24-item scale developed by Grasmick, Tittle, Bursick, and Arneklev (1993) was used to measure self control (Mansfield et al., 2004). Self control was defined as self-regulation, 
or a capacity to control behavior, and included six components: impulsivity, simple tasks, risk-seeking, physical activity, self-centered and temper (Baumeister \& Exline, 2000). This construct has some similarities to learned resourcefulness, which includes selfstatements to control emotional responses, application of problem-solving strategies, tendency to delay immediate gratification, and perceived self-efficacy (Rosenbaum, 1980a).

\section{Correlation of age, learned resourcefulness, stressors, and academic}

performance. The present study found that when learned resourcefulness was correlated with age, stressors, and academic performance, age remained a significant predictor of academic performance $(p=.042)$. Previous studies regarding these variables have produced mixed results in various age groups, although there are few studies of college students. In a sample of younger and older caregivers of elders, age was found to play a significant difference in learned resourcefulness abilities, but gender was not (Intrieri \& Rapp, 1994). A correlational study of 132 Thai adolescents with asthma (ages 12-17) reported that age was significantly related to learned resourcefulness, suggesting that learned resourcefulness may increase with age (Preechawong et al., 2007). However, learned resourcefulness was measured by only three items of the 17-item Children's Self Control Scale (Rosenbaum \& Ronen, 1991). Few studies have explored gender, age, and learned resourcefulness in school-age children and adolescents.

\section{Correlation of gender, learned resourcefulness, stressors, and academic}

performance. Although there were only four males who participated in the current study, the four males revealed a higher level of learned resourcefulness than the females in the 
sample. This finding is in contrast with Rosenbaum's theory, which suggests that learned resourcefulness is not gender related, and in contrast with previous research, which focuses on specific age groups, including college students, and uses the Self Control Schedule to measure learned resourcefulness (Turkel \& Tezer, 2008). Learned resourcefulness was not found to be gender dependent in 22 school aged children, and no differences in learned resourcefulness level and gender were found in a convenience sample of 132 Thai adolescents (aged 12-17) with asthma (Preechawong et al., 2007; Zauszniewski et al., 2002). No gender differences on the Self Control Scale were reported when examining relationships among learned resourcefulness, drinking and smoking in 175 male and female college students at a large, private university in upstate New York (Carey et al., 2001). The sample consisted of 109 women and 62 men.

\section{Correlation of race/ethnicity, learned resourcefulness, stressors, and academic}

performance. The current study also found that the mean score on the Self Control Schedule (SCS) for African American students was higher than in Caucasian students. This finding corresponds to previous research using the same instrument. In two studies of both Black and White South African university students, Black students scored significantly higher than White students (Edwards \& Riordan, 2001). The first study included a small sample of Black students $(\mathrm{N}=16)$ and 184 White students. However, the second study, which confirmed findings of the first, included a larger sample: 100 Black and 138 White students. The mean scores of the White students were reported as 15.2, while the scores of the Black students were significantly higher $(M=33.0)$. The SCS had sound psychometric properties for the White group (Cronbach's alpha $=.82$ ), in 
contrast with several weak item-scale correlations and a much lower Cronbach’s alpha (.52) for the Black group, raising questions regarding problems of cross-cultural testing (Edwards \& Riordan, 2001; Rosenbaum, 1980a, 1988). The Self-Control Schedule was developed in Israel, possibly affecting perceptions, style, and applicability of learned resourcefulness skills according to culture and ethnicity.

The differences in psychometric properties in the Edwards and Riordan (2001) study could also reflect the effects of environment on the development of learned resourcefulness abilities. The White students in the two studies in South Africa were from middle class and affluent backgrounds, while many of the Black students were reported to be from economically deprived areas (Edwards \& Riordan, 2001). Rosenbaum’s theory suggests that learned resourcefulness may be learned throughout life in the context of specific situational factors or environment, including the home and family (Akgun, 2004; Rosenbaum, 1990; Zauszniewski et al., 2002). For example, perceptions of parenting styles were found to influence the learned resourcefulness of Turkish adolescent high school students and another study of 315 Turkish university students revealed that the level of separation anxiety experienced in the past was a significant predictor of learned resourcefulness and psychological disorder symptoms (Ceyhan, 2006; Turkel \& Tezer, 2008).

Another researcher found that learned resourcefulness is related to social loneliness and not intimate or global loneliness, suggesting that interaction within the social environment is an important contributor of learned resourcefulness abilities (McWhirter, 1997b). The study included 625 college students at a large university in the 
Southwestern United States. However, using the Self Control Schedule as a unidimensional measure of learned resourcefulness was cited as one of the possible limitations of the study, potentially limiting its ability to predict types of loneliness. The researcher states that, instead, the SCS may actually be a multidimensional instrument (McWhirter, 1997b).

Demographics of participants. Participants of the current study reflected the evolving college student demographics discussed in Chapters I and II (Greer \& Chwalisz, 2007; Leppel, 2002; Pascarella \& Terenzini, 1991, 2005; Tinto, 1993). Although the mean age of the 53 students in the sample was 24.8 , with $83.2 \%$ of the respondents between the ages of 20 and 29 and almost half (49.1\%) reporting current age as 20 or 21, there were five students between 31 and 38 and four students between the ages of 40 and 54. The majority of the students (71.7\%) lived off campus without a roommate, were working part-time (52.8\%), 18.9\% were married, and 23\% reported having children. The influx of these nursing students who are older, married, have children, are employed, and commute to campus now must balance school, family, and work, creating additional stressors and more unique coping skills needed to achieve academic goals (Gigliotti, 2004; Nicholl \& Timmons, 2005; Robotham \& Julian, 2006; Zeitlin-Ophir et al., 2004).

Perception of personal and academic stressors. The current study provides support for the perception of both personal and academic stressors in baccalaureate nursing students and additional evidence that these stressors are similar to college students in other majors. Results revealed several stressors in the junior level nursing student participants, mostly related to academics, such as competition, meeting deadlines, 
work overload, and anxiety about taking tests. Students were surveyed near the end of the academic year, just prior to final exams, and this timing may have influenced their responses. These findings confirm previous research, which found that academic related stressors, such as taking tests, writing papers, grades, too little time, and the constant pressure of studying, were the most irritating to nursing and other college students in the United States and other countries (Beck et al., 1997; Beck \& Srivastava, 1991; Gadzella et al., 1998; Schafer, 1996; Robotham \& Julian, 2006).

For example, in a qualitative study of 12 nursing students, four major themes emerged from the data: meeting conflicting demands, feeling overworked, feeling unprepared, and seeking support and respect from faculty (Magnussen \& Amundsen, 2003). In a comparative study of stress in a random sample of 146 nursing students in 1988 and 146 nursing students in 2000, similar academic stressors were found by using the same questionnaire for both groups: intense amount of work and examinations in the educational environment (Lindop, 1999). Both male and female Midwestern college students $(\mathrm{N}=249)$ reported pressures, conflict, and self-imposed stress on the Student-life Stress Inventory (Misra et al., 2000). Stressors involving academic work, including long hours of study, exam and grades, and lack of free time were reported in a descriptive correlational study of 94 baccalaureate nursing student in Canada. However, the questionnaire used in the study was a combination of scales and was not tested for reliability, but researchers report that face and content validity were established by a panel of expert faculty and students (Beck \& Srivastava, 1991). 
Participants in the current study also reported personal stressors, such as delays in reaching goals, daily hassles, and lack of money, which are in the SSI Frustrations subscale. These frustrations were also cited frequently in 249 college students, using the SSI, although the focus of the study was student academic stress in comparison to faculty perceptions (Misra et al., 2000). Frustrations have been a major finding in several other studies of college students (Gadzella et al., 1992; Gadzella \& Guthrie, 1993; Gadzella, 1994; Gigliotti, 2004). A study examining perceived multiple role stress and social support in 132 married associate degree nursing students (85.8\% Caucasian) at 11 community colleges in New York and New Jersey found that the meaning of the support, who gave it, and what kind received was most important in reducing maternal-student role stress in two age group subsamples: under $37(n=73)$ and 37 and older $(n=59)$ (Gigliotti, 2004).

In addition to the present study, only one other study explores the impact of both categories of college student stressors-academic and personal in relation to academic performance (Gwele \& Uys, 1998). Unlike the present study, which used one instrument to measure personal and academic stressors, both the Perceived Stress Scale (PSS) to measure general stress and the Clinical Stress Questionnaire to measure stress related to nursing clinical experiences, were used. The purpose of the study was to compare the outcomes and placement of clinical experience for two groups of nursing students, one group in the old curriculum and the other group in the revised program. The findings of this comparative descriptive study of 101 nursing students, conducted in the Republic of South Africa, suggest that students who demonstrate higher stress levels, especially in the 
clinical settings, describe feelings of anger, apprehension, fear, and being overwhelmed, which, in turn, negatively affects academic performance (Gwele \& Uys, 1998).

Unique stressors of nursing students. Several previous studies report that nursing students perceive additional and unique stressors, such as clinical experiences and preparation for the NCLEX-RN licensure exam (Eddy \& Eppeneter, 2002; Gibbons et al., 2008; Gwele \& Uys, 1998; Hamill, 1995; Higginson, 2006; Kleehammer et al., 1990; Oermann \& Lukomski, 2001; Pagana, 1988; Shipton, 2002). For example, qualitative interviews with 10 graduates of a baccalaureate program who were successful on the first attempt of the NCLEX-RN and nine who were unsuccessful indicated that successful students were proactive in test preparation and took responsibility for learning, while unsuccessful students tended to perceive responsibility of others and were less able to manage stress (Eddy \& Eppeneter, 2002). However, the current study did not examine those particular stressors. The instrument used to measure stressors in the present study (Student-life Stress Inventory) measures stressors in college students of all majors, not just nursing, and, therefore, focuses on stressors that would be applicable to the general college population (Gadzella, 1991).

Gender and perception of stress. In the current study, total stress scores on the Student-life Stress Inventory showed that the four male participants perceived less stress than females. Scores for males ranged from 106 to 127, while scores for females ranged from 95 to 187, with a higher score indicating higher perception of stress. This finding confirms several studies which report that females perceive higher levels of stress than males (Akgun, 2004; Beck et al., 1997; Dixon \& Robinson Kurpius, 2008; Gadzella, 
1994b; Gadzella \& Carvalho, 2006; Gadzella, Ginther, et al., 1991; Misra et al., 2000). Using the SSI to measure stressors in 249 students (186 females and 63 males) at a Midwestern university, the results showed that females had higher scores than males on several types of stressors, such as self-imposed stress, pressure, and frustration and higher scores on all four categories of reactions to stressors (Misra et al., 2000). The study states that the participants were mostly Caucasian sophomores.

College level and perception of stress. Some studies reveal that the types and levels of perceived stressors vary according to college level (Misra et al., 2000). Freshman and sophomore students tend to perceive higher levels and different types of stressors than juniors and seniors. For example, freshmen and sophomores, regardless of age, must cope with the transition to college life and academics. It is well known that the highest attrition of college students of any major is at the freshman level, and for nursing students, during the first year of the program, usually at the junior level. The junior level students in the current study may have more resources for managing stress than they did before they entered the nursing major at the beginning of the academic year. However, at the end of the junior year, they may be worried about successfully entering the senior year of the program and beginning to consider what it may be like to graduate.

Reactions to stressors. Participants in the current study revealed emotional reactions, followed by behavioral, cognitive, and physiological. The reported major emotional reactions to stressors were fear, anxiety, and worry, followed by crying, and being irritable towards others. The highest mean was for the emotional reactions of fear, anxiety, and worry $(M=4.11)$. Students had already been admitted to the nursing 
program a year before data were collected, but were perhaps worried about staying in the program and entering the senior year. These results confirm previous findings of other college students (Gadzella et al., 1998; Misra et al., 2000). The most common reactions to stressors in 249 male and female college students (mostly sophomores and Caucasian), using the SSI, were emotional and cognitive (critical thinking, problem-solving, and analysis) (Misra et al., 2000). The anxiety associated with tests, rather than the test itself, was reported to create both physiological (sweating, exhaustion) and emotional (fear, anxiety, anger) reactions in 126 psychology students at a Southwestern state university (Gadzella et al., 1998).

\section{Theoretical Implications of Study}

The conceptual framework developed for the current study displayed in Figure 8 is based on the work of Hans Selye $(1974,1976)$ and the Transactional Model (Lazarus \& Folkman, 1984) and depicts the impact of stressors and learned resourcefulness on nursing student academic performance. The model focuses on the transaction between people and their external environment and suggests that stress is an imbalance between demands and resources and occurs when pressure exceeds the perceived ability to cope. Stress is a result of how a specific stressor and the potential resources to cope with it are appraised. The model proposes that if stressors are perceived as positive or challenging rather than a threat, and if the stressed person is confident that he/she possesses adequate rather than deficient coping strategies, stress may not necessarily occur during the presence of a stressor (Folkman et al., 1986; Lazarus \& Folkman, 1984). 


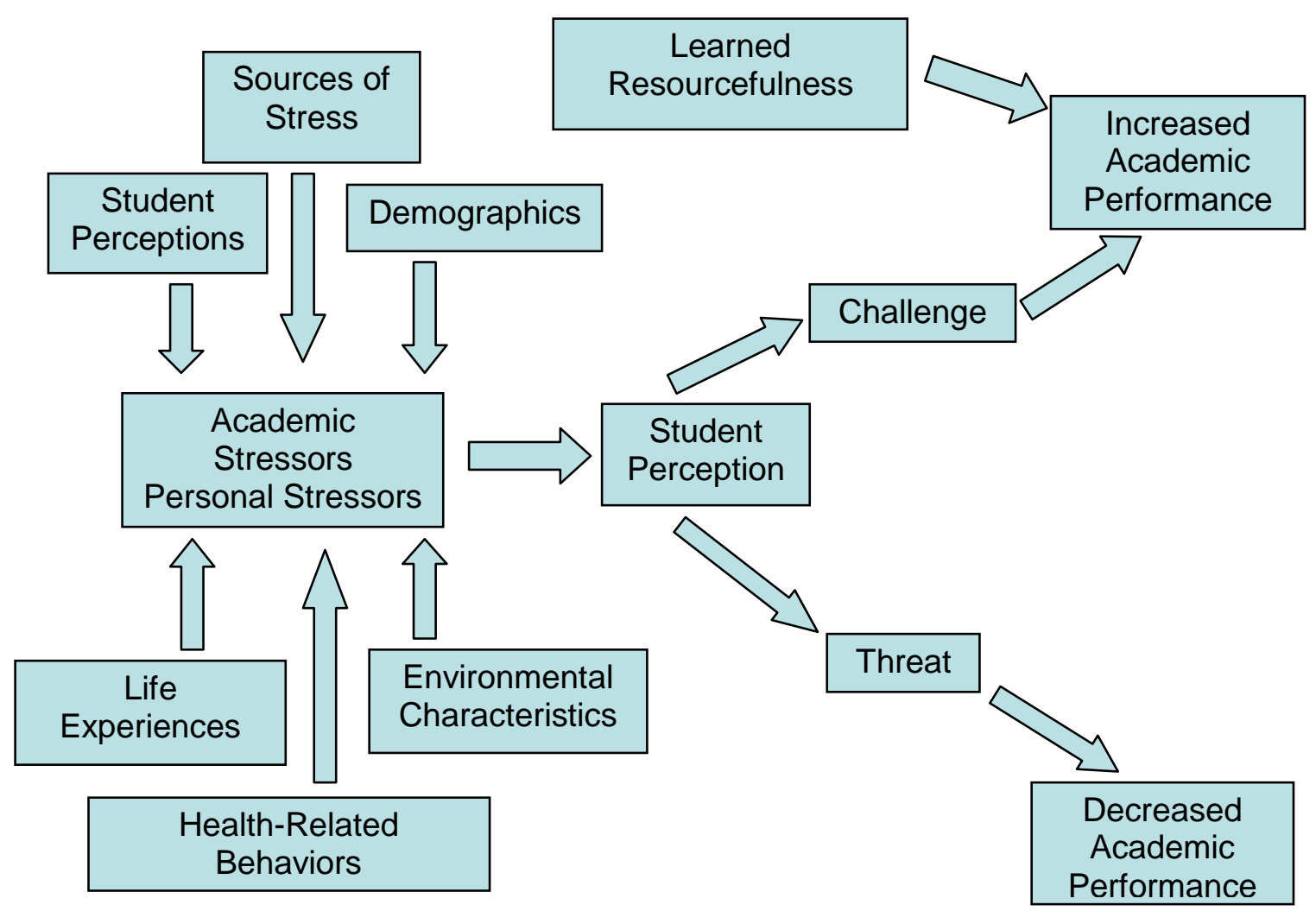

Figure 8. Stressors, Academic Performance, and Learned Resourcefulness

Some components of the theoretical framework were supported by the results of the study. Participants reported an overall level of stress in the moderate range, as measured by the Student-life Stress Inventory (Gadzella, 1991). Many types of specific academic stressors were revealed, such as meeting deadlines, work overload, and competition, and others regarding competition, procrastination, worrying about tests, and perfectionism, which are self-imposed. Personal stressors revolved around frustrations, including daily hassles, delays, and lack of resources. Emotional reactions to stressors, such as fear, anxiety, and worry, were reported most frequently. Results also revealed that participants also had physiological reactions, including exhaustion, sweating, 
trembling, and weight gain. These physiological reactions are related to the health-related component of the framework, suggesting that these students may be susceptible to healthrisk behaviors, such as decreased exercise and physical fitness and overeating as responses to stressors.

The results of the study provided evidence that demographics may impact both personal and academic stressors. Age, gender, and race/ethnicity were found to influence the levels of stressors and learned resourcefulness. Age was a significant predictor of academic performance $(p<.01)$ and both males and African-American/Black participants had higher learned resourcefulness scores than females and Caucasians. The sample for the study represented the evolving demographics of college students. The age range was from 20 to $54(M=24.8)$. However, there were only four males and 9.4\% AfricanAmerican or Black participants. No significant relationships among stressors, academic performance, and learned resourcefulness were found, which does not support the remainder of the theoretical framework.

\section{Explanation of Unanticipated Findings}

The fact that significant correlations among stressors, academic performance, and learned resourcefulness were not found in the current study may be due to several limitations, especially the small sample size $(\mathrm{N}=53)$. Some students did not complete every question, creating gaps in data on both instruments, and further limiting the total amount of data available for final analysis ( $\mathrm{N}=45$ for the SSI and $\mathrm{N}=49$ for the SCS).

The study's small sample had a resulting restricted statistical power, increasing the risk of Type I error, making it more difficult to provide significant findings, and decreasing its 
generalizability to other nursing students. Because relationships for these variables had not been previously examined in nursing students and decreased variability was a goal, data for the study was based on one institution and one level of the program. Differences in demographic variables, student characteristics, and location may affect results when applied to another university. In addition, there may be limitations of using self-report GPA to measure academic performance in this sample. Participants in the study had similar GPA’s because at least a 3.5 was required to enter the junior level of the nursing program.

Two of the research questions involved analyses of age, race/ethnicity, gender, marital status, work status, enrollment status, stressors, academic performance, and learned resourcefulness. Analyses results for marital status, work status, and enrollment status must be interpreted with caution because the number of students in the total sample and subgroups in each category were too small. The sample was mostly Caucasian (84.9\%) and consisted of only 7.5\% males, making it difficult to determine correlations related to race/ethnicity and gender. However, results revealed that the mean score on the Self Control Scale measuring learned resourcefulness was higher for males and for African American or Black participants than females and Caucasians. Males perceived less total stress than females on the Student-life Stress Inventory. Age was also found to be significant when correlated with stressors, academic performance, and learned resourcefulness. The study should be replicated with a larger, more diverse sample in other institutions to examine the validity of these findings. 
Another major factor regarding sample size was that it was very difficult to recruit nursing students for the study. Nursing faculty at the institution used were very accommodating to the researcher, and allowed entrance after all junior level classes ended. However, several students and faculty mentioned that some researchers had previously attempted to administer surveys without prior approval from the School of Nursing Research Committee and the university Institutional Review Board. Some students reported that researchers had tried to recruit them outside of the School of Nursing building. In addition, students stated that a previous researcher claimed that her survey would take 20 minutes, when it actually took almost an hour. Therefore, students approached for the current study appeared skeptical regarding how long completing two surveys would actually take. Surveys were required to be completed outside of class time, but students were not always willing or able to stay after class, as they had school, work, and family obligations, which limited extra time.

There were several practical difficulties that were encountered when conducting this research study, such as obtaining permission from schools of nursing, professors, nursing students, and administrators who are concerned about the amount of time that surveys may take either inside or outside the classroom setting. Students and faculty might not have valued the importance of the research being conducted. They might have experienced difficulty seeing the relevance to them, to the school, or even to the nursing profession. Many students think that "taking care” of patients is the only focus of nursing. Another important limitation of the current study was that there were too many predictors for the sample size of only 53 participants. A direct relationship exists between 
the correlation and the ratio of participants (n) to the number of variables (k). The specific ratio is (k-1) (n-1). The degree to which the expected value of $R^{2}$ exceeds zero when it is zero in the population depends upon both the size of the sample and the number of variables. The larger the sample in a study, the more likely it represents the population from which it is drawn. It is usually recommended that at least 10 participants for each predictor be used (Howell, 2007). Therefore, in order to examine all of the variables in the current study: age, race/ethnicity, gender, marital status, work status, enrollment status, learned resourcefulness, stressors, and academic performance, at least 80 participants were necessary.

Another limitation of the study was that the data from the instruments were selfreport (Richardson, 2004). Students were asked to rate their own perceptions of the variables, and of demographic data, including GPA. These data may not be accurate, either because the student did not remember accurately or because they wanted to portray themselves as socially acceptable (Crowne \& Marlowe, 1964). Research participants tend to underreport behaviors viewed to be inappropriate by researchers and over-report behaviors believed to be appropriate. Some students tend to give consistently high or low ratings (over-rater or under-rater bias). Students who answered the surveys gave their perception of what they thought the question was asking (interpretation) and what they thought the answer should be (Isaac \& Michael, 1995). Self-report instruments include structured questions, which guide the participant to think in those specific directions about the variables, rather than opening up other possibilities. 
Surveys often make the respondent feel special or unnatural, which may cause responses to be slanted or artificial (halo effect). Surveys also tend to arouse "response sets” such as proneness or acquiescence to agree with positive statements or questions (Isaac \& Michael, 1995). The nursing students in the current study might have been concerned that the answers to the surveys or participation in the study would affect their grade or how people (especially professors) would view them, left out information, or answered surveys the way she or he thought the researcher expected or wanted them to. It also might have increased student stress when becoming a participant in the study and influenced the way in which questions on the surveys were answered. Also, students answered the surveys during the last week of classes, just prior to final exams. This factor could have affected the level of stress perceived and answers on the surveys.

The Self-Control Schedule was developed in Israel (Rosenbaum, 1980a). Could this affect perceptions, style, and applicability of learned resourcefulness skills according to culture and ethnicity? Edwards and Riordan (2001) found significantly different psychometric properties between White and Black South African university students on the Self-Control Schedule (higher for the White group), citing a need for research exploring cultural differences in coping strategy patterns. Clarification of the Self Control Schedule factor structure in a study of 583 college students at a large southwestern United States university revealed a three-factor solution that accounted for $36.37 \%$ of the total variance and further validation of the instrument with that population. The researchers viewed the instrument as Western regarding problem-solving and managing internal 
stressors and proposed that more studies involving other racial/ethnic and cultural groups should be conducted to validate the Self Control Schedule (McWhirter et al., 2008).

Only one study has investigated the psychometric properties of the Self Control

Schedule in a non-Western sample. Internal validity for the translated version of SCS was reported as .81 in a study of 77 pregnant HIV positive and 103 pregnant HIV negative women in Thailand. The researchers recommend further psychometric testing with other pregnant women and in more diverse samples to improve the instrument's cross-cultural applicability (Boonpongmanee et al., 2002).

Confounding or spurious variables, which cannot be directly measured because their effects are not easily separated from those of the other variables in the study, despite possible effects, may have influenced the results of the current study. Examples of confounding variables might have been the nursing student's prior experience with stress and perceptions of those experiences: number and types encountered, age encountered, coping methods used, effectiveness of coping methods, and people or other resources available at the time. Another confounding variable might have been the student's prior experience in college (if any) and prior experience in high school or lower grades. What was their performance? What was their perception of reasons for how they performed? Another confounding variable is the difference in the four classroom environments among junior level students in the sample. Students answered the surveys in different environments: temperature, light, noise, and at different times and days. There were different characteristics of each group of students, expectations for each course in the program, and differences in course content and faculty. Nursing courses 
generally include the same cohort of students who are progressing throughout the program. Members of this group can display very supportive, competitive, or destructive behaviors toward each other. A student's peer group significantly affects cognitive growth and development in college (Pascarella, 2001).

Another factor is that there are different types of stressors involved for each level of a nursing program. The junior level student is usually taking the first set of nursing courses, which is a new and stressful situation, while the senior level student is nearing graduation, which includes another set of stressors, such as expectations after graduation (passing the NCLEX-RN licensure exam the first time and securing employment). Socioeconomic level and social or family support are other confounding variables which cannot be directly measured, but may affect the influence of stress on academic performance and the possible mediating effect of learned resourcefulness. Some measurement of socioeconomic status, including financial aid, could have been included on the demographic sheet, but that can open up sensitive issues. Future research could include partial and semipartial correlations to control for certain confounding variables such as marital status, prior experience with stress, or prior experience in college. However, confounding variables are usually difficult to measure.

\section{Implications for Practice}

In spite of these limitations, the findings of the present study further validate levels and types of stressors in baccalaureate nursing students and suggest directions for the reduction and management of stress, and evaluation and innovation of teaching strategies and curricula. First, there is a need for nursing faculty and administrators to 
increase understanding of stressors and learned resourcefulness in nursing students and to provide support in coping. Secondly, there is a need for students to have a better understanding of stressors and learned resourcefulness. What is the relationship? How can it help? Finally, both faculty and students need to explore ways to decrease stressors and to increase learned resourcefulness in dealing with these stressors. Faculty and counselors can assess stressors and determine levels of learned resourcefulness in nursing students. Curriculum changes could be made which still provide a quality program, but decrease stressors for students. In addition, skill training and counseling that matches specific limitations in cognitive and behavioral skills, such as problem-solving, could be implemented.

An excellent example of a preventative and treatment approach that has been available for over 30 years and shown to be successful in numerous research studies is stress inoculation training (Meichenbaum, 2007). Like the construct of learned resourcefulness, stress inoculation is based on the transactional, dynamic view of stress and coping: appraisal of the stressor(s), perception of available coping mechanisms, and perceived demands necessary to respond successfully (Lazarus \& Folkman, 1984). The major goal of the program is to prevent and reduce stressors and is flexible and adaptive, depending upon the population and types of stressors involved.

Stress inoculation is a complex, multifaceted, training program designed to intervene at the psychosocial level to enhance awareness, mobilize preparedness, and develop mastery, resilience, and learned resourcefulness when faced with diverse stressful situations, such as depression, domestic violence, illness, or trauma 
(Meichenbaum, 2007). The length can vary from 20 minutes in preparing patients for surgery and as long as 40 1-hour weekly and biweekly sessions for psychiatric clients. The usual length is 8-15 sessions, plus bolster and follow-up sessions conducted during a 3-12 month period (Meichenbaum, 2007).

The stress inoculation program consists of three overlapping and interlocking phases: (a) conceptual education, (b) skills acquisition and consolidation, and (c) application and follow-through, and is adapted to the individual, family, group, or population, and to the types of stressor(s) experienced. For example, the program has been used successfully for groups, such as nurses, policemen, and educators, who are exposed to persistent stressors related to the profession, augmenting coping mechanisms and confidence in using a repertoire of coping skills (Meichenbaum, 2007).

A stress inoculation program could be developed and implemented specifically for nursing students to develop a stronger and more comprehensive repertoire of learned resourcefulness behaviors and cognitions. Once the level of learned resourcefulness was assessed for each student entering the nursing program, the stress inoculation program could be tailored to that particular student throughout the program. This important intervention could positively affect student learning, decrease stress, improve coping, and increase self-confidence and self-efficacy. Long-term effects could be to increase retention and increase the numbers of qualified nursing students to alleviate the nursing shortage and enhance the complex components of health care. 


\section{Recommendations for Further Research}

The current study was the first to examine stressors, academic performance, and learned resourcefulness in nursing students. The findings suggest that many stressors exist, which may be affecting reactions, learning, and problem-solving, and that learned resourcefulness, or self-control abilities, may vary according to age, gender, and race. The sample was small $(\mathrm{N}=53)$. The study found higher learned resourcefulness scores for males and for African American or Black participants and males perceived less total stress than females. Age was a significant variable when correlated with stressors, academic performance and learned resourcefulness. Further research is necessary to examine the relationships of these variables and to validate these findings in a larger, more diverse, sample of baccalaureate nursing students. Other studies should explore these variables in nursing students across the United States, not just in the Southeastern area, and in different levels of nursing programs, not just the junior level. Larger scale quantitative studies involving more than one baccalaureate nursing program could be conducted.

In addition to quantitative studies, qualitative and mixed methods studies would be important to understand the components of the learned resourcefulness construct in baccalaureate nursing students. These studies would provide a rich source of data to build a solid knowledge base (Maxwell, 2005). Qualitative studies could be implemented to possibly uncover other variables involved in the nursing student experience besides sources and types of stressors and to reveal methods used to deal with these stressors. Little research has been conducted to capture rich descriptions of what it is like to be a 
nursing student and qualitative studies would give voice to the participants, rather than having them complete constructed surveys with fixed questions that are frequently part of quantitative research.

Qualitative or mixed methods studies would provide a more comprehensive understanding of the faculty-student relationship and educational environment, resulting in an overall enhancement of the quality of nursing education programs. What is it really like to be a student from the perspective of those who actually live the experience? Do faculty and administrators have a broad enough and deep enough understanding of the student perspective of stressors, be able to display appropriate sensitivity, and provide the best possible curricula and environment to learn? Or, are nursing education programs developed and monitored using ideas and experiences just from the faculty member's perspective rather than from the student's perspective?

The current study’s importance lies in its initial appraisal of both academic and personal stressors and its initial examination of learned resourcefulness as a possible coping strategy in baccalaureate nursing students. Several studies, including this one, have provided evidence that stressors exist in nursing students. Many other studies have established a significant relationship of stressors to academic performance. The evolving demographics of college students displayed in the current study emphasize the importance of examining both personal and academic stressors.

A construct such as learned resourcefulness, which has been shown to significantly influence behavior in other populations and situations, and can be learned throughout life, has great potential to control levels of stress and increase problem- 
solving in nursing students. College students are not always adept at recognizing stressors, may perceive it as a weakness, and frequently do not seek necessary counseling or other assistance (Robotham \& Julian, 2006). In addition, depression is a major problem in nursing and other college students (Dixon \& Kupius, 2008; Haines, Norris, \& Kashy, 1996). Higher levels of learned resourcefulness, or components of the construct, have been shown to be preventative of depression (Burns, Rude, Simons, Bates, \& Thase, 1994; Dixon \& Robinson Kurpius, 2008; Lewinsohn \& Alexander, 1990).

Learned resourcefulness could provide the tools to cope with the types of stressors that nursing students must contend with on a daily basis and could positively influence academic performance and retention. Highly resourceful and low resourceful people do not differ in ability to learn self-control skills. They differ in the ability to implement these skills on a long-term basis (Rosenbaum, 1990). Studies involving stress inoculation training, both short-term and long-term, on nursing students would offer valuable data regarding the effectiveness of learning learned resourcefulness and coping with stressors (Meichenbaum, 2007). Learned resourcefulness, which promotes internal control, may be important in decreasing stress and shifting locus of control, to promote healthy behaviors, and to improve enrollment levels of nursing students.

An assessment of a student's level of learned resourcefulness could provide more accurate and productive guidance for choosing appropriate intervention strategies throughout a nursing program, resulting in a more comprehensive picture for curriculum evaluation, and graduates with the clinical judgment and in-depth knowledge necessary to care for more acutely-ill clients in a complex, rapidly changing health care environment. 
Nursing students will have a better understanding of their experience in the program which could help to alleviate stress, and improve their learning. Producing more graduates who are better-prepared and less-stressed will not only help alleviate the critical nursing shortage, but also, improve the quality of health care in the United States. Therefore, this study provides significance to both theory and practice in higher education and in nursing. 


\section{REFERENCES}

Abramson, L.Y., Seligman, M.E., \& Teasdale, J. D. (1978). Learned helplessness in humans: Critique and reformulation. Journal of Abnormal Psychology, 87(1), 4974.

Abu Tariah H. S., \& Al-Sharaya, H. S. (1997). Stresses reported by second year nursing students. Nurse Educator, 22, 33.

Aikens, J. E., Wallender, J. L., Bell, D. S., \& Cole, J. A. (1992). Daily stress variability, learned resourcefulness, regimen adherence, and metabolic control in Type I diabetes mellitus: Evaluation of a path model. Journal of Counseling and clinical psychology, 60(1), 113-118.

Akgun, S. (2004). The effects of situation and learned resourcefulness on coping responses. Social Behavior and Personality, 32(5), 441-448.

Akgun, S., \& Ciarrochi, J. (2003). Learned resourcefulness moderates the relationship between academic stress and academic performance. Educational Psychology, 23(3), 287-294.

Al-Kandari, F., \& Vidal, V. (2007). Correlation of the health-promoting lifestyle, enrollment level, and academic performance of College of Nursing students in Kuwait. Nursing and Health Sciences, 9, 112-119.

American Psychological Association. (2001). Publication manual of the American Psychological Association (5th ed.). Washington, DC: Author. 
Antonovsky, A. (1979). Health, stress, and coping. San Francisco: Jossey-Bass.

Antonovsky, A. (1987). Unraveling the mystery of health: How people manage stress and stay well. San Francisco: Jossey-Bass.

Astin, A. W. (1984). Student involvement: A developmental theory for higher education. Journal of College Student Personnel, 25, 297-308.

Astin, A.W. (1991). Assessment for excellence: The philosophy and practice of assessment and evaluation in higher education. New York: Macmillan.

Bandura, A. (1977). Self-efficacy: Toward a unifying theory of behavior change. Psychological Review, 84, 191-215.

Bandura, A. (1978). The self-system in reciprocal determinism. American Psychologist, 33, 344-358.

Bandura, A. (1982). Self-efficacy mechanism in human agency. American Psychologist, $37,122-147$.

Bandura, A. (1986a). The explanatory and predictive scope of self-efficacy theory. Journal of Social and Clinical Psychology, 4, 359-373.

Bandura, A. (1986b). Social foundations of thought and action: A social cognitive theory. Englewood Cliffs, NJ: Prentice-Hall.

Bandura, A. (1993). Perceived self-efficacy in cognitive development and functioning. Educational Psychologist, 28(2), 117-149.

Bandura, A. (1997). Self-efficacy: The exercise of control. New York: W. H. Freeman. Barling, J. (1999). Parents’ job insecurity affects children’s academic performance through cognitive difficulties. Journal of Applied Psychology, 84(3), 437-444. 
Baron, R. M., \& Kenny, D. A. (1986). The moderator-mediator variable distinction in social psychological research: Conceptual, strategic, and statistical considerations. Journal of Personality and Social Psychology, 51, 1173-1182.

Baumeister, R., \& Exline, J. (2000). Self-control, morality, and human strength. Journal of Social and Clinical Psychology, 19(1), 29-42.

Bean, J. P. (1990). Why students leave: Insights from research. In D. Hossler \& J. P. Bean (Eds.), The strategic management of college enrollments (pp. 147-169). San Francisco: Jossey-Bass.

Beck, D. L., \& Srivastava, R. (1991). Perceived level and sources of stress in baccalaureate nursing students. Journal of Nursing Education, 30(3), 127-133.

Beck, D. L., Hackett, M. B., Srivastava, R., McKim, E., \& Rockwell, B. (1997).

Perceived level and sources of stress in university professional schools. Journal of Nursing Education, 36(4), 180-186.

Beddoe, A. E., \& Murphy, S. (2004). Does mindfulness decrease stress and foster empathy among nursing students? Journal of Nursing Education, 43(7), 305-312.

Betts, J. R., \& Morell, D. (1998). The determinants of undergraduate grade point average. The Journal of Human Resources, 34(2), 268-293.

Bilgin, M., \& Akkapulu, E. (2007). Some variables predicting social self-efficacy expectation. Social Behavior and Personality, 35(6), 777-788.

Boonpongmanee, C., Zauszniewski, J., \& Boonpongmanee, S. (2002). Psychometric properties of the Self-Control Schedule: Thai version. Research in Nursing and Health Care, 25(6), 471-478. 
Brewin, C. R., Andrews, B., \& Furnham, A. (1996). Intergenerational links and positive self-cognitions: Parental correlates of optimism, learned resourcefulness, and selfevaluation. Cognitive Therapy and Research, 20(3), 247-263.

Bryant, M. J., Simons, A. D., \& Thase, M. E. (1999). Therapist skill and patient variables in homework compliance: Controlling an uncontrolled variable in cognitive therapy outcome research. Cognitive Therapy and Research, 23(4), 381-399.

Burns, D. D., Rude, S., Simons, A. D., Bates, M. A., \& Thase, M. E. (1994). Does learned resourcefulness predict the response to cognitive behavioral therapy for depression? Cognitive Therapy and Research, 18(3), 277-291.

Busato, V. V., Prins, F. J., Elshout, J. J., \& Hamaker, C. (1998). Learning styles: A crosssectional and longitudinal study in higher education. British Journal of Educational Psychology, 68, 427-441.

Carey, M. P., Carey, K. B., Carnrike, C. L. M., Jr., \& Meisler, A. W. (2001). Learned resourcefulness, drinking, and smoking in young adults. The Journal of Psychology, 124(4), 391-395.

Ceyhan, A. A. (2006). The prediction of learned resourcefulness, anxiety, and psychological symptoms from early separation anxiety. Educational Sciences: Theory and Practice, 6(1), 72-79.

Chemers, M. M., Hu, L., \& Garcia, B. F. (2001). Academic self-efficacy and first-year college student performance and adjustment. Journal of Educational Psychology, 93(1), 55-64. 
Cheung, C. K. (1998). Abilities and academic achievement among college students. Journal of Genetic Psychology, 159(2), 147-162.

Chitty, K. K., \& Black, B. P. (2007) Professional nursing: Concepts and challenges (5 ${ }^{\text {th }}$ ed.). St. Louis: Saunders Elsevier.

Cohen, S., Karmack, T., \& Mermelstein, R. (1983). A global measure of perceived stress. Journal of Health and Social Behavior, 42, 385-396.

Constantinople, A., Cornelius, R., \& Gray, J. (1988). The chilly climate: Fact or artifact? Journal of Higher Education, 59(5), 527-550.

Crowne, D. P., \& Marlowe, D. (1964). The approval motive: Studies in evaluative dependence. New York: Wiley.

Curtin, L. (1996). Nursing into the $21^{\text {st }}$ century. Springhouse, PA: Springhouse Corporation.

Derogatis, L. R. (1987). The Derogatis stress profile (DSP): Qualifications of psychological stress. In G. Fava \& T. Wise (Eds.), Research paradigms in psychosomatic medicine (pp. 30-54). New York: Basel, Karger.

Diekelmann, N. L. (1992). Learning-as-testing: A Heideggerian hermeneutical analysis of the lived experiences of students and teachers in nursing. Advances in Nursing Science, 14(3), 72-83.

Diekelmann, N. L. (1993). Behavioral pedagogy: A Heideggerian hermeneutical analysis of the lived experiences of students and teachers in baccalaureate nursing education. Journal of Nursing Education, 32(6), 245-250. 
Dixon, S. K., \& Robinson Kurpius, S. E. (2008). Depression and college stress among university undergraduates: Do mattering and self-esteem make a difference? Journal of College Student Development, 49(5), 412-424.

Dutta, A. P. (2001). Measuring and understanding stress in pharmacy students. Virginia Commonwealth University, U. S.

Dyson, R., \& Renk, K. (2006). Freshman adaptation to university life: Depressive symptoms, stress, and coping. Journal of Clinical Psychology, 62, 1231-1244.

Eddy, L. L., \& Epeneter, B. J. (2002). The NCLEX-RN experience: Qualitative interviews with graduates of a baccalaureate nursing program. Journal of Nursing Education, 41(6), 273-278.

Edwards, D., \& Riordan, S. (2001). Learned resourcefulness in Black and White South African university students. The Journal of Social Psychology, 134(5), 665-675.

Entwistle, N., \& McClune, V. (2004). The conceptual bases of study strategy inventories. Educational Psychology Review, 16(4), 325-345.

Entwistle, J., \& Tait, H. (1990). Approaches to learning, evaluations of teaching, and preferences for contrasting academic environments. Higher Education, 19, 169194.

Folkman, S., Lazarus, R. S., Gruen, R. J., \& DeLongis, A. (1986). Appraisal, coping, health status, and psychological symptoms, Journal of Personality and Social Psychology, 50, 571-572. 
Friedlander, L. J., Reid, G. J., Shupak, N., \& Cribbie, R. (2007). Social support, selfesteem, and stress as predictors of adjustment to university among first-year undergraduates. Journal of College Student Development, 48(3), 259-274.

Gadzella, B. M. (1991). Student-life stress inventory. Commerce, TX: Author.

Gadzella, B. M. (1994a). Locus of control differences among stress groups. Perceptual and Motor Skills, 79, 1619-1624.

Gadzella, B. M. (1994b). Student-life Stress Inventory: Identification of and reactions to stressors. Psychological Reports, 74(2), 395-402.

Gadzella, B. M. (2004). Three stress groups on their stressors and reactions to stressors in five studies. Psychological Reports, 94, 562-564.

Gadzella, B. M., \& Baloglu, M. (2001). Confirmatory factor analysis and internal consistency of the Student-life Stress Inventory. Journal of Instructional Psychology, 28(2), 84-94.

Gadzella, B. M., \& Carvalho, C. (2006). Stress differences among female students. American Journal of Psychological Research, 2(1), 21-27.

Gadzella, B. M., Fullwood, H. L., \& Ginther, D. W. (1991). Student-life Stress Inventory. Paper presented at Texas Psychological Association Convention, San Antonio, TX. (ERIC 350 345).

Gadzella, B. M., Fullwood, H. L., \& Tomcala, M. (1992). Students’stressors and reactions to stress. Paper presented at Southwestern Psychological Association Convention, Austin, TX. 
Gadzella, B. M., Ginther, D. W., Tomcala, M., \& Bryant, G. W. (1991). Differences between men and women on stress producers and coping strategies. Psychological Reports, 69, 561-562.

Gadzella, B. M., \& Guthrie, D. (1993). Analysis of stress inventory. Proceedings of the Texas Academy of Science, 96th Annual Meeting. University of North Texas, Denton, 413-431.

Gadzella, B. M., Masten, W., \& Stacks, J. (1998). Students’ stress and their learning strategies, test anxiety, and attributions. College Student Journal, 32(3), 416-422.

Gibbons, C., Dempster, M., \& Moutray, M. (2008). Stress and eustress in nursing students. Journal of Advanced Nursing, 61(3), 282-290.

Gigliotti, E. (2004). Types and sources of social support and maternal-student role stress in married associate degree nursing students. Issues in Mental Health Nursing, 25, 415-432.

Gintner, G. G., West, J. D., \& Zarski, J. J. (2001). Learned resourcefulness and situationspecific coping with stress. The Journal of Psychology, 123(3), 295-304.

Goldman, C. (1997). Stress and the college student. Education, 117(4).

Grasmick, H. G., Tittle, C. R., Bursick, R. J., \& Arneklev, B. J. (1993). Testing the core empirical implications of Gottfredson and Hirschi’s General Theory of Crime. Journal of Research in Crime and Delinquency, 30(1), 5-29.

Greer, T. M., \& Chwalisz, K. (2007). Minority-related stressors and coping processes among African-American college students. Journal of College Student Development, 48(4), 388-404. 
Grigorenko, E., \& Sternberg, R. (1997). Styles of thinking, abilities, and academic performance. Exceptional Children, 63(3), 295-312.

Gupchup, G. V., Borrego, M. E., \& Konduri, N. (2004). The impact of student life stress on health related quality of life among doctor of pharmacy students. College Student Journal, 38(2), 292-301.

Gwele, N. S., \& Uys, L. R. (1998). Levels of stress and academic performance in baccalaureate nursing students. Journal of Nursing Education, 37(9), 404-407.

Haack, M. R. (1988). Stress and impairment among nursing students. Research in Nursing and Health, 11, 125-134.

Haines, M. E., Norris, M. P., \& Kashy, D. A. (1996). The effects of depressed mood on academic performance in college students. Journal of College Student Development, 37(5), 519-526.

Hamama, R., Ronen, T., \& Feigin, R. (2000). Self-control, anxiety, and loneliness in siblings of children with cancer. Social Work in Health Care, 31(1), 63-83.

Hamill, C. (1995). The phenomenon of stress as perceived by Project 2000 student nurses: A case study. Journal of Advanced Nursing, 21, 528-536.

Higginson, R. (2006). Fears, worries and experiences of first-year pre-registration nursing students: A qualitative study. Nurse Researcher, 13(3), 32-49.

Howard, J. R. \& Henney, L. (1998). Student participation and instructor gender in the mixed-age college classroom. Journal of Higher Education, 69 (4), 384-405.

Howell, D. C. (2007). Statistical methods for psychology $\left(6^{\text {th }}\right.$ ed.). Belmont, CA: Thomson Wadsworth. 
Hudd, S. S., Dumlao, J., Erdmann-Sager, D., Murray, D., Phan, E., Soukas, N., et al. (2000). Stress at college: Effects on health-habits, health status and self-esteem. College Student Journal, 34(2), 217-227.

Institute of Medicine. (2001). Crossing the quality chasm: A new health system for the $21^{\text {st }}$ century. Washington, DC: National Academies Press.

Institute of Medicine. (2003). Health professions education: A bridge to quality. Washington, DC: National Academies Press.

Intrieri, R. C., \& Rapp, S. R. (1994). Self-control skillfulness and caregiver burden among help seeking elders. Journal of Gerontology, 49(1), 19-23.

Isaak, M. I., Graves, K. M., \& Mayers, B. O. (2006). Academic, motivational, and emotional problems identified by college students in academic jeopardy. Journal of College Student Retention, 8(2), 171-183.

Isaac, S., \& Michael, W. B. (1995). Handbook in research and evaluation for education and the behavioral sciences ( $3^{\text {rd }}$ ed.). San Diego: Educational and Industrial Testing Services.

Joel, L. A. (2006). The nursing experience: Trends, challenges, and transitions $\left(5^{\text {th }}\right.$ ed.). New York: McGraw-Hill.

Jones, M. C., \& Johnston, D. W. (1997). Distress, stress, and coping in first-year student nurses. Journal of Advanced Nursing, 26, 475-482.

Jones, M. C., \& Johnston, D. W. (2000). Reducing stress in first level and student nurses: A review of the applied stress management literature. Journal of Advanced Nursing, 32(1), 66-74. 
Kalsner, L. (1992). The influence of development and emotional factors on success in college. Higher Education Extension Service Review, 3(2).

Kanfer, F. H. (1977). The many faces of self-control, or behavior modification changes its focus. In R. B. Stuart (Ed.), Behavioral self-management: Strategies, techniques and outcomes. New York: Brunner/Mazel.

Kanfer, F. H., \& Hagerman, S. (1981). The role of self-regulation. In L. P. Rehm (Ed.), Behavior therapy for depression: Present status and future directions (pp. 143179). New York: Academic Press.

Kanji, N., White, A., \& Ernst, E. (2006). Autogenic training to reduce anxiety in nursing students: Randomized controlled trial. Journal of Advanced Nursing, 53(6), 729735.

Kennett, D. J. (1994). Academic self-management counseling: Preliminary evidence for the importance of learned resourcefulness on program success. Studies in Higher Education, 19(3), 295-307.

Kennett, D. J., \& Ackerman, M. (1995). Importance of learned resourcefulness to weight loss and early success during maintenance: Preliminary evidence. Patient Education and Counseling, 25, 197-203.

Kennett, D. J. \& Keefer, K. (2006). Impact of learned resourcefulness and theories of intelligence on academic achievement of university students: An integrated approach. Educational Psychology, 26(3), 441-457. 
Kennett, D. J., O’Hagan, F. T., \& Cezer, D. (2008). Learned resourcefulness and the long-term benefits of a chronic pain management program. Journal of Mixed Methods Research, 2, 317-339.

Kennett, D. J., \& Stedwill, A.T. (1996). Cooperative learning in a university setting: Evidence for the importance of learned resourcefulness. Studies in Higher Education, 21(2), 177-186.

Kleehammer, K., Hart, A. L., \& Keck, J. F. (1990). Nursing students’ perceptions of anxiety-producing situations in the clinical setting. Journal of Nursing Education, 29, 183-187.

Kobasa, S. C. (1979). Stressful life events, personality, health: Inquiry into hardiness. Journal of Personality and Social Psychology, 37, 1-11.

Lazarus, R. S., \& Folkman, S. (1984). Stress, appraisal, and coping. New York: Springer.

Leonardi, A., Syngollitou, E., \& Kiosseoglou, G. (1998). Academic achievement, motivation, and future selves. Educational Studies, 24(2), 153-163.

Leppel, K. (2002). Similarities and differences in the college persistence of men and women. The Review of Higher Education, 25(4), 433-450.

Levenson, H. (1981). Differentiating among internality, powerful others, and chance. In H. M. Lefcourt (Ed.), Research with the locus of control construct, volume I. New York: Academic Press, 15-63. 
Lewinsohn, P., \& Alexander, C. (1990). Learned resourcefulness and depression. In M. Rosenbaum (Ed.), Learned Resourcefulness: On Coping Skills, Self-Control, and Adaptive Behavior (pp. 202-217). New York: Springer.

Lindblom-Ylanne, S., \& Lonka, K. (1999). Individual ways of interacting with the learning environment-Are they related to study success? Learning Instruction, 9, $1-18$.

Lindop, E. (1999). A comparative study of stress between pre- and post-Project 2000 students. Journal of Advanced Nursing, 29(4), 967-973.

Lo, R. (2002). A longitudinal study of perceived level of stress, coping and self-esteem of undergraduate nursing students: An Australian case study. Journal of Advanced Nursing, 39(2), 119-126.

Lonka, K., \& Lindblom-Ylanne, S. (1996). Epistemologies, conceptualizations of learning, and study practices in medicine and psychology. Higher Education, 31, 5-24.

Lumley, M. A., \& Provenzano, K. M. (2003). Stress management through written emotional disclosure improves academic performance among college students with physical symptoms. Journal of Educational Psychology, 95(3), 641-649.

Magnussen, L., \& Amundsen, M. J. (2003). Undergraduate nursing student experience. Nursing and Health Sciences, 5, 261-267.

Maloney, M. T. (1993). An examination of the role that intercollegiate athletic participation plays in academic achievement. Journal of Human Resources, 28(3), 550-570. 
Manderino, M. A., Ganong, L. H., \& Darnell, K. F. (1988). Survey of stress management content in baccalaureate nursing curricula. Journal of Nursing Education, 27(7), 321-325.

Mansfield, P. M., Pinto, M. B., Parente, D. H., \& Wortman, T. I. (2004). College students and academic performance: A case of taking control. NASPA Journal, 41(3), 551567.

Maxwell, J. A. (2005). Qualitative research design: An interactive approach (2 $\left.{ }^{\text {nd }} \mathrm{ed}.\right)$. Thousand Oaks, CA: Sage.

McWhirter, B. T. (1997a). A pilot study of loneliness in ethnic minority college students. Social Behavior and Personality, 25(3), 295-304.

McWhirter, B. T. (1997b). Loneliness, learned resourcefulness, and self-esteem in college students. Journal of Counseling and Development, 75, 460-469.

McWhirter, B. T., Burrow-Sanchez, J. J., \& Townsend, K. C. (2008). Measuring learned resourcefulness in college students: Factor structure of the Self-Control Schedule (SCS). College Student Journal, 42(4), 1099-1109.

Meichenbaum, D. (1977). Cognitive-behavior modification: An integrative approach. New York: Plenum.

Meichenbaum, D. (1985). Stress-inoculation training. New York: Pergamon Press. Meichenbaum, D. (2007). Stress-inoculation training: A preventative and treatment approach. In P. M. Lehrer, R. L. Woolfolk, \& W. S. Sime (Eds.), Principles and Practice of Stress Management (3 ${ }^{\text {rd }}$ ed.) (pp. 497-518). New York: Guilford Press. 
Metzner, B. W., \& Bean, J. P. (1987). The estimation of a conceptual model of nontraditional undergraduate attrition. Research in Higher Education, 27(1), 15-37.

Misra, R., McKean, M., West, S., \& Russo, T. (2000). Academic stress of college students: Comparison of student and faculty perceptions. College Student Journal, 34(2), 236-245.

Morris, C. G. (1990). Contemporary psychology and effective behavior ( $7^{\text {th }}$ ed.). Glenview, IL: Scott, Foresman.

Mouw, J. T., \& Khanna, R. K. (1993). Prediction of academic success: A review of the literature and some recommendations. College Student Journal, 27, 328-336.

Murphy, M. C., \& Archer, J., Jr. (1996). Stressors on the college campus: A comparison of 1985 and 1993. Journal of College Student Development, 37(1), 20-28.

Nicholl, H., \& Timmons, F. (2005). Programme-related stressors among part-time undergraduate nursing students. Journal of Advanced Nursing, 50(1), 93-100.

North Carolina Institute of Medicine. (2004, May). Task Force on the North Carolina Workforce Report. Durham, NC: Author.

Oermann, M. H. (1998). Differences in clinical experiences of ADN and BSN students. Journal of Nursing Education, 37(5), 197-201.

Oermann, M. H., \& Lukomski, A. P. (2001). Experiences of students in pediatric nursing clinical courses. Journal of Studies in Pediatric Nursing, 6(2), 65-72.

Oermann, M. H., \& Standfest, K. M. (1997). Differences in stress and challenge in clinical practice among ADN and BSN students in varying clinical courses. Journal of Nursing Education, 36, 228-233. 
Omigbodun, O. O., Odukogbe, A. A., Omigbodun, A. O., Omigbodun, A. O., Yusuf, O. B., Bella, T. T., \& Olayemi, O. O. (2006). Stressors and psychological symptoms in students of medicine and allied health professions in Nigeria. Social Psychiatry and Psychiatric Epidemiology, 41, 415-421.

Omigbodun, O. O., Onibokun, A. C., Yusuf, B. O., Odukogbe, A. A., \& Omigbodun, A. O. (2004). Stressors and counseling needs of undergraduate nursing students in Ibadan, Nigeria. Journal of Nursing Education, 43(9), 412-415.

Orpen, C. (1996). The interactive effects of social support and test anxiety on student academic performance. Education, 116(3), 464-465.

Pagana, K. D. (1988). Stress and threats reported by baccalaureate nursing student in relation to an initial clinical experience. Journal of Nursing Education, 27, 418424.

Pagana, K. D. (1989). Psychometric evaluation of the Clinical Stress Questionnaire (CSQ). Journal of Nursing Education, 28, 169-174.

Pascarella, E. T. \& Terenzini, P. T. (1991). How college affects students: Findings and insights from twenty years of research. San Francisco: Jossey-Bass.

Pascarella, E. T., \& Terenzini, P. T. (2005). How college affects students: A third decade of research. San Francisco: Jossey-Bass.

PEW Health Professions Commission. (November, 1995). Critical challenges: Revitalizing the health professions for the twenty-first century. San Francisco: University of California, San Francisco Center for the Health Professions. 
Porter-O’Grady, T. (2001). Profound change: $21^{\text {st }}$ century nursing. Nursing Outlook, 49(4), 182-186.

Preechawong, S., Zauszniewski, J. A., Heiner, M. M., Musil, C. M., Kercsmar, C., \& Aswinanonh, R. (2007). Relationships of family functioning, self-esteem, and resourceful coping of Thai adolescents with asthma. Issues in Mental Health Nursing, 28, 21-36.

Pryjmachuk, S., \& Richards, D. A. (2007). Predicting stress in preregistration nursing students. British Journal of Health Psychology, 12, 125-144.

Rather, M. L. (1992). “Nursing as a way of thinking”-Heideggerian hermeneutical analysis of the lived experience of the returning RN. Research in Nursing \& Health, 15, 47-56.

Redden, E. M., Tucker, R. K., \& Young, L. (1983). Psychometric properties of the Rosenbaum schedule for assessing self-control. Psychological Record, 33, 77-86.

Richards, P. S. (1985). Construct validation of the self-control schedule. Journal of Research in Personality, 19, 208-218.

Richardson, J. T. (2004). Methodological issues in questionnaire-based research on student learning in higher education. Educational Psychology Review, 16(4), 347358.

Robotham, D., \& Julian, C. (2006). Stress and the higher education student: A critical review of the literature. Journal of Further and Higher Education, 30(2), 107117. 
Rokke, P. D., Tomhave, J. A., \& Jocic, Z. (2000). Self-management therapy and educational group therapy for depressed elders. Cognitive Therapy and Research, 24(1), 99-119.

Rollant, P. D., \& Curlette, W. (1994). A comparison of the effects of interventions on stress coping resources of beginning associate degree nursing students. Paper presented at the Annual Meeting of the American Educational Research Association, New Orleans, LA.

Rosenbaum, M. (1980a). A schedule for assessing self-control behaviors: Preliminary findings. Behavior therapy, 11, 109-121.

Rosenbaum, M. (1980b). Individual differences in self-control behaviors and tolerance of painful stimulation. Journal of Abnormal Psychology, 89, 581-590.

Rosenbaum, M. (1983). Learned resourcefulness as a behavioral repertoire for the selfregulation of internal events: Issues and speculations. In M. Rosenbaum, C. M. Franks, \& Y. Jaffe (Eds.), Perspectives on behavior therapy in the eighties (pp. 54-73). New York: Springer.

Rosenbaum, M. (1988). Learned resourcefulness, stress, and self-regulation. In S. Fisher \& J. Reason (Eds.), Handbook of life stress cognition and health (pp. 483-496). Chichester, England: Wiley.

Rosenbaum, M. (1990). Foreword. In M. Rosenbaum (Ed.), Learned resourcefulness: On coping skills, self-control, and adaptive behavior (pp. xiv). New York: Springer.

Rosenbaum, M., \& Ben-Ari, K. (1985). Learned helplessness and learned resourcefulness: Effects of noncontingent success and failure on individuals 
differing in self-control skills. Journal of Personality and Social Psychology, 48(1), 198-215.

Rosenbaum, M., \& Ben-Ari Smira, K. (1986). Cognitive and personality factors in the delay of gratification of hemodialysis patients. Journal of Personality and Social Psychology, 51(2), 357-364.

Rosenbaum, M., \& Jaffe, Y. (1983). Learned helplessness: The role of individual differences in learned resourcefulness. British Journal of Social Psychology, 22, 215-225.

Rosenbaum, M., \& Palmon, N. (1984). Helplessness and resourcefulness in coping with epilepsy. Journal of Consulting and Clinical Psychology, 52, 244-253.

Rosenbaum, M., \& Rolnick, A. (1983). Self-control behaviors and coping with seasickness. Cognitive Therapy and Research, 7, 93-98.

Rosenbaum, M., \& Ronen, T. (1991). Parents’ and children’s appraisals of each other’s anxiety while facing a common threat. Journal of Clinical Child Psychology, 26(1), 43-52.

Sales, B. D., \& Folkman, S. (Eds.). (2000). Ethics in research with human participants. Washington, DC: American Psychological Association.

Sarid, O., Anson, O., Yaari, A., \& Margalith, M. (2004). Academic stress, immunological reaction, and academic performance among students of nursing and physiotherapy. Research in Nursing and Health, 27, 370-377.

Schafer, W. (1996). Passing the test of college stress. In W. Schafer (Ed.), Stress management for wellness (pp. 543-563). Orlando: Harcourt Brace. 
Schmeck, R. R., Ribich, F. D., \& Ramanaiah, N. V. (1977). Development of a self-report inventory for assessing individual differences in learning processes. Applied Psychological Measurement, 1, 413-431.

Seligman, M. E. (1975). Helplessness: On depression, development and death. San Francisco: Freeman.

Seligman, M. E., Maier, S. F., \& Greer, J. (1968). The alleviation of learned helplessness in the dog. Journal of Abnormal and Social Psychology, 73, 256-262.

Selye, H. (1974). Stress without distress. New York: Lippincott.

Selye, H. (1976). The stress of life. New York: McGraw-Hill.

Severiens, S. E., \& Ten Dam, G. T. (1997). Gender and gender identity differences in learning styles. Educational Psychology, 17, 79-93.

Sharif, F., \& Armitage, P. (2004). The effect of psychological and educational counseling in reducing anxiety in nursing students. Journal of Psychiatric and Mental Health Nursing, 11, 386-392.

Sheard, M. (2009). Hardiness, commitment, gender, and age differentiate university academic performance. British Journal of Educational Psychology, 79(1), 189204.

Shipton, S. P. (2002). The process of seeking stress-care: Coping as experienced by senior baccalaureate nursing students in response to appraised clinical stress. Journal of Nursing Education, 41(6), 243-256.

Spielberger, C. D. (1980). Test anxiety inventory. CA: Consulting Psychologist Press. 
Struthers, C. W., Perry, R. P., \& Menec, V. H. (2000). An examination of the relationships among academic stress, coping motivation, and performance in college. Research in Higher Education, 41(5), 581-592.

Ting, S-M. R. (2000). Predicting Asian Americans' academic performance in the first year of college: An approach combining SAT scores and noncognitive variables. Journal of College Student Development, 41, 442-449.

Ting, S-M. R., \& Robinson, T. L. (1998). First-year academic success: A prediction combining cognitive and psychosocial variables for Caucasian and African American students. Journal of College Student Development, 39(6), 599-610.

Tinto, V. (1993). Leaving college: Rethinking the causes and cures of student attrition, (2nd ed.). Chicago: The University of Chicago Press.

Trockel, M. T., Barnes, M. D., \& Egget, D. L. (2000). Health-related variables and academic performance among first-year college students: Implications for sleep and other behaviors. Journal of American College Health, 49(3), 125-131.

Tuckman, B., \& Sexton, T. (1990). The relation between self-beliefs and self-regulated performance. Journal of Social Behavior and Personality, 5, 465-472.

Turkel, Y. D. \& Tezer, E. (2008). Parenting styles and learned resourcefulness of Turkish adolescents. Adolescence, 43(169), 143-152.

Vanhanen, L., \& Janhonen, S. (2000). Factors associated with students’ orientations to nursing. Journal of Advanced Nursing, 31, 1054-1062.

Vermunt, J. D. (2005). Relationships between student learning patterns and personal and contextual factors and academic performance. Higher Education, 49(3), 205-234. 
Vermunt, J. D., \& Vermetten, Y. J. (2004). Patterns in student learning: Relationships between learning strategies, conceptions of learning, and learning orientation. Educational Psychology Review, 16(4), 359-384.

Wells, M. I. (2007). Dreams deferred but not deterred: A qualitative study on undergraduate nursing student attrition. Journal of College Student Retention: Research, Theory, and Practice, 8(4), 439-456.

Wenzel, S. L. (1992). Length of time spent homeless: Implications for employment of homeless persons. Journal of Community Psychology, 20, 57-71.

Yonge, O., Myrick, F., \& Haase, M. (2002). Student nurse stress in the preceptorship experience. Nurse Educator, 27(2), 84-88.

Zajacova, A., Lynch, S. M., \& Espenshade, T. J. (2005). Self-efficacy, stress, and academic success in college. Research in Higher Education, 46(6), 677-706.

Zauszniewski, J. A., Chung, C. W., Chang, H., \& Krafcik, K. (2002). Predictors of resourcefulness in school-aged children. Issues in Mental Health Nursing, 23, $385-401$.

Zauszniewski, J. A., Eggenschwiler, K., Preechawong, S., Roberts, B. L., \& Morris, D. L. (2006). Effects of teaching resourcefulness skills to elders. Aging and Mental Health, 10(4), 404-412.

Zeitlin-Ophir, I., Melitz, O., Miller, R., Podoshin, P., \& Mesh, G. (2004). Variables affecting the academic and social integration of nursing students. Journal of Nursing Education, 43(7), 326-329. 
Zheng, J. L., Saunders, K. P., Shelley, M. C., II, \& Whalen, D. F. (2002). Predictors of academic success for freshmen residence hall students. Journal of College Student Development, 43(2), 267-283.

Zimmerman, M. L., Goldston, J. T., \& Gadzella, B. M. (1977). Prediction of academic performance for college students by sex and race. Psychological Reports, 41, 1183-1186. 


\section{Appendix A}

\section{Letter of Invitation to Participate}

I am currently involved in a research project exploring the relationships of learned resourcefulness, stressors, and academic performance in baccalaureate nursing students. Learned resourcefulness is the ability to regulate emotions and thoughts when faced with everyday problems or hassles. The study is performed as partial fulfillment of the requirements for my PhD degree in Higher Education at the University of North Carolina Greensboro, under the supervision of Dr. David Ayers, Assistant Professor in the School of Education.

Your participation in this project will provide useful information and enhanced understanding of this topic. You qualify for participation because you are enrolled either full-time or part-time in a baccalaureate nursing program and meet the following inclusion criteria: (a) age 18 or above, (b) able to read and write English, and (c) able to give informed consent. You will be asked to complete two (2) brief survey instruments and a brief background questionnaire. The total time involved in participation will be approximately 30 minutes.

Participation in this study is strictly voluntary. You may withdraw from the study at any point without penalty. Participation is not associated with your class grade. All data from this project are confidential and will be used for research purposes only. Names of participants will not be connected to information and scores. There is minimal risk to participants in this study. There is a slight risk of breach of confidentiality due to the link between participants' responses and their identity. If you have questions at any time during your participation, please contact me. If you have concerns, please feel free to decline from participation at any point in this project.

Thank you for your assistance in this research project.

Sincerely,

Anne-Marie Goff RN MSN PhD Candidate

910-395-2165 (H)

910-547-4092 (C) 


\section{Appendix B}

\section{Informed Consent Form}

You have been asked to participate in a research study conducted by Anne-Marie Goff, a doctoral student in the School of Education at the University of North Carolina Greensboro. This study is supervised by Dr. David Ayers, Assistant Professor in the School of Education. This research involves the study of learned resourcefulness (the ability to regulate emotions and cognitions when experiencing everyday problems or hassles) in relation to stressors and academic performance of baccalaureate nursing students. This study is part of Anne-Marie Goff's doctoral dissertation. Data will be collected using a brief demographic data sheet and two standardized paper and pencil surveys: The Student-life Stress Inventory (SSI) and the Self-Control Schedule (SCS). The total time involved in participation will be approximately 30 minutes.

All information obtained in this study is strictly confidential unless disclosure is required by law. Informed consent forms and other identifying information will be kept separate from the data. An ID number will be assigned to each set of actual data in order to protect the confidentiality of the participants. Your name will not be associated with the research findings in any way and only the researcher will know your identity. Any records that would identify you as a participant in this study will be kept in a locked file cabinet in Anne-Marie Goff's office at UNC Wilmington and will be destroyed by her approximately three years after the study is completed. The results of this research will be published in Ms. Goff's dissertation and possibly in subsequent journals or books. Only aggregate data will be reported. You may request a copy of the summary of the final results by indicating your interest at the end of this form.

As a result of your participation in this research, you may develop greater personal awareness of your repertoire of learned resourcefulness skills and the types of personal and academic stressors that you are experiencing while a nursing student. Results of this study may lead to a better understanding of factors associated with nursing student stress. This understanding may inform policies and practices designed to reduce nursing student stress, and improve learning, academic performance, and retention. Ultimately the findings may increase the number of qualified nursing graduates, address the nursing shortage, and enhance the quality of health care in the United States. There are minimal risks to participants in this study. There is a slight risk of a breach of confidentiality due to the link between participants' responses and their identity. However, measures that will be implemented to minimize this risk are described above. If you experience distress while participating in this study, or if you have any concerns about your rights or how you are being treated, please contact Eric Allen in the Office of Research and Compliance at UNCG at 336-256-1482. Questions about this project or your benefits or risks associated with being in this study can be answered by Anne-Marie Goff, who may be contacted at 910-395-2165 or Dr. David Ayers, at 336-256-1368.

Participation in this study is strictly voluntary. Participation is not associated with your course grades or your status as a nursing student at UNC Greensboro. If you have any questions about any aspect of this study or your involvement, please tell the 
researcher before signing this form. If significant new information relating to the study becomes available which may relate to your willingness to continue to participate, this information will be provided to you. You have the right to refuse to participate or to withdraw at any time, without penalty. If you do withdraw, it will not affect you in any way. If you choose to withdraw, you may request that any of your data which has been collected be destroyed unless it is in a de-identifiable state. No compensation will be provided for participation. However, you may choose to be entered into the optional gift card drawing for research participants. Six Visa gift cards of $\$ 25$ each will be available. The drawing, which will take place after all data has been collected, and dispersing of prizes, will be conducted by a graduate student who is not associated with the student participants.

By signing this consent form, you are agreeing that you read, or it has been read to you, and you fully understand the contents of this document and are openly willing consent to take part in this study. All of your questions concerning this study have been answered. By signing this form, you are agreeing that you are 18 years of age or older and are agreeing to participate, or have the individual specified above as a participant participate, in this study described to you by Anne-Marie Goff. Two copies of this informed consent form have been provided. Please sign both, return one copy to the researcher, and keep the other for your files.

NAME OF PARTICIPANT (please print)

SIGNATURE OF PARTICIPANT

SIGNATURE OF RESEARCHER
DATE

DATE

Check here to enter the optional gift card drawing for participants.

Check here to receive a summary of research results. 


\section{Appendix C}

\section{Demographic Data Sheet}

1. Current age:

3. Race/Ethnicity

$\begin{array}{ll}\text { 1.___ African-American } & \text { or Black } \\ \text { 2.___ Caucasian } \\ \text { 3.__ Asian } \\ \text { 4._American Indian }\end{array}$

4. Current Marital Status

1.

2.

3.

.
Married Widowed Divorced
2. Gender: 1.

2. Male Female

5. Number of Living Children:

6. Living Arrangements This Semester (Check all that apply):

1. Live in residence hall or apartment on campus

2. L_Live in apartment, condo, or house off campus

3. Have room-mates

4.___Live with parents or other family members

5. ___ Other

9._ No Answer

7. Current College Enrollment Status: 1 Junior 2.___ Senior

1. ___ Full-time (12 credit hours or more)

2. ___ Part-time (less than 12 credit hours)

8. GPA Last Semester:

9. Work Status:

1. Working full-time

4. Other

2. W__ Working part-time 9._No Answer

3._Unemployed, laid off, looking for work

10. If currently working, please describe the type of work you do: 


\section{Appendix D}

\section{Self-Control Schedule}

This questionnaire is designed to find out how different people view their thinking and their behavior. A statement may range from very characteristic of you to very uncharacteristic of you.

There are no right or wrong answers. We simply want to know how you feel each statement applies to you.

Please answer every item, and circle only one answer for each item. Use the following code to indicate whether a statement describes your thinking or behavior.

\section{-3 Very uncharacteristic of me, extremely undescriptive -2 Rather uncharacteristic of me, quite undescriptive -1 Somewhat uncharacteristic of me, slightly undescriptive +1 Somewhat characteristic of me, slightly descriptive +2 Rather characteristic of me, quite descriptive +3 Very characteristic of me, extremely descriptive}

1. When I do a boring job, I think about the less boring parts of the job and about the reward I will receive when I finish.

2. When I have to do something that makes me anxious, I try to visualize how I will overcome my anxiety while doing it.

3. By changing my way of thinking, I am often able to change my feelings about almost anything.

4. I often find it difficult to overcome my feelings of nervousness and tension without outside help.

5. When I am feeling depressed, I try to think about pleasant events.

6. I cannot help thinking about mistakes I made.

7. When I am faced with a difficult problem, I try to approach it in a systematic way.

8. I usually do what I'm supposed to do more quickly when someone is pressuring me.

9. When I am faced with a difficult decision, I prefer to postpone it even if I have all the facts.

10. When I have difficulty concentrating on my reading, I look for ways to increase my concentration.

\begin{tabular}{|lllllll}
-3 & -2 & -1 & +1 & +2 & +3 \\
& & & & & & \\
-3 & -2 & -1 & +1 & +2 & +3 \\
& & & & & & \\
-3 & -2 & -1 & +1 & +2 & +3 \\
-3 & -2 & -1 & +1 & +2 & +3 \\
-3 & -2 & -1 & +1 & +2 & +3 \\
-3 & -2 & -1 & +1 & +2 & +3 \\
-3 & -2 & -1 & +1 & +2 & +3 \\
-3 & -2 & -1 & +1 & +2 & +3 \\
-3 & -2 & -1 & +1 & +2 & +3 \\
-3 & -2 & -1 & +1 & +2 & +3 \\
\hline
\end{tabular}


11. When I plan to work, I remove everything that is not relevant to my work.

12. When I try to get rid of a bad habit, I first try to find out all the reasons why I have the habit.

13. When an unpleasant thought is bothering me, I try to think about something pleasant.

14. If I smoked two packs of cigarettes a day, I would need outside help to stop smoking.

15. When I feel down, I try to act cheerful so that my mood will change.

16. If I carried the pills with me, I would take a tranquilizer whenever I felt tense and nervous.

17. When I am depressed, I try to keep myself busy with things I like.

18. I tend to postpone unpleasant tasks even if I could perform them immediately.

19. I need outside help to get rid of some of my bad habits.

20. When I find it difficult to settle down and do a task, I look for ways to help me settle down.

21. Although it makes me feel bad, I cannot help thinking about all sorts of possible catastrophes.

22. I prefer to finish a job that I have to do before I start doing things I really like.

23. When I feel physical pain, I try not to think about it.

24. My self-esteem increases when I am able to overcome a bad habit.

25. To overcome bad feelings that accompany failure, I often tell myself that it is not catastrophic and I can do something about it.

26. When I feel that I am too impulsive, I tell myself to stop and think before I do anything.

27. Even when I am terribly angry at someone, I consider my actions very carefully.

28. Facing the need to make a decision, I usually find out all the alternatives instead of deciding quickly and spontaneously.

29. Usually, I first do the things I really like to do even if there are more urgent things to do.

30. When I realize that I am going to be unavoidably late for an important meeting, I tell myself to keep calm.

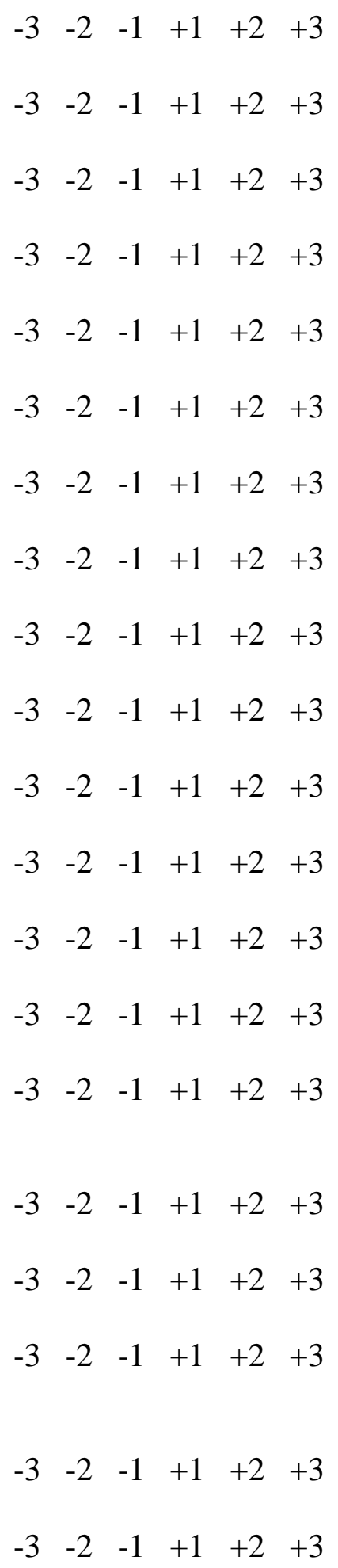


31. When I feel pain in my body, I try to divert my thoughts from it.

32. When I am faced with a number of things to do, I usually plan my work.

33. When I am short of money, I decide to record all my expenses in order to budget more carefully in the future.

34. If I find it difficult to concentrate on a task, I divide it into smaller segments.

35. Quite often, I cannot overcome unpleasant thoughts that bother me.

36. When I am hungry and have no opportunity to eat, I try to divert my thoughts from my stomach or try to imagine that I am satisfied.

$\begin{array}{llllll}-3 & -2 & -1 & +1 & +2 & +3 \\ -3 & -2 & -1 & +1 & +2 & +3 \\ -3 & -2 & -1 & +1 & +2 & +3 \\ -3 & -2 & -1 & +1 & +2 & +3 \\ -3 & -2 & -1 & +1 & +2 & +3 \\ -3 & -2 & -1 & +1 & +2 & +3\end{array}$

Rosenbaum, M. (1980). A schedule for assessing self-control behaviors: Preliminary findings. Behavior Therapy, 11, 109-121. Copyright 1980 by the Association for Advancement of Behavior Therapy. Used with permission of the publisher and author.

Scoring Instructions:

3. Reverse the scoring of the following eleven items: 4,6,8,9,14,16,18,19,21,29,35. For example: If a subject circled item $4,-3$ the reverse score would be +3 . Similarly -1 would be $+1,-2$ will be +2

4. Sum up all the scores of the individual items. The total score of the scale could range from $-108(36 \mathrm{x}-3)$ to $+108(36 \mathrm{x}+3)$. For normal populations the score is usually +25 with a standard deviation of 20 . 


\title{
Appendix E
}

\author{
Student-Life Stress Inventory \\ Bernadette M. Gadzella, Ph.D., 1991 Copyright \\ Texas A\&M University-Commerce
}

\section{Note: Do \#52 on Answer Sheet first.}

Rate your overall level of stress as 1= Mild, 2= Moderate, 3= Severe

This inventory contains statements dealing with student-life stress. Read it carefully and respond to each statement as it has related or is relating to you as a student. Use the 5-letter scale which indicates the level of your experiences with:

1= Never, 2= Seldom, 3= Occasionally, 4= Often, and 5= Most of the time. Record your responses on the accompanying answer sheet.

\section{STRESSORS:}

\section{A. As a student:}

1. I have experienced frustrations due to delays in reaching my goal.

2. I have experienced daily hassles which affected me in reaching my goals.

3. I have experienced lack of sources (money for auto, books, etc.)

4. I have experienced failures in accomplishing the goals that I set.

5. I have not been accepted socially (became a social outcast).

6. I have experienced dating frustrations.

7. I feel I was denied opportunities in spite of my qualifications.

\section{B. I have experienced conflicts which were:}

8. Produced by two or more desirable alternatives.

9. Produced by two or more undesirable alternatives.

10. Produced when a goal had both positive and negative alternatives.

\section{I have experienced pressures:}

11. As a result of competition (on grades, work, relationships with spouse and/or friends).

12. Due to deadlines (papers due, payments to be made, etc.).

13. Due to an overload (attempting too many things at one time).

14. Due to interpersonal relationships (family and/or friends expectations, work responsibilities). 


\section{I have experienced:}

15. Rapid unpleasant changes.

16. Too many changes occurring at the same time.

17. Changes which disrupted my life and/or goals.

E. As a person:

18. I like to compete and win.

19. I like to be noticed and be loved by all.

20. I worry a lot about everything and everybody.

21. I have a tendency to procrastinate (put off things that have to be done).

22. I feel I must find a perfect solution to the problems I undertake.

23. I worry and get anxious about taking tests.

\section{REACTIONS TO STRESSORS:}

F. During stressful situations, I have experienced the following:

24. Sweating (sweaty palms, etc.)

25. Stuttering (not being able to speak clearly)

26. Trembling (being nervous, biting finger-nails, etc.)

27. Rapid movements (moving quickly from place to place)

28. Exhaustion (worn out, burned out)

29. Irritable bowels, peptic ulcers, etc.

30. Asthma, bronchial spasms, hyperventilation

31. Backaches, muscle tightness, (cramps), teeth-grinding

32. Hives, skin itching, allergies

33. Migraine headaches, hypertension, rapid heartbeat

34. Arthritis, overall pains

35. Viruses, colds, flu

36. Weight loss (can't eat)

37. Weight gain (eat a lot)

G. When under stressful situations, I have experienced:

38. Fear, anxiety, worry

39. Anger

40. Guilt

41. Grief, depression

H. When under stressful situations, I have:

42. Cried

43. Abused others (verbally and/or physically)

44. Abused self

45. Smoke excessively

46. Was irritable towards others

47. Attempted suicide

48. Used defense mechanism 
49. Separated myself from others

\section{With reference to stressful situations, I have:}

50. Thought and analyzed about how stressful the situations were.

51. Thought and analyzed whether the strategies I used were most effective. 


\section{Appendix F}

\section{Answer Sheet to Student-Life Stress Inventory}

Bernadette M. Gadzella, Ph.D., 1991

East Texas State University

52. Rate your overall level of stress:

1. Mild 2. Moderate

3. Severe

Respond to each statement in the Student-Life Stress Inventory by recording the level of your experiences on the 5-point scale with 1 = Never, 2 = Seldom, 3 = Occasionally, $4=$ Often, and $5=$ Most of the time.

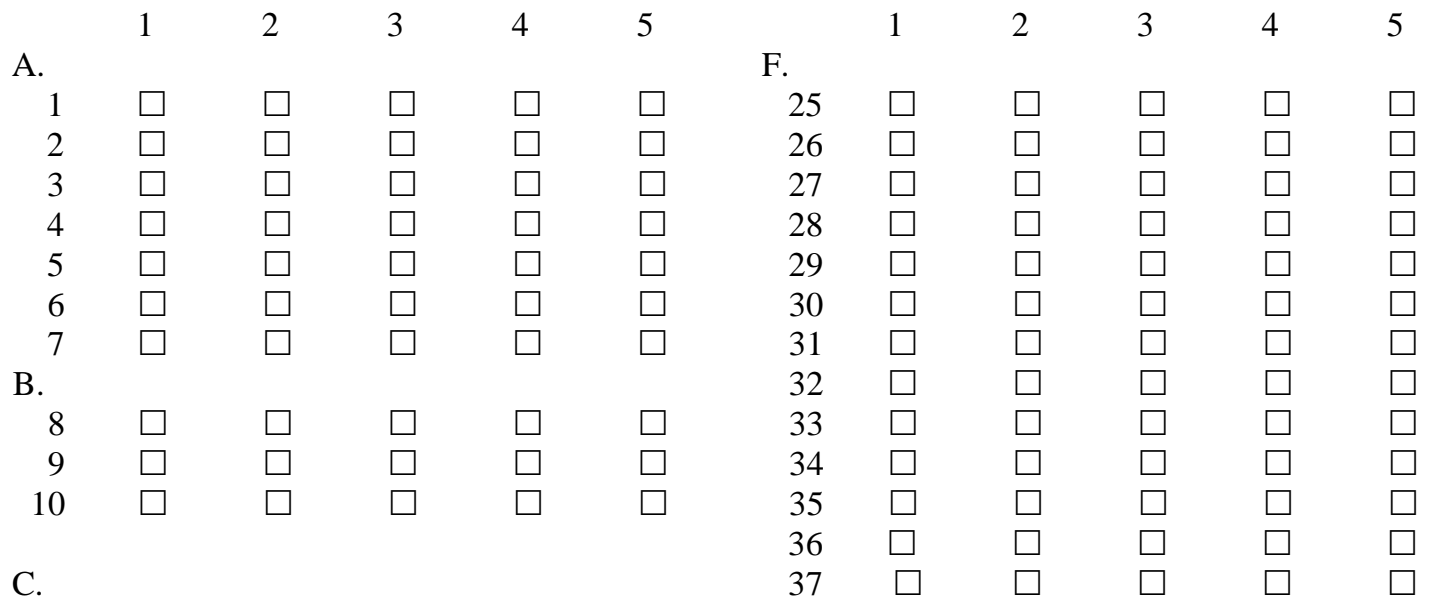

$\begin{array}{llllllll}11 & \square & \square & \square & \square & \square & & \\ 12 & \square & \square & \square & \square & \square & \text { G. } & \\ 13 & \square & \square & \square & \square & \square & 38 & \square \\ 14 & \square & \square & \square & \square & \square & 39 & \square \\ & & & & & & 40 & \square \\ & & & & & & 41 & \square\end{array}$

D.

$\begin{array}{llllll}15 & \square & \square & \square & \square & \square \\ 16 & \square & \square & \square & \square & \square \\ 17 & \square & \square & \square & \square & \square\end{array}$

E.

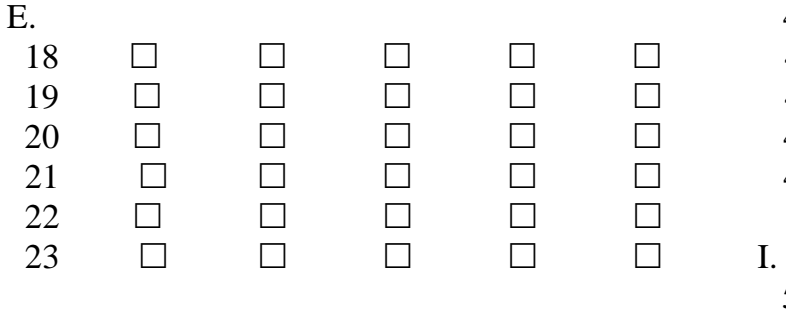

F.

H.

$\begin{array}{cccccc}\text { 42 } & \square & \square & \square & \square & \square \\ 43 & \square & \square & \square & \square & \square \\ 44 & \square & \square & \square & \square & \square \\ 45 & \square & \square & \square & \square & \square \\ 46 & \square & \square & \square & \square & \square \\ 47 & \square & \square & \square & \square & \square \\ 48 & \square & \square & \square & \square & \square \\ 49 & \square & \square & \square & \square & \square\end{array}$

I. 50 